\title{
Risks, Insurance, Shocks: \\ Case Study and Experimental Evidence from Colombia
}

Dissertation zur Erlangung des wirtschaftswissenschaftlichen Doktorgrades der Wirtschaftswissenschaftlichen Fakultät der Universität Göttingen

vorgelegt von

Stephan Dietrich

aus München

Göttingen, 2013 
Erstgutachterin: Marcela Ibanez

Zweitgutachter: Stephan Klasen

Tag der mündlichen Prüfung: 18.12.2013 


\section{Danksagung}

An erster Stelle möchte ich meiner Erstgutachterin Marcela Ibanez danken, die mich auf dem Weg in die Forschung selbst auf Kosten ihrer Freizeit unterstützt hat und mir die unvergessliche Möglichkeit gegeben hat, das wunderbare Kolumbien kennen zu lernen. Außerdem möchte ich meinen Zweit- und Drittgutachtern Prof. Stephan Klasen und Prof. Oliver Mußhoff für ihre Hilfe danken. Darüber hinaus seien auch die vielen Kollegen und Freunde am Courant Center und der Universität Göttingen erwähnt, die meinen Horizont in verschiedenste Richtungen erweitert haben und eine wichtige Quelle für Ratschläge aber auch Ablenkung waren.

Dank gebührt auch den vielen kolumbianischen Helfern, die mich nach allen Möglichkeiten unterstützt haben und im Lauf der gemeinsamen Arbeit zu Freunden wurden. Zudem wäre ohne die Hilfe der Tabakbauern in Santander und der Studenten der Universidad Nacional de Medellin diese Arbeit niemals möglich gewesen.

Nicht zuletzt möchte ich meinen Eltern danken, die mich in allen Entscheidung unterstützt haben und mir immer die Freiheit gegeben haben, meinen eigenen Weg zu gehen, was mich Dank Oma Charlos Großzügigkeit auch in entlegenere Teile dieser Welt geführt hat.

München, 12.5.2014 
Ich versichere an Eides Statt, dass ich die eingereichte Dissertation "Risks, Insurance, Shocks: Case Study and Experimental Evidence from Colombia" selbstständig verfasst habe. Anderer als der von mir angegebenen Hilfsmittel und Schriften habe ich mich nicht bedient. Alle wörtlich oder sinngemäß den Schriften anderer Autorinnen und/oder Autoren entnommenen Stellen habe ich kenntlich gemacht. 


\section{Contents}

\begin{tabular}{ll}
\hline 1. Introduction and Overview & 1
\end{tabular}

2. Impact of Weather Insurances on Small Scale Farmers: A Natural Experiment 11

Introduction . . . . . . . . . . . . . . . . . . . . . . . . 11

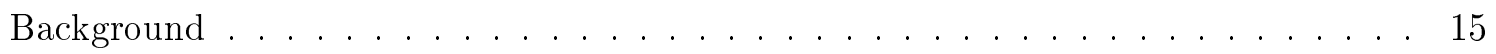

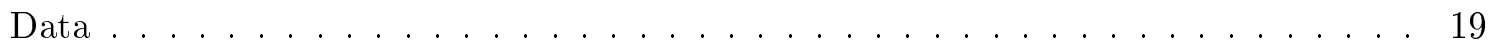

Descriptive Statistics and Balance Tes . . . . . . . . . . . . . . . . . 19

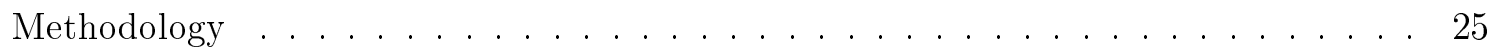

Impact on Household Loans . . . . . . . . . . . . . . . . . . . . . . . . 27

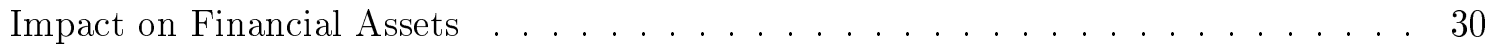

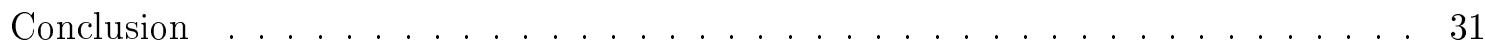

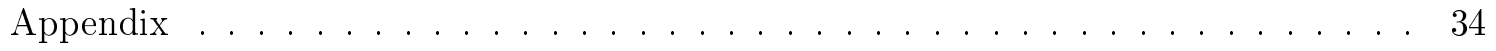

3. Lucky for those who get it: Impact of Insurance Indemnifications on the Resilience to Shocks of Small Scale Farmers 36

Introduction . . . . . . . . . . . . . . . . . . . . . . . 36

Background . . . . . . . . . . . . . . . . . . . . . . . 39

Data and Descriptive Analysis . . . . . . . . . . . . . . . . . . . . . . 41

Econometric Framework $\ldots \ldots \ldots$. . . . . . . . . . . . . . . . . . . 48

Determinants of Indemnification Payments . . . . . . . . . . . . . . . . . 50

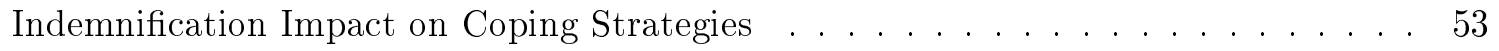

Indemnification Impact on Financial Well-Being . . . . . . . . . . . . . . . . . . . 53

Robustness Checks . . . . . . . . . . . . . . . . . . 56

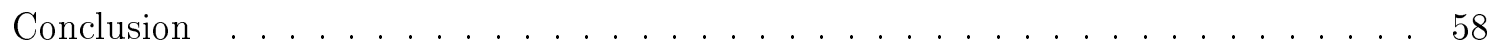

4. Impacts of Agricultural Insurances on the Production of Small Holder Farm-

$\begin{array}{ll}\text { ers in Colombia } & 60\end{array}$

Introduction . . . . . . . . . . . . . . . . . . . . . . . 60

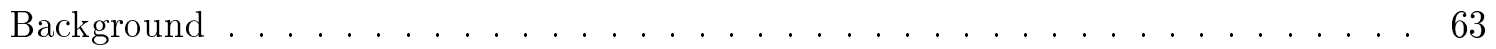

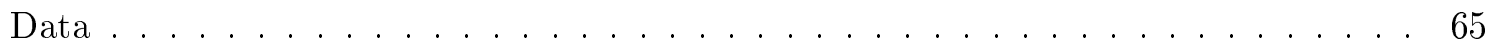




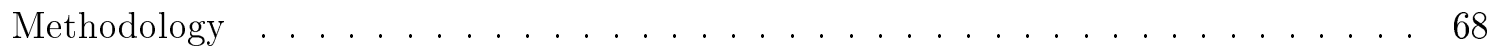

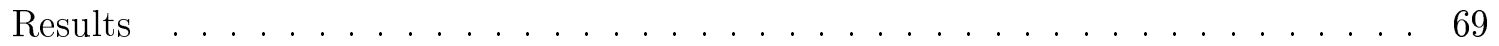

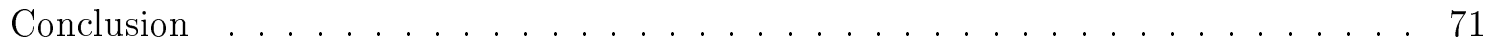

5. A Blessing in Disguise? On the Development of Social Ties 73

Introduction . . . . . . . . . . . . . . . . . . . . . . . 73

Experimental Design . . . . . . . . . . . . . . . . . 76

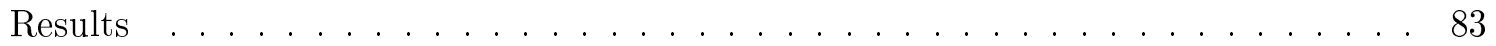

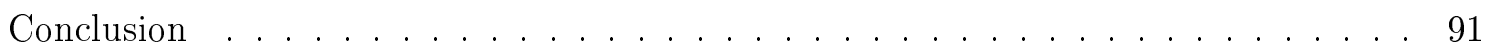

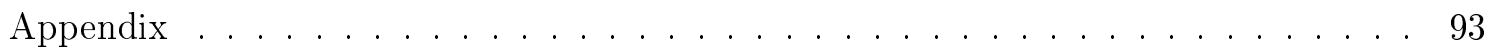




\section{List of Figures}

1 Risk-Management Chain . . . . . . . . . . . . . . . . . . 5

$2.1 \quad$ Research Neighborhoods and Tobacco Company Affiliation. . . . . . . . . . . . 20

3.1 Prevalence of self reported Shocks . . . . . . . . . . . . . . . . . . 45

3.2 Overlap of Losses between indemnified and non-indemnified HH $(2009+2010)$. 46

4.1 Ring-Test Screen . . . . . . . . . . . . . . . . . . . . . 76

4.2 Ring-Test Example . . . . . . . . . . . . . . . . . . . . . . . . . . . . 78

4.3 Shock Timing within Networks $\ldots \ldots \ldots \ldots$. . . . . . . . . . . 81

4.4 Network Collaboration by Period $\ldots \ldots \ldots \ldots \ldots$. . . . . . . . . 85

4.5 Experiment Introduction Screens $\ldots \ldots \ldots$. . . . . . . . . . . . . 93

4.6 Endowment Task Screen $\ldots \ldots \ldots \ldots$

4.7 Transfer Decision Screen $\ldots \ldots \ldots \ldots$. . . . . . . . . . . . . . . . . . 94 


\section{List of Tables}

2.1 Insurance Program Development, 2004-2010 . . . . . . . . . . . . . . . . 16

2.2 Household Characteristics and Differences between Protabaco and Coltabaco Framers . . . . . . . . . . . . . . . . . 22

2.3 Outcome Variables and Differences between Protabaco and Coltabaco Framers 25

2.4 Insurance ITT Impact on HH Loans . . . . . . . . . . . . . . . . . . . . 28

$2.5 \quad$ Insurance ITT Impact on Cross Sectional Variables, $2010 \quad \ldots \ldots \ldots$. . . . . . . 32

2.7 Multivariate Probit and Seemingly Unrelated Regression of Insurance ITT Impact on $\mathrm{HH}$ Capitalization . . . . . . . . . . . . . . . . . . . . . . . 34

2.6 Complete Heckman Selection Models of Impact of Insurance on Loan Outcomes conditional on the Prevalence of Loans in the Household . . . . . . . . . . . . . 35

3.1 Descriptive Statistics and Balance Table . . . . . . . . . . . . . . . . . . 43

3.2 Descriptive Statistics of Outcome Variables . . . . . . . . . . . . . . . . . . 48

3.3 Determinants of claims and indemnifications, 2009-2010 . . . . . . . . . . . . 52

3.4 Indemnity Impact on Coping Strategies, 2009-2010 . . . . . . . . . . . . . . 54

3.5 Indemnity Impact on Financial Well Being, $2010 \ldots \ldots$. . . . . . . . . . 55

3.6 Treatment Coefficients of Robustness Checks on the Impact of Indemnity Payments on HH Coping Strategies and Financial Well Being . . . . . . . . . . . . 58

4.1 Descriptive Statistics and Company Differences . . . . . . . . . . . . . . 66

4.2 Insurance adoption and $\mathrm{HH}$ shocks (\%) by neighborhoods . . . . . . . . . . 68

$4.3 \quad$ Fixed Effect Estimations on Insurance Impacts on HH loans, 2009-2010 . . . . 70

4.4 Fixed Effect on Insurance Impacts on Farm Output, 2009-2010 . . . . . . . . . 71

4.1 Ring-Test Value Combinations $\ldots \ldots \ldots \ldots$. . . . . . . . . . 77

4.2 Summary of Treatments $\ldots \ldots \ldots \ldots \ldots$. . . . . . . . . . . 80

4.3 Social Tie Angle in 1st and 3rd Stage by Treatments . . . . . . . . . . . . . . . 84

4.4 Fixed Effect Estimation of Frequency of Shocks Effects on Social Ties . . . . . 88

4.5 Fixed Effect Estimation of Social Tie Effect of Covariance of Shocks . . . . . . 89

$4.6 \quad$ Fixed Effects Estimation of Shock Frequency Effect by 1st Stage Categories . . 90

$4.7 \quad$ Fixed Effects Estimation of Covariance Effect by 1st Stage Categories . . . . . 91

4.8 Fixed Effect Estimation of Social Tie Effect of Chances to help . . . . . . . . . 95 
4.9 Definition of Variables $\ldots \ldots \ldots \ldots \ldots \ldots$ 


\section{Acronyms}

$\begin{array}{ll}\text { ATE } & \text { Average Treatment Effect } \\ \text { Coeff. } & \text { Coefficient } \\ \text { COP } & \text { Colombian Pesos } \\ \text { FE } & \text { Fixed Effects } \\ \text { HH } & \text { Household } \\ \text { ITT } & \text { Intend to Treat } \\ \text { IPCC } & \text { Intergovernmental Panel on Climate Change } \\ \text { mio. } & \text { million } \\ \text { OLS } & \text { Ordinary Least Squares } \\ \text { StD } & \text { Standard Deviation }\end{array}$




\section{Introduction and Overview}

Risks are a major impediment for households to escaping poverty (World Bank, 2013). Investments that could improve the well-being are declined if failures cause catastrophic consequences. In addition to households own decision to face risks, external shocks such as natural disasters or wars can drag them into chronic poverty (Carter et al., 2007).

In a world without risks households that can accumulate assets, even at a slow pace, grow out of poverty if the time span is large enough (Carter and Barrett, 2006). The accumulated assets generate incomes and the returns to assets diminish the richer the household becomes. In this setting a convergence towards a universal welfare equilibrium would be expected at some point. However, reality suggests that some are stuck in poverty while others manage to grow out of poverty. One approach used to explain the existence of poverty traps is based on models with multiple equilibria (Carter and Barrett, 2006). Households that are able to accumulate assets follow a growth path while households below a critical level are drawn towards an equilibrium in poverty. Below this line of demarcation the efforts to accumulate assets become unbearable, leading to a depletion of assets and chronic poverty. In this regard, disasters can have important impacts. In cases where shocks drop assets below the critical level, households are pushed from the growth path onto the one leading to poverty, making recovery dependent on external help (Carter et al., 2007; Kovacevic and Pflug, 2011).

What can be done to help households overcome these risk barriers? Insurances for poor households have been paid increasing attention in the last decade as a tool to reduce risks (Churchill and Matul, 2012). Efficient insurances are expected to encourage the decision maker to take risks and to strengthen their resilience to adverse events. In cases where an insured household suffers a shock, indemnification payments mitigate the financial impacts. This allows households to remain on the growth path, which would have otherwise pushed them on the path to chronic poverty. Furthermore, as catastrophic outcomes become less

likely, insurance can encourage households to pursue opportunities (World Bank, 2013). For instance, the decision to take up a loan is facilitated by insurance as it reduces the risk to 
default on the loan after shocks.

So why are most poor households exposed to uninsured risks? In the absence of market frictions ex ante insurance and ex post credit are substitutes, which would eliminate all uninsured risks. Yet, most households in developing countries have no or limited access to formal insurance and credit. Therefore these households have to rely on informal coping strategies. There is a whole range of informal mechanisms including for example transfers and remittances, resource liquidation, changes in income sources and migration that allow households to mitigate the impacts of shocks (Morduch, 1999, Fafchamps and Lund, 2003, Dercon, 2002; Barnett and Skees, 2008). However, these instruments are incomplete. Especially when it comes to large collective shocks, as for instance natural disasters, losses can overwhelm the capacity of these instruments. In that case household might be forced to cut down on consumption, which can have long term and even irreversible impacts particularly on the children in the household (Carter and Maluccio, 2003; Jacoby and Skoufias, 1997).

The prospect of climate change further underlines the importance of effective risk management tools. The fifth assessment report of the Intergovernmental Panel on Climate Change (IPCC) just reaffirmed that extreme weather events will further increase in the course of the century in many parts of the world. Thereby making poor regions that depend on small scale farming the most vulnerable to climatic changes (Feigenberg et al., 2010, Samson et al., 2011). In the past these regions were already disproportionately affected. Between 1970 and 2008, 95\% of all deaths from natural disasters were registered for developing countries (Field et al. 2012). This is not only related to a population imbalance but also to differences in the capacity of states, communities and households to handle risks.

In this dissertation I present novel findings that analyze the effects of insurances on the resilience to shocks and household's risk taking behavior. Moreover, the question is raised as to whether there could actually be something good about shocks, as they could trigger processes of social cohesion. The four chapters of this dissertation focus on two specific forms of insurances. Firstly, an agricultural insurance and secondly an insurance network exogenously formed in experiments. However, there is a whole range of insurances that correspond to the different circumstances and needs of their users. Generally, insurance can be simply defined as a transfer of resources from good to bad times in exchange for a premium, which enables households to smooth consumption regardless of whether risks are realized or not (World Bank, 2013). 


\section{Informal Insurance}

There are different types of informal insurances. On the one hand households can use selfinsurance mechanisms. Through this they either accumulate resources in good times to deplete them in bad times or they diversify income sources combining different activities such as farm and non-farm earnings (Dercon, 2002). On the other hand, individuals can rely on their social networks to insure themselves against risks. In this case, members transfer resources of money or kind to those in need with the implicit agreement that they will repay the help received. Risk sharing agreements of this type are not enforceable as they are not based on a contract. Instead they rest upon social assets such as trust and reciprocity to sustain collaboration. In contrast to self-insurance mechanisms, informal arrangements do not distribute risks across time but among members of a network.

Informal insurance mechanisms are often prevailing in developing countries, where the supply of formal insurance is still low. Yet, informal insurance can be a complement to formal insurance in all parts of the world (Dercon, 2002). The economic crisis in southern Europe or the heavy floods in Germany earlier this year showed that informal insurance mechanism can kick in when formal insurances are not available.

However, there are limitations to the efficiency of informal insurances. First of all, lacking enforceability of the agreements can result in low amounts of collaboration and weak networks (Morduch, 1999). Moreover, if individuals run short of resources to reciprocate the help received, for example after two periods of adverse shocks or in cases where all members of a network are affected at the same time, informal insurances become overcharged (Barnett and Skees, 2008, Dercon, 2002, Skoufias, 2003).

\section{Formal Insurance}

First traces of formal insurance date back to the ancient world. A written documentation of what can be considered a formal insurance are mentioned in a report from the Roman historian Livy (Trenerry, 1926). He reports that in 215 B.C. the Roman Empire that was stuck in the war against the advancing troops of Carthaginian leader Hannibal, offered insurance for cargo ships against enemy attacks and storms. In return for the delivery and marketing of supplies for the Roman armies in Spain three companies were guaranteed indemnification in case of transportation losses (Trenerry, 1926). However, this ancient documentation is also the first 
report of insurance fraud. The historian notes that two of the three companies claimed losses after they (supposedly) deliberately sunk their old vessels. As in the origins of insurance, information asymmetry problems (moral hazard and adverse selection) often persist, which is one of the reasons many insurance programs have failed in developing countries (Hazell et al., 1986). Although the insurance policy value of poor households is low, high fixed costs lead to large premiums and often make insurance not affordable to poor households (Skees, 2008). Moreover, the lack of infrastructure and the low attractiveness of these markets for insurance companies resulted in a very limited supply of insurance products in developing countries. Yet, in the last couple of years the development of new insurance technologies led to a sudden growth of micro insurances (A Microinsurance Compendium Vol. II, 2012). These insurance products are designed to meet the requirements of markets with poor customers and small insurance values. In Latin America around 45-50 million microinsurance contracts were sold according to estimates, which represents about one tenth of all contracts worldwide A Microinsurance Compendium Vol. II, 2012). Life insurances (including funeral insurance) take on the largest share, but the innovation of index insurance schemes also spurred a number of contracts in the agricultural sector. Despite the remarkable growth rates of micro insurances, consistent findings on the demand for these products show that the most vulnerable and poorest households are less likely to purchase these insurances (Gine et al., 2008; BinswangerMkhize, 2012). Explanations for this pattern include the mistrust of new products, the basis risk that describes the chance of incurring losses that are not indemnified despite having the insurance and the existing informal insurance alternatives (Mobarak and Rosenzweig, 2012).

\section{Analytical Framework}

The four essays that comprise this dissertation touch on the interplay of risk, risk management and their effect on welfare outcomes. Figure 1 displays a simplified relationship between these elements. From the microeconomic perspective, which I take on throughout all four essays, perceptions of risk are shaped by information on past shocks and trends. Thus the first requirement for efficient ex ante risk management is an accurate identification of risks. Based on this, households or individuals decide on their risk portfolio. Hence, through this ex ante risk management tool, individuals adopt different forms of formal or informal insurance mechanisms. In cases where a risk is realized and a shock occurs, ex post risk management 
tools are required to compensate for losses. Efficient risk management leads to resilience to shocks and successful outcomes in the absence of shocks. However, inefficiencies can lead to catastrophic outcomes and crises.

\section{Risk 2.Exposure 3.Realization 4.Outcome}

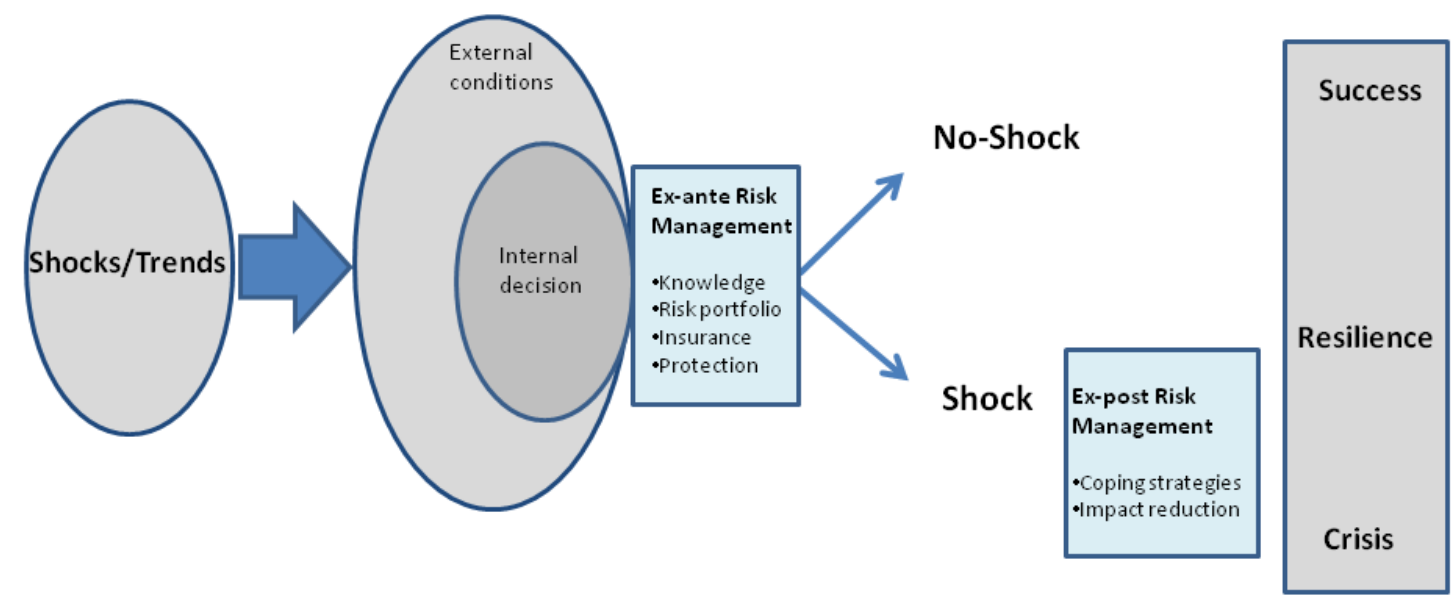

Adapted from World Development Report Concept Note 2014

Figure 1: Risk-Management Chain

\section{Research Focus}

The geographical research focus is put on Colombia throughout all chapters. As the most recent publications on this topic focus on Asia (particularly India) and Africa, this work presents findings in a geographical context that has been underrepresented despite it's high need for efficient risk management. Colombia has been exposed to a large range of shocks in the last decades. Firstly, the ongoing civil conflict that has caused displacements of nearly 6 million people and cost the life of more than 177000 civilians between 1958 and 2012.1 Furthermore, in 2010 and 2011 the weather phenomenon La Niña resulted in heavy rains and floods causing major damages that affected about 3 million Colombians and resulted in

\footnotetext{
${ }^{1} \mathrm{http}: / /$ www.centrodememoriahistorica.gov.co (access 2.11.2013)
} 
emergency relief programs summing up to about 400 million. US\$ in humanitarian aid 2

The first part of the dissertation focuses on the analysis of the impacts of an agricultural insurance. The analyzed insurance is relatively new and covers weather related losses. This insurance is based on a traditional scheme in which indemnification payments are triggered upon individual verifications of damages. Essays 1 to 3 are devoted to an evaluation of this insurance program. In the first essay I present the results of the effect of the insurance program on household loans, assets, expenses and income. The special way in which the insurance was offered allows a quasi experimental identification of the program impacts. The second essay investigates the link between ex ante insurance and ex post risk management. More precisely, it analyzes to what extent indemnification payments affected the resilience to shocks. Inconsistencies in the allocation of indemnification payments and a surprisingly low risk reduction associated with the insurance offer the rare opportunity to compare indemnified and non-indemnified households conditional on their losses. The third essay analyzes if purchasing the insurance affected the risk taking behavior of farmers. Particularly, the chapter describes the findings on how the insurance impacts household loans and productive outcomes. The data used in the analysis correspond to a survey that was especially designed to address the research questions. For that purpose data from nearly 500 tobacco producing households were collected in Santander, Colombia.

The second part of the dissertation focuses on the effect of shocks on the development of social ties. While adverse shocks cause large human and economic losses, the recent literature emphasizes that something good can result from shocks. Following this intuition, the fourth essay aims at investigating how the exposure to shocks affects social cohesion. In particular, we consider whether the frequency and covariance of shocks affect the development of social ties in informal insurance networks. To account for the endogenous formation of networks and to get control of the structure of shocks, laboratory experiments were implemented. The experiments were conducted in the computer lab of the Universidad Nacional in Medellin, Colombia, with 540 students.

\footnotetext{
${ }^{2}$ http://www.colombiahumanitaria.gov.co (access 2.11.2013)
} 


\section{Essay Summaries}

Essay 1 The expected effects of agricultural insurance are twofold. Firstly, agricultural insurances are regarded as an instrument to promote farm investments. Secondly, insurance indemnification are assumed to decrease the need to apply inefficient coping strategies and hence reduce households vulnerability to shocks. Yet, evidence on the impacts of agricultural insurance particularly on poor farmers is limited. This essay explores the impacts of agricultural insurance on loans and other financial assets of small scale farmers. The identification strategy benefits from a quasi natural experimental setup in which only one out of two companies offered the insurance to their contract farmers. Farmers of both companies are comparable regarding household characteristics and the mode of operation of both companies is very similar. Moreover, farmers maintain long term relations with their tobacco company so that self selection into program access is not a problem. As the actual decision to purchase the insurance was voluntary, Intend-to-Treat treatment effects are estimated. The effects of the insurance are examined after two consecutive years of adverse shocks hence in times of need for efficient risk management. The findings indicate that access to the insurance decreased the vulnerability to debt traps: eligible farmers were less likely to use informal loans and less likely to use loans to repay debts. Moreover, the program was associated with higher savings and mobile assets, which especially seems to hold for households that were exposed to shocks. The results suggest that access to the program increased households resilience to shocks particularly households with fewer resources.

Essay 2 The second essay investigates how indemnification payments affected the ex post risk management and welfare of farmers in the aftermath of shocks. In contrast to the previous essay this analysis explores the impacts of indemnification payments. Thereby the findings contribute novel evidence on the specific impact channels of agricultural insurances. Detailed survey data and tobacco company records are used to compare indemnified and nonindemnified program participants conditional on their exposure to shocks. The first finding of the analysis suggests that the risk reducing effect of the insurance was surprisingly low. The data point out that buying the insurance did not prevent several households from suffering substantial losses that were not compensated by the insurance. Uni- and multivariate regressions indicate that inconsistencies in the allocation of indemnification payments were not 
related to household characteristics. Therefore indemnifications for insured households were as if random conditional on their losses. OLS models controlling for the exposure to shocks are estimated to quantify the indemnification impacts on coping strategies and the financial resources of households. The findings indicate that indemnified households were less likely to reduce resources comprised of assets and savings after shocks compared to non-indemnified program participants. Moreover, indemnified households reported significantly less loans and less pending debts by the beginning of the next year. The results imply that indemnified households had less need to engage in ex post coping activities and were better equipped to face risks in upcoming harvests. Yet, the results also indicate that the program was connected to noticeable inconsistencies that hampered the risk reduction of the insurance.

Essay 3 Small holder farmers often invest less than the marginal productivity and marginal costs would suggest. Either loans are not accessible or risks associated with loans make farmers abstain from credit. However, capital is an integral component of the farm production and capital constraints can cause input allocation inefficiencies. The third essay asks whether adopting the insurance took effect on loans and the farm output. Instead of analyzing the impacts of access to the insurance program, the actual decision to purchase the insurance is used as treatment variable. Household fixed effects estimations and spatial differences in the diffusion of this recently lunched insurance are used to identify the impacts. However, no significant effects of the insurance program on credit access nor on productivity become evident. The problems with the implementation of the insurance program could have undermined trust in the program, explaining this finding. Alternatively, due to risk aversion farmers might adapt to the possibilities offered by the insurance only gradually, so the short term effects could be limited.

Essay 4 The last essay refrains from the formal insurance and instead uses a laboratory experimental approach. The essay presents novel evidence on the effects of the structure of shocks on social ties. The literature on the effects of shocks shows mixed evidence. There seem to be settings in which shocks increase social cohesion while in other cases they have the contrary effect. What aspects of a shock determine whether there is a positive or a negative effect on social development? The advantage of laboratory experiments is that it allows the researcher to take control of the endogenous formation of networks as well as the timing and 
types of shocks. The hypothesis is based on the assumption that repeated interaction of individuals promotes the development of social ties. Carried over to the context of informal insurance networks this suggests that successful collaboration after shocks increases the social ties of its members. To measure the impact of shocks on social cohesion a three stage design is used. In the first stage social ties are measured using the Ring-Test of Social Value Orientation. Participants have to decide how to distribute their endowment between themselves and another anonymous participant. The second stage is a repeated solidarity game in which a negative shock can destroy the income that a participant had generated in a real effort task. In cases of a shock, non-affected participants decided whether to transfer a fix amount to the affected participant. In the third stage a slightly modified version of the previous Ring-Test of Social Value Orientation is repeated, which allows to measure social ties of subjects before and after the treatments. The findings show that more frequent shocks led to significant increases in social ties. However, the covariance of shocks reduced social ties compared to idiosyncratic shocks, which can be attributed to the lower number of opportunities to help affected network members.

\section{Outlook}

Despite the growing academic interest in insurances for the poor, a large range of open questions still remains unsolved. The increasing number of established insurance products in developing countries will provide data to shed more light on the long term effects of formal insurances. Does access to formal insurance reduce the vulnerability to shock induced poverty or is the number of risks farmers face too diverse to be affected by a single insurance? A frequently observed problem of formal insurances for the poor is the low demand for these products (Churchill and Matul, 2012). Therefore mechanisms to incorporate the most vulnerable households in insurance programs still need to be explored. Moreover, evidence on the inter-linkages of formal insurance and other ex ante risk management efforts is still limited. How does introducing formal insurance in previously informally insured communities affects the portfolio of ex ante risk management efforts? This refers not only to a crowding out of informal insurance but even more to other risk management activities. An insured farmer faces less incentives to avoid shocks as they will be indemnified by the insurance. Therefore formal insurance, even of index insurances, decreases the need to engage in other ex ante risk 
management actions. Yet, in terms of efficiency it would be preferable to avoid shocks in the first place rather than compensate for losses. In that sense, tools to increase the awareness to risks and the promotion of protection efforts might help farmers to improve their risk management. To give an example for an innovative approach in the private sector, a start up company in Kenya offers a mobile phone based information service for small holder cattle farmers that gives advice on matters related to farm risks sending reminders on due vaccinations, giving productive advice and recording individual statistics of the farmer. ${ }^{3}$ Services like this could help complement the risk management portfolio of poor households, sharpening the awareness to risks and facilitating decisions that seemed too risky before.

\footnotetext{
${ }^{3}$ The service icow has gained much attention as one out of several innovative start ups based in Nairobi. See www.icow.co.ke for more information.
} 


\title{
Impact of Weather Insurances on Small Scale Farmers: A Natural Experiment $\dagger^{\dagger}$
}

\begin{abstract}
Agricultural insurances appear as a promising alternative to reduce rural households vulnerability due to weather shocks and to promote agricultural investments. Yet, there is still limited evidence on the impacts of weather insurances in low income countries. This paper explores the impacts of a subsidized insurance program in Colombia that covered to poor rural households. We investigate the impacts of the insurance program after a period of severe droughts. Our identification strategy benefits from a natural experimental setup where the product was available to some of the producers but not for others. In particular, out of two tobacco companies working in the same region under very different conditions one implemented the agricultural insurance program while the other one did not. Nonetheless, farmers of both companies are very similar and maintain long term relationships with their tobacco company. We study the effect of the insurance estimating Intend-to-Treat treatment effects. Our results indicate that the insurance program reduced the likelihood to take up informal loans to repay debts. Moreover, access to the insurance was positively associated with savings and ownership of liquid assets.
\end{abstract}

\section{Introduction}

In 2012 weather related disasters affected about 100 million people and caused an estimated damage of more than 130 billion US Dollars worldwide! 1 In the absence of effective risk

\footnotetext{
${ }^{\dagger}$ Joint work with Marcela Ibanez

${ }^{1}$ http://www.emdat.be/ (access 1.11.2013)
} 
management instruments weather shocks make small scale farmers particularly vulnerable to poverty (Dercon, 2004). Datt and Hoogeveen (2003) show for example that in the Philippines a drought related to "El Niño" was the main driver of a $9 \%$ increase in poverty. Inefficient risk management can also lead to long term poverty even affecting the next generation Skoufias, 2003). Evidence from South Africa and India suggests that children living in household that were affected by shocks had lower school attendance rates and weight-for-height and heightfor-age than non-affected households (Carter and Maluccio, 2003; Jacoby and Skoufias, 1997). In the absence of formal financial access households often rely on costly informal loans leading to further dependencies and a vicious circle of increasing indebtedness Carter and Olinto, 2003, Bose, 1998). However, informal protection mechanisms have a limited ability to protect households in the case of covariate shocks like climate risks (Barnett and Skees, 2008). As a result, households might be forced to deplete their asset restricting them from future production and investment opportunities (Barnett and Skees, 2008; Macours, 2013). Agricultural insurances are regarded a promising tool to improve households risk management Churchill and Matul, 2012). The risk reduction associated with insurances can promote investments in more productive technologies while indemnity payments can decrease the need to apply inefficient coping strategies. In this paper we investigate the impacts of an agricultural insurance that covered poor small holder farmers.

We focus on an agricultural insurance program implemented in Colombia in 2004. The country has been severely affected by climatic shocks over the last decade. The Center for Research on the Epidemiology of Disasters - CRED - estimates that about 4 million people or $10 \%$ of the Colombian population was affected by weather related events between 2000 and 2009. ${ }^{2}$ Furthermore, climate change is expected to affect particularly small scale farm holders (IDEAM, 2001). According to estimates by the Institute of Hydrological, Meteorologic and Environmental studies - IDEAM - increases in temperature could lead to a desertification of $3.1 \%$ of the national territory adversely affecting yields and livelihoods of farmers. The agricultural insurance program that we analyze covers seven climate risks (droughts, excessive rain, hail, excessive winds, land slides, flooding, pest). The program is subsidized by the Colombian government who covers 30 to 60 percent of the premium depending on whether take up is individual or in groups. In this traditional insurance indemnity payments are

\footnotetext{
${ }^{2}$ http://www.emdat.be/result-country-profile (access 1.11.2013)
} 
determined case by case upon field verifications 3 By 2010, about 10 products and 45.000 hectares were covered by the program.

In this study we focus on the impact of the agricultural insurance on tobacco farmers, a group which is highly vulnerable to poverty. About two thirds of the tobacco producers are landless and cultivate in share-cropping agreements with landlords. The productive investment is mainly financed by tobacco companies who offer individual contracts determining the number of hectares to be cultivated, the value of the productive credit and the tobacco prices to be paid. Under this contracting scheme, production risks are assumed directly by the tobacco farmers who are required to repay production loans at the end of the harvest cycle or in case of negative shocks over the next cropping seasons. At the same time tobacco is highly sensitive to weather variability and farmers experience large yield fluctuations.

To identify the insurance impacts on household loans and financial assets, we explore a natural experimental set up. Two tobacco companies dominate the production in Colombia: Protabaco and Coltabaco. Both companies produce tobacco under equal contract farming conditions and operate in the same areas. Yet, while Protabaco offered the insurance program to their contracted farmers, Coltabaco did not. Farmers in both companies are comparable in terms of socioeconomic characteristics previous to the implementation of the program. Moreover, as farmers maintain long-term relations and produce for the same company for years, self-selection into the program is unlikely to occur. As the decision to purchase the insurance is voluntary for eligible farmers, we estimate the Intend-to-Treat effects of the program. We observe households after two consecutive years of climatic shocks and thus have the rare opportunity to quantify the impacts of the program in times of need. Our findings indicate that access to the insurance decreased the vulnerability to debt traps. Eligible farmers were less likely to use informal loans and less likely to use loans to repay debts. Moreover, the program was associated with higher savings and liquid assets. Hence, the results suggest that the insurance program improved households resilience to shocks.

In a theoretical analysis based on a simple growth model with stochastic capital drops that represent shocks, Kovacevic and Pflug 2011 show that insurance could decrease the likelihood of being trapped in poverty for non-poor households, whereas households below the critical capital level would not benefit from insurance.

\footnotetext{
${ }^{3}$ Attempts to implement index based insurances have been frustrated by the lack of weather data.
} 
Over the last years there has emerged a new empirical literature on the impact of agricultural insurance for poor households. A study of Gine et al. (2008) on the demand for index insurance in India showed that poorer and more risk averse farmers were less likely to purchase the insurance probably due to lack of experience with the new insurance product. Hence, more vulnerable farmers benefited less from the program as they were less likely to participate in the first place. The low demand for insurance products, especially of the most vulnerable households, is an often cited problem that limits the impacts of these products (Churchill and Matul, 2012). In a cross sectional study on the effect of a life insurance product on the demand for other financial services in Ghana, Giesbert et al. (2011) find a mutual reinforcing relationship between the access to the insurance and formal loans and savings. As this insurance is distributed by banks, the authors suggest that the effect is related to an increased familiarity with other financial products. This hypothesis contradicts evidence from a framed field experiment in Malawi where access to rainfall insurance led to a $13 \%$ decrease in credit take up for high yield seeds compared to the control group without the insurance (Gine and Yang, 2009). The effects of index based insurances on investments and production decisions were analyzed in three randomized controlled trials. Cole et al. (2013) show that a rainfall index insurance in India shifted investments towards higher risk, higher return cash crops while Mobarak and Rosenzweig (2013) report a positive effect of rainfall insurance on the risk taking behavior measured by the yield sensitivity to rainfalls. Similarly, Cai et al. (2011) show that insurance participation is associated with increases in the sow production of farmers in China.

This paper contributes to the literature in several ways. While most of the recent empirical evidence evaluates the impact of index based insurances, we focus on a traditional insurance program. In comparison with traditional insurances, index based insurances have the advantage of lower transaction cost and less information asymmetry. Yet, the implementation of index based insurances depends on the availability of historical weather data. Since many developing countries face information restrictions, traditional insurance might be the option available for many countries. An evaluation of the potential of a traditional insurance to reduce households vulnerability to poverty is very important when planning how to set up this type of programs in other regions. Moreover, we explore a natural experimental set up in the implementation of the insurance program. The main benefit of this type of analysis is that 
participants in the program are unaware that they will be monitored. Hence the evaluation does not induce strategic behavior from participants in the program. In other words, the program is evaluated under every day conditions and not under the lime light circumstances of an experimental approach. Furthermore, we have the rare opportunity to analyze the insurance impact after a period of severe climatic shocks. By looking at the insurance impacts on loans and financial assets, this allows to shed novel light on the effect of agricultural insurances on coping strategies of households in the aftermath of shocks.

The paper is organized as follows: Section 2 presents a description of the insurance program. Section 3 explains the setup of the natural experiment and Section 4 presents the data and provides descriptive statistics. Section 5 explains the empirical methodology. In Sections 6 and 7 we discuss the estimation results on household loans and financial assets. In the last section we conclude.

\section{Background}

In 1993 the Colombian Government established the legal framework for the agricultural insurance program and created the National Fund for Agricultural Risks -FNRA- (Fondo Nacional de Riesgos Agropecuarios) administered by Finagro. Yet, the agricultural insurance program only started to operate in 2004. The insurance protects agricultural producers from the main climatic risk: excessive rain, flooding, hail, excessive wind, drought, land slides and pest related with climatic events. The policyholders benefit from a subsidy of 30 to 60 percent of the premium depending whether take up is individual or in groups. Table 2.1 presents a summary of the evolution of the program in terms of products covered, hectares and value insured and loss ratios since the insurance started in 2004. By 2010 the insurance program covered 11 crops and included a catastrophic insurance policy. Less than $1 \%$ of the agricultural land was covered by the program. The only company offering this agricultural insurance was Mapfre.

Among the crops covered by the program, tobacco is particularly interesting as the way in which the program was implemented for this crop can be regarded as a natural experiment

allowing a clear identification of the impacts. Moreover, the group of beneficiaries in the tobacco sector are poor smallholder farmers. Hence, the scope for a poverty reduction effect of the insurance is large for this group of farmers.

In Colombia about 13000 hectares of tobacco are cultivated per year generating about 
Table 2.1: Insurance Program Development, 2004-2010

\begin{tabular}{lccccc}
\hline Year & Covered Crops & $\begin{array}{c}\text { Hectares } \\
\text { Insured }\end{array}$ & $\begin{array}{c}\text { Value Insured } \\
\text { (approx. US \$) }\end{array}$ & $\begin{array}{c}\text { Loss Ratios } \\
\text { (indemnity/premiums) }\end{array}$ & $\begin{array}{c}\text { Insurance } \\
\text { Company }\end{array}$ \\
\hline \hline 2004 & cotton & 1157 & 4019507 & 0.02 & La Previsora \\
\hline 2005 & cotton & 4216 & 14610375 & 1.54 & La Previsora \\
\hline 2006 & cotton, banana & 2789 & 4217340 & 1.24 & La Previsora \\
\hline 2007 & cotton, banana, maize & 30102 & 86353432 & 0.81 & Mapfre \\
\hline 2008 & $\begin{array}{l}\text { cotton, banana, maize, } \\
\text { tobacco, rice, sorghum }\end{array}$ & 35900 & 80520536 & & Mapfre \\
& $\begin{array}{l}\text { cotton, banana, maize, } \\
\text { tobacco, rice, sorghum, } \\
\text { potato, tomato, onions, } \\
\text { forestry }\end{array}$ & 29250 & 63523721 & & \\
\hline 2010 & $\begin{array}{l}\text { cotton, banana, maize, } \\
\text { tobacco, rice, sorghum, } \\
\text { potato, tomato, onions, } \\
\text { forestry, peanut, catastrophic }\end{array}$ & 45740 & 261068000 & & \\
\hline \hline
\end{tabular}

Source: Ministry of Agriculture and Rural Development. Numbers for 2010 from Fasecolda.

15000 jobs. Two companies dominate the tobacco market: Coltabaco, which was incorporated by Philip Morris in 2005 and Protabaco which was acquired by British American Tobacco in 2011. Both companies are comparable in the number of employees, the estimated revenue and their market share ${ }^{4}$ Moreover, both companies produce tobacco under equal contract farming schemes. The tobacco companies negotiate individual contracts with the farmers setting the number and type of plants to be grown. Based on this contract, the companies allocate credit in input material and cash that is repaid when the farmers hand in the cured tobacco leaves. During the production cycle, the company offers technical assistance and monitors the cultivation. In exchange, farmers are required to sell their complete harvest to the company.

As discussed with more detail in the descriptive statistics, farmers working for the different companies are very similar in socioeconomic characteristics. We focus on tobacco as it is mainly produced by poor small farm holders who are highly vulnerable to poverty. In Santander, our research area, the average size of a tobacco field is one hectare. According to our field interviews, we find that more than $90 \%$ of the tobacco farmers earned less income per adult household member than the prescribed minimum wage. $5^{5}$ Most of the tobacco producers do not own the land. Instead, about half of the farmers cultivate under shared cropping paying about

\footnotetext{
${ }^{4}$ Protabaco employs around 1000 workers while Coltabaco employs around 900. See www.bat.com and www.pmi.com (access 8.10.2013).

${ }^{5}$ The minimum wage is approx. 3200 US\$ per year compared to approximately 1500 US\$ income per adult.
} 
one fifth of the farm returns to the land owners. The main varieties of tobacco are Burley and Black tobacco, which are typically cultivated in rotation over 3 months production cycles. The tobacco cultivation is, however, very sensitive to weather related events. The timing of the rain is essential to the quality of the tobacco leaves and if the rainy season sets in too late or too heavily the tobacco plants suffer from pests, underdevelopment or die. Under the agricultural contract scheme, farmers assume all the risk associated with crop failures. Hence, after losses they are hold responsible and must repay the value of the loan in the next cropping season. To deal with crises farmers typically rely on informal insurance networks who provide very costly credits.

In 2008 when the agricultural insurance was introduced in the tobacco sector, it was available only to Protabaco farmers while farmers of Coltabaco did not have access to this or any other agricultural insurance. Since the companies are very similar and work under very similar conditions with almost identical farmers, the implementation of the insurance program can be regarded as a natural experiment. This set up allows us to compare farmers living in the same areas but producing for different companies.

One potential concern with our identification strategy is whether farmers self-selected into different companies once that the insurance program was available. We find that farmers maintain long term relations with their company. About $90 \%$ of farmers who cultivated tobacco in the main harvest of 2005 still produced tobacco for the same company in 2010. Furthermore, we find no systematic differences in household characteristics for households who changed company compared with those who kept a stable relation that could lead us to infer that people self selected in or out of the program.

\section{The Insurance Policy}

Protabaco engaged in the agricultural insurance program in 2008. Yet, the marketing of the insurance varied across regions. In our research region, the decision to buy the insurance was voluntary. Once farmers signed the production contract they were informed about the insurance program and could decide whether to purchase it or not. In 2008 about 17 percent of the eligible farmers took the insurance product while by 2010 take up was close to 85 percent.

The premium of the insurance sums up to $6.85 \%$ of the estimated production costs.

\footnotetext{
${ }^{6}$ About $5.6 \%$ of our sample changed company in the research period 2009-2010
} 
Thereby $60 \%$ is subsidized by the public fund, $20 \%$ by the tobacco association (Fondo del Tabaco) and another $6 \%$ by the tobacco company so that farmers only have to pay $14 \%$ of the premium plus the value added taxes (16\%). This amounts to approximately 100000 COP (approx. 50 US\$) per hectare for Burley tobacco. All administrative work is carried out by the insurance and the tobacco company so that farmers only need to sign the papers during the contracting phase with the tobacco company. In cases of a loss, farmers inform officials of the tobacco company, who forward the claim to the insurance company. Within eight days after receiving the report, the inspection should take place. The independent inspector estimates how the shock will affect the final yield based on his experience. Indemnification payments are triggered when weather events reduce the yield, $y_{i}$, below $70 \%$ of the historic yield, $h_{i} \cdot 7$ The insurance covers production cost, $c$, after the plots have been established, hence risk associated with transplantation of the plants or the curing phase are not covered 8 In cases of a damage a deductible of $15 \%$ of the estimated costs has to be carried by the insured. The following formula is used to assess the value of indemnity payments.

\section{Indemnification $=\left(0.7 * h_{i}-y_{i}\right) * \frac{c}{h_{i}}-0,15 * c$}

During the research period indemnities were triggered in several cases. In our sample around $40 \%$ of the insured households received an indemnity in either 2009 or 2010. Yet, the verification processes have not been free of problems. For our sample of producers, the verification took only place 20 days after the claim. Moreover, about $11 \%$ of farmers that claimed a loss reported that their damages were never inspected. A practical burden was that insured farmers tended to report every loss, even small ones and thereby overcharged the verification process. This might be due to the fact that many farmers did not properly understand the insurance conditions. The tobacco company organized meetings to explain the insurance system but literacy problems often limited comprehension of the insurance terms. This contributed to low confidence and satisfaction levels of farmers with the insurance program 4

\footnotetext{
${ }^{7}$ The historic yield represents the average of the last four production periods. If no historical data exist, regional information is used as reference.

${ }^{8}$ In 2010, the production cost per hectare was estimated to be 6.7 mil. COP for Burley tobacco. The indemnification considers the cost per production unit. Hence, the cost per hectare is divided by the historical yield.

${ }^{9}$ In $2011,64 \%$ of the participants in our survey reported to be unsatisfied or very unsatisfied with the program. Besides, $71 \%$ of the participants in the survey reported little or no confidence in the insurance scheme.
} 


\section{Data}

In order to evaluate the impacts of the insurance, we conducted surveys with tobacco producers in Santander, Colombia. Following a pilot study, we interviewed households between February and March 2011. The survey was carried out in four municipalities: San Gil, Barichara, Villa Nueva and Curiti. After identifying production nucleus in each municipality, farmers were randomly selected using producer lists of the two tobacco companies of 2008. Out of 2242 tobacco farmers in the research region, 587 were randomly selected to be interviewed. Indemnified households were oversampled in order to get a sufficient amount of treated households .10 Subtracting untraceable households and duplicates (selected farmers living in the same household) a total of 468 households was finally interviewed. Out of these, 306 produced for Protabaco and 130 for Coltabaco in the main harvest of 2010. In order to have comparability, we randomly selected farmers who worked with different companies but who lived in the same neighborhoods. Figure 2.1 displays a map of the research region and illustrates the main neighborhoods showing whether we interviewed farmers from both tobacco companies or only one company per neighborhood. About $96 \%$ of the interviewed households had neighbors producing for the other company. Therefore these farmers living in the same neighborhoods were equally exposed to covariate shocks.

To analyze the insurance impacts on households capitalization we included detailed questions on household loans for the year 2009 and 2010. This includes information on whether households used loans from banks, cooperatives or informal sources, the value of loans, the nominal interest rate and maturity and the main motivations to take up the loan. Moreover, we asked for households aggregated debts, savings, assets, income, expenditures at the time of the interview. Additionally, to examine the comparability of the farmers of both companies, we included several questions on characteristics of the household in 2005 when the insurance program was not yet implemented.

\section{Descriptive Statistics and Balance Test}

Descriptive statistics are presented in Table 2.2. Most of the household heads were male (91 percent) with an average age of 47 years and a low education level having completed only

\footnotetext{
${ }^{10}$ The findings are robust to including probability weights that regard company, insurance and indemnification likelihoods. Estimation results with probability weights can be found in the appendix.
} 


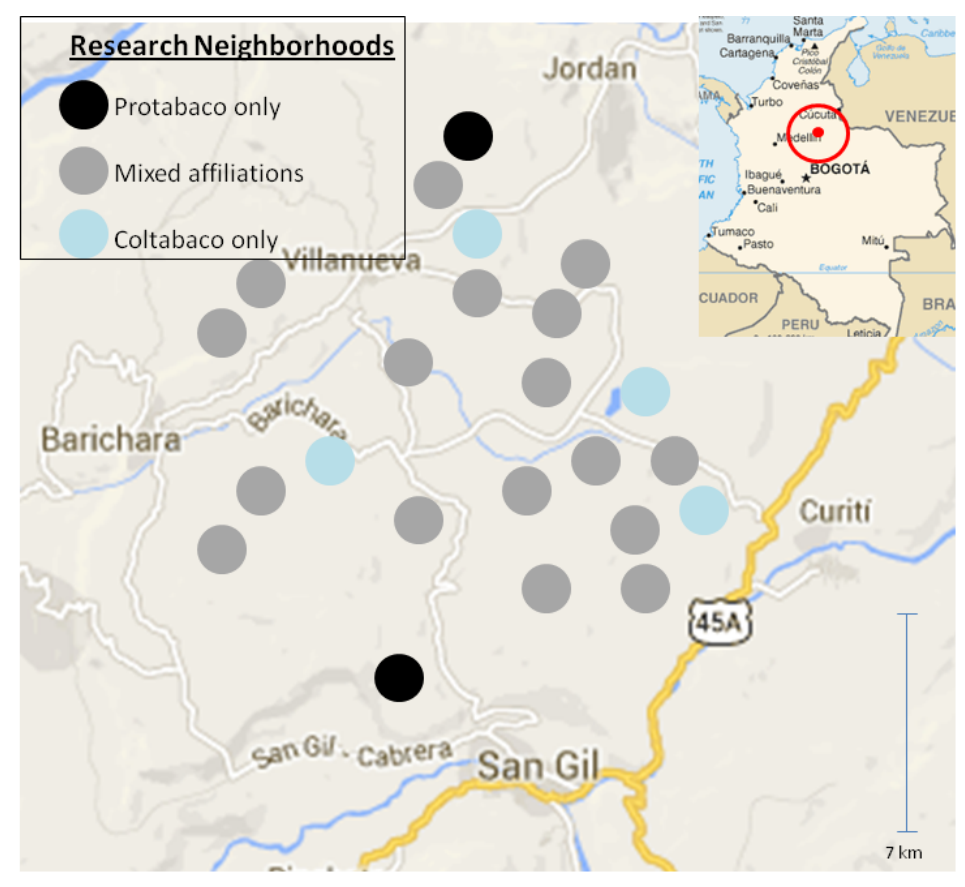

Source: google maps and http://atlasdesantander.blogspot.de/(8.10.2013)

Figure 2.1: Research Neighborhoods and Tobacco Company Affiliation

three years of schooling. Participants lived relatively close to populated areas with an average duration of the journey from their homes to the next town of 35 minutes. The participation in community associations was relatively high and 62 percent of the participants belong at least to one organization. Comparing households economic characteristics in 2005, three years before the insurance program started, we find that farmers producing for both companies are not different. About half produced tobacco either under shared cropping agreements or on rented land. Households reported on average assets worth 17.7 mio. COP (approx. 8800 US\$), which was mainly driven by land property. Liquid assets excluding land property summed on average up to 2 mio. COP per household. A large proportion of the farmers had debts ( 80 percent) and for 47 percent of the respondents debts were above the average value of liquid assets (2.5 mio. COP). On average farmers are rather experienced having cultivated tobacco for more than 20 years. Tobacco was the main source of income for farmers and about half of the cultivated hectares were planted with tobacco. About 83 percent cultivated Burley in the main harvest (January-March). The index of technology innovation indicates that on average farmers have adopted two to three of the new production techniques such as the use of certified seeds, construction of water reservoirs, use of soil studies, implementation of seedling techniques and use of system of registers. Regarding the exposure to shocks the region was 
struck by two consecutive years with adverse weather events. In the main harvest of 2009 a major drought caused substantial damages and in the second harvest of 2010 a drought led to significant crop failures. In both years more than $80 \%$ of the sampled households reported a shock, which was mainly driven by climatic events. In our sample the damages triggered insurance indemnifications for 35 percent of the insured farmers in 2009 and 2010 . We included a detailed section on household shocks in the surveys, which cover the types of shocks and how they affected the household financially. Yet, one concern with self reported losses is that it might be biased by the insurance as it increases the awareness to losses or might be a tool to strategically express the discontent with the insurance. Therefore we use the mean tobacco losses per hectare on the neighborhood level to approximate farmers exposure to covariate shocks 11 Besides that we report the absolute amount of non-tobacco losses as for example of non-tobacco crops, health and other idiosyncratic shocks. The descriptive statistics suggest that the covariate losses per hectare were similar in size for 2009 and 2010 and exceeded the non-tobacco losses. The total amount of self reported losses summed on average up to 3.5 mio. COP (approx. $1750 \mathrm{US} \$$ ), which represented more than 40 percent of the total household income of 2010 .

The second column of Table 2.2 presents the coefficients on differences between farmers with and without access to the insurance 12 As suggested, farmers of both companies are similar regarding most socioeconomic characteristics. The only difference can be noticed in the highest debt category in 2005 where farmers with access to the insurance being more likely to fall in this category. We also find significant differences on the size of the cultivated tobacco plots in 2005 and the number of hectares cultivated with the Burley variety in the main harvest of 2005. However, this seems to be related to differences in company demand rather than inherent dissimilarities of farmers of both companies.

\footnotetext{
${ }^{11}$ Alternatively rainfall data could be applied to approximate losses, but as rainfall data is scarce and the research region is relatively small there would be too little detail to capture differences within the research region.

${ }^{12}$ As access to the insurance only changed marginally over time, the results are only presented for 2010 but equally hold for the year 2009 .
} 
Table 2.2: Household Characteristics and Differences between Protabaco and Coltabaco Framers

\begin{tabular}{|c|c|c|c|c|}
\hline & \multicolumn{2}{|r|}{ Constant } & \multicolumn{2}{|c|}{ Insurance Access } \\
\hline & $\mathrm{N}$ & Coeff. & Coeff.. & t-value \\
\hline Male hh head (d.) & 468 & $0.90 * * *$ & 0.01 & $(0.26)$ \\
\hline Age (years) & 465 & $47.56^{* * *}$ & -0.72 & $(-0.57)$ \\
\hline Education HH head (years) & 463 & $3.59 * * *$ & 0.09 & $(0.38)$ \\
\hline Children & 468 & $1.18^{* * *}$ & -0.19 & $(-1.66)$ \\
\hline Remoteness (min. to next town) & 457 & $35.57^{* * *}$ & -0.61 & $(-0.28)$ \\
\hline Memberships in associations & 468 & $0.57 * * *$ & 0.09 & $(1.27)$ \\
\hline Renter 2005 (d.) & 468 & $0.48^{* * *}$ & 0.05 & $(1.08)$ \\
\hline Owner 2005 (d.) & 468 & $0.41^{* * *}$ & -0.04 & $(-0.82)$ \\
\hline Other Land Possession Status 2005 (d.) & 468 & $0.10^{* * *}$ & -0.03 & $(-0.97)$ \\
\hline Rooms 2005 & 468 & $2.77^{* * *}$ & -0.02 & $(-0.13)$ \\
\hline Assets 2005 (mio. COP) & 468 & $17.34^{* * *}$ & 0.06 & $(0.02)$ \\
\hline Liquid assets 2005 (mio. COP) & 468 & $1.49 * * *$ & 0.73 & $(1.47)$ \\
\hline Productive assets 2005 (mio. COP) & 468 & $0.91^{* * *}$ & 0.37 & $(1.20)$ \\
\hline \multicolumn{5}{|l|}{ Debt categories 2005} \\
\hline$\$ 0 \mathrm{COP}$ & 455 & $0.21 * * *$ & -0.04 & $(-1.16)$ \\
\hline$\$ 1-\$ 0.5$ mio. COP & 455 & $0.03^{*}$ & 0.01 & $(0.61)$ \\
\hline$\$ 0.5$ - $\$ 1$ mio. COP & 455 & $0.14^{* * *}$ & -0.05 & $(-1.48)$ \\
\hline$\$ 1$ mio. - $\$ 2.5$ mio. COP & 455 & $0.21^{* * *}$ & -0.03 & $(-0.80)$ \\
\hline$\$ 2.5$ mio.- $\$ 4$ mio. $\mathrm{COP}$ & 455 & $0.19 * * *$ & -0.04 & $(-1.01)$ \\
\hline$>\$ 4$ mio. COP & 455 & $0.20 * * *$ & $0.15^{* *}$ & $(3.27)$ \\
\hline Experience tobacco (years) & 464 & $21.60 * * *$ & 1.17 & $(0.88)$ \\
\hline Tobacco hectare 2005 & 429 & $1.64^{* * *}$ & 0.12 & $(0.96)$ \\
\hline Non tobacco hectare 2005 & 439 & $1.18^{* * *}$ & $0.29 * *$ & $(3.02)$ \\
\hline Burley main harvest 2005 (d.) & 429 & $0.83^{* * *}$ & $0.13^{* * *}$ & $(4.61)$ \\
\hline Prod. technology $2005^{1}$ & 429 & $2.72^{* * *}$ & -0.03 & $(-0.27)$ \\
\hline Irrigation system 2005 (d.) & 429 & $0.04^{*}$ & 0.00 & $(0.10)$ \\
\hline Land diversification $2005^{2}$ & 444 & $0.43^{* * *}$ & 0.02 & $(1.04)$ \\
\hline Covariate Tobacco Losses per hectare $2009^{3}$ & 468 & $1.70 * * *$ & 0.13 & $(1.60)$ \\
\hline Covariate Tobacco Losses per hectare $2010^{3}$ & 465 & $1.73^{* * *}$ & -0.03 & $(-0.31)$ \\
\hline Non-Tobacco Losses $2009^{4}$ & 468 & $1.07^{* * *}$ & 0.31 & $(1.59)$ \\
\hline Non-Tobacco Losses $2010^{5}$ & 468 & $1.60 * * *$ & -0.11 & $(-0.36)$ \\
\hline \multicolumn{5}{|c|}{$\begin{array}{l}* \mathrm{p}<0.05,{ }^{*} 0.05<\mathrm{p}<0.01 . \mathrm{d} \text {. if dummy variable. }{ }^{1} \text { Production index } 0-5 \text { measurement } \\
\text { technologica innovations like certified seeds, dikes, soil studies, seedling technique and system of } \\
\text { registers. }{ }^{2} \text { Share of tobacco land on total cultivated hectares. }{ }^{3} \text { Mean self reported tobacco losses per } \\
\text { hectare on the neighborhood (vereda) level in mio. COP. }{ }^{4} \text { Non-Tobacco losses including } \\
\text { agricultural and non agricultural losses in mio. COP. }\end{array}$} \\
\hline
\end{tabular}




\section{Outcome Variables}

Table 2.3 displays the descriptive statistics of the outcome variables and simple differences between farmers with and without access to the insurance. As several variables are available for 2009 and 2010 we present the descriptive statistics by years. The first set of outcome variables is devoted to different aspects of household loans. As explained, farmers finance the production of tobacco with productive loans from the companies. Hence, all households in our sample use loans to finance the tobacco cultivation. Protabaco farmers received on average 3.5 mio. COP per hectare of Burley tobacco in the main harvest whereas Coltabaco farmers received on average 4.1 mio. $\operatorname{COP}(\mathrm{t}-$ Test $\mid \operatorname{Pr}(|\mathrm{T}|>|\mathrm{t}|)=0.34)$. Ideally, one would like to consider the effect of the insurance program on productive loans. However, as the company determines the technological cultivation package, and the value of the loan per hectare, the estimated ITT coefficient could potentially reflect technological differences. For that reason in the analysis, we consider the effect on other forms of loans besides the tobacco company loans what we refer to as private loans. The data indicate that about 54 percent of the households had at least one private loan. The most common source of funding were cooperative loans (33 percent in 2009 or 2010) followed by bank loans (24 percent) and informal loans (9 percent). On average each household reported loans worth 2.5 mio COP, which is only slightly less than the average income per household member. The mean bank and cooperative loans were similar in size whereas the value of informal loans reached on average only one third of the formal loans (see table 2.3). A simple comparison of farmers with access to the insurance program to those without access does not show any significant differences in loan values. Private loans were typically used to finance additional production inputs for tobacco and non-tobacco crops (41 percent), consumption (16 percent), to repay pending debts (14 percent) or other purposes (12 percent). Simple differences indicate that farmers with access to the insurance more often reported using loans for other purposes, which included investments in the house, education, shocks or other not further defined purposes 13 In addition to that we collected information on loan conditions including the maturity in month and the nominal monthly interest rate. The average loan was over 18 month with an interest rate of about $2 \%$. Yet, farmers with access to the insurance were associated with larger maturities and lower interest rates.

The second set of outcome variables refer to different aspects of households financial well

\footnotetext{
${ }^{13}$ As prevalence of these categories is low we combined them into one category.
} 
being. Information on households savings were collected using a categorical variable that included the following saving ranges: No saving or saving of less that 1 monthly minimum wage (500 $000 \mathrm{COP}$ ), savings of 1 to 2 monthly minimum wages (500 $000 \mathrm{COP}$ to 1 mio. COP) and savings of more that 1 mio. COP. The descriptive statistics indicate that most households had either depleted or had never managed to build up savings and about $77 \%$ of the households reported being in the lowest category at the end of 2010. However, farmers with access to the insurance were on average more likely to posses savings. In addition, we collected detailed information on assets including land property, machines, livestock and other assets. Yet, especially for those households that owned their land, a large variance of asset values was reported, which was often related to farmers having problems to assign values to their land ${ }^{14}$ Therefore we decided to use log values of assets to reduce the impacts of outliers on the estimation results. Liquid and productive assets in 2010 were significantly larger for the group of farmers that had access to the insurance. Furthermore, we asked for household expenses so that we could aggregate a consumption measure per household member and year. On average households reported about 2.9 mio. COP (approx 1460 US\$) per capita, which was similar for eligible and ineligible farmers. Lastly, we collected information on households income per capita which summed on average up to 2.4 mio. COP in 2010. This is slightly less than the reported expenses, which could suggest that household aggregated debts in this year. Thereby farmers with access to the insurance reported on average higher total and tobacco incomes than farmers without access to the insurance.

\footnotetext{
${ }^{14}$ To regard outliers we excluded 20 observations above a two standard deviation range which corresponded to assets worth 140 mio. COP.
} 
Table 2.3: Outcome Variables and Differences between Protabaco and Coltabaco Framers

\begin{tabular}{|c|c|c|c|c|c|c|c|c|}
\hline & \multicolumn{4}{|c|}{2009} & \multicolumn{4}{|c|}{2010} \\
\hline & \multirow[b]{2}{*}{$\mathrm{N}$} & Constant & \multicolumn{2}{|c|}{ Insurance Access } & \multicolumn{2}{|r|}{ Constant } & \multirow{2}{*}{$\begin{array}{c}\text { Insurance } \\
\text { Coeff. }\end{array}$} & \multirow{2}{*}{$\begin{array}{l}\text { Access } \\
\text { t-value }\end{array}$} \\
\hline & & Coeff. & Coeff. & t-value & $\mathrm{N}$ & Coeff. & & \\
\hline \multicolumn{9}{|l|}{ Loans } \\
\hline \multicolumn{9}{|l|}{ Loan Value (mio. COP) } \\
\hline Loan (total) & 467 & $0.97 * * *$ & 0.20 & $(0.98)$ & 468 & $2.47 * * *$ & 0.62 & $(1.67)$ \\
\hline Bank Loan & 467 & $0.36^{* *}$ & 0.13 & $(0.92)$ & 468 & $1.10^{* * *}$ & 0.43 & $(1.60)$ \\
\hline Cooperative Loan & 468 & $0.54^{* * *}$ & 0.09 & $(0.66)$ & 468 & $1.00 * * *$ & 0.32 & $(1.49)$ \\
\hline Informal Loan & 468 & $0.07^{*}$ & -0.01 & $(-0.39)$ & 468 & $0.37^{* * *}$ & -0.13 & $(-1.45)$ \\
\hline \multicolumn{9}{|l|}{ Loan Motive } \\
\hline Investment & 468 & $0.24^{* * *}$ & 0.03 & $(0.63)$ & 468 & $0.41 * * *$ & 0.09 & $(1.88)$ \\
\hline Repay Debt & 468 & $0.04^{*}$ & 0.00 & $(0.12)$ & 468 & $0.14^{* * *}$ & -0.05 & $(-1.78)$ \\
\hline Consumption & 468 & $0.07 * *$ & 0.02 & $(0.57)$ & 468 & $0.16^{* * *}$ & -0.01 & $(-0.41)$ \\
\hline Other & 468 & $0.05^{*}$ & 0.03 & $(1.28)$ & 468 & $0.12^{* * *}$ & $0.08^{*}$ & $(2.15)$ \\
\hline \multicolumn{9}{|l|}{ Loan Conditions } \\
\hline Interest Rate (\%) & 85 & $3.19^{* * *}$ & -1.36 & $(-1.96)$ & 235 & $2.30 * * *$ & -0.28 & $(-0.83)$ \\
\hline Maturity (Month) & 143 & $18.28^{* * *}$ & 2.60 & $(0.83)$ & 280 & $18.71^{* * *}$ & $5.24^{* *}$ & $(2.60)$ \\
\hline \multicolumn{9}{|l|}{ Financial Assets ${ }^{1}$} \\
\hline \multicolumn{9}{|l|}{ Savings } \\
\hline$\$ 0-\$ 0.5$ mio. COP & & & & & 468 & $0.85^{* * *}$ & $-0.13^{* *}$ & $(-3.07)$ \\
\hline$\$ 0.5$ mio. - $\$ 1$ mio. COP & & & & & 468 & $0.08^{* *}$ & 0.06 & $(1.77)$ \\
\hline$>\$ 1$ mio. $\mathrm{COP}$ & & & & & 468 & $0.06^{*}$ & $0.07^{*}$ & $(2.24)$ \\
\hline \multicolumn{9}{|l|}{ Assets } \\
\hline $\log$ Assets & & & & & 434 & $1.55^{* * *}$ & 0.25 & $(1.13)$ \\
\hline log Liquid Assets & & & & & 409 & $-0.29^{*}$ & $0.52 * * *$ & $(3.41)$ \\
\hline log Productive Assets & & & & & 369 & $13.32^{* * *}$ & $0.43^{* *}$ & $(2.25)$ \\
\hline \multicolumn{9}{|l|}{ Consumption } \\
\hline Consumption & & & & & 452 & $2.92^{* * *}$ & 0.21 & $(1.29)$ \\
\hline Food Consumption & & & & & 452 & $1.75^{* * *}$ & 0.03 & $(0.04)$ \\
\hline Non-Food Consumption & & & & & 433 & $0.51^{* * *}$ & 0.02 & $(0.80)$ \\
\hline \multicolumn{9}{|l|}{ Income } \\
\hline Income & & & & & 464 & $2.36^{* * *}$ & $0.75^{* *}$ & $(2.95)$ \\
\hline Tobacco Income & & & & & 447 & $1.26 * * *$ & $0.56^{* * *}$ & $(3.52)$ \\
\hline
\end{tabular}

\section{Methodology}

Our identification strategy benefits from a natural experimental setup in which one out of two groups of comparable farmers, had access to the insurance program while the other did not. As access to the program is exogenous for farmers, it is possible to assume farmers of both companies were comparable before the program was implemented. This condition implies that the expected value of variable $Y$, before the program was implemented $(T=0)$ is the 
same for farmers who took up the program and farmers who did not take it $(Y(1)$ and $Y(0)$, respectively):

(1) $E\left(Y_{i}(1) \mid T=0\right)=E\left(Y_{i}(0) \mid T=0\right)$

As participation in the program for eligible farmers was voluntary, we use access to the insurance program as treatment variable. By doing so we compare households with and without access to the insurance regardless of their treatment participation decision. This Intent-toTreat (ITT) approach is less restrictive than using the actual insurance status as it avoids self-selection issues related to the decision to purchase the insurance. When access to the program is exogenously determined, a OLS regressions, of the outcome variable $Y_{i}$ on a dummy variable $T_{i}$ that takes value equal to one for participants with access to the program and zero otherwise. Differences in observable characteristics between eligible and non-eligible farmers can be corrected including those characteristics $X_{i}$ in the regression:

(2) $Y_{i}=\beta_{0}+\beta_{1} T_{i}+\beta^{\prime} X_{i}+u_{i}$

The coefficient $\beta_{1}$ reflects the impact of access to program (ITT), while $\beta^{\prime}$ refers to the coefficients of the control variables and $u_{i}$ to the error term. For the variables on household loans we make use of the panel structure and estimate random effects models to account for possible serial correlation of the outcome variables. As only about half of the households used private loans in 2009 and 2010, we estimate Tobit models that regard the cluster of loan values at zero. However, a concern with estimations on loan outcomes is that there could be an underlying selection mechanisms. The decision to take up a loan could affect the source of funding or the purpose for which the capital was used and thus farmers that reported private loans could form a self selected, non-random group. Therefore we additionally present the treatment coefficient of heckman selection models in which we model the decision to use a private loan $L_{i}$ as a function of the observed differences $X_{i}$ and the distance to the next lending institution $Z_{i}$ :

(3) $L_{i}=\gamma^{\prime} Z_{i}+\delta^{\prime} X_{i}+u_{i s} u_{i s} \sim N(0,1)$

Therefore loan outcomes $y_{i}$ are observed only if the outcome of the selection equation (3) is positive. The distance to the next lending institution approximates the transaction cost, which is expected to affect the likelihood to take up a loan regardless of the loan source or loan motivation. In order to model the distance to the next lending institution we use the 
remoteness to the next town and dummies for the municipality in which the household lives.

\section{Estimation Procedure}

For the loan outcome variables that are available for 2009 and 2010 we present the ITT treatment coefficients of two estimation models. The first model is estimated for the pooled data considering the selection equation (3) using heckman selection models. Not surprisingly, we find a significant selection procedure through the prevalence of private loans on loan values, yet, no significant selection effects were found for the remaining loan variables ${ }^{15}$ The second model corresponds to equation (2) considering the panel structure of the loan outcome data estimating random effects models. For the outcome variables on financial assets for which we only have information in one point in time we present ordinary OLS coefficients according to equation (2) and Multinomial Logit coefficients for the categorical savings variable. As control variables we include the observed differences among producers from both companies and the loans granted by the tobacco companies. It has to be noted that the ITT yields only a lower bound estimate of the average treatment effect, as several households did not adopt the insurance despite having access to it Angelucci and Attanasio, 2006). As mentioned, in the sample $64 \%$ out of the eligible farmers purchased the insurance in 2009 and $85 \%$ in 2010 .

As the research region was adversely affected by climatic shocks in the analyzed period we further present results focusing on the sub-group of households that reported having been affected by a shock. By doing so we make sure that impacts were not driven by differences in the exposure to shocks and are able to examine whether program effects were different for shock affected households. In the last step we look at heterogeneous effects by poorer and wealthier households. Therefore we define sub-groups by the median of assets in 2005 . Low asset households reported on average assets worth 379000 COP (approx. 190 US\$). In contrast to that, the wealthier sub-group had on average 17.8 mio. COP (approx. 9000 US\$). The share of households with access to the insurance remains constant in these sub-groups.

\section{Impact on Loans}

The estimated ITT coefficients on loan outcomes are displayed in Table 2.4. Panel A in table 2.4 considers the ITT effects on the value of private loans. We find that access to the

\footnotetext{
${ }^{15} \mathrm{~A}$ table with the complete estimations results on loan outcomes including the selection and the main equation can be found in the appendix.
} 


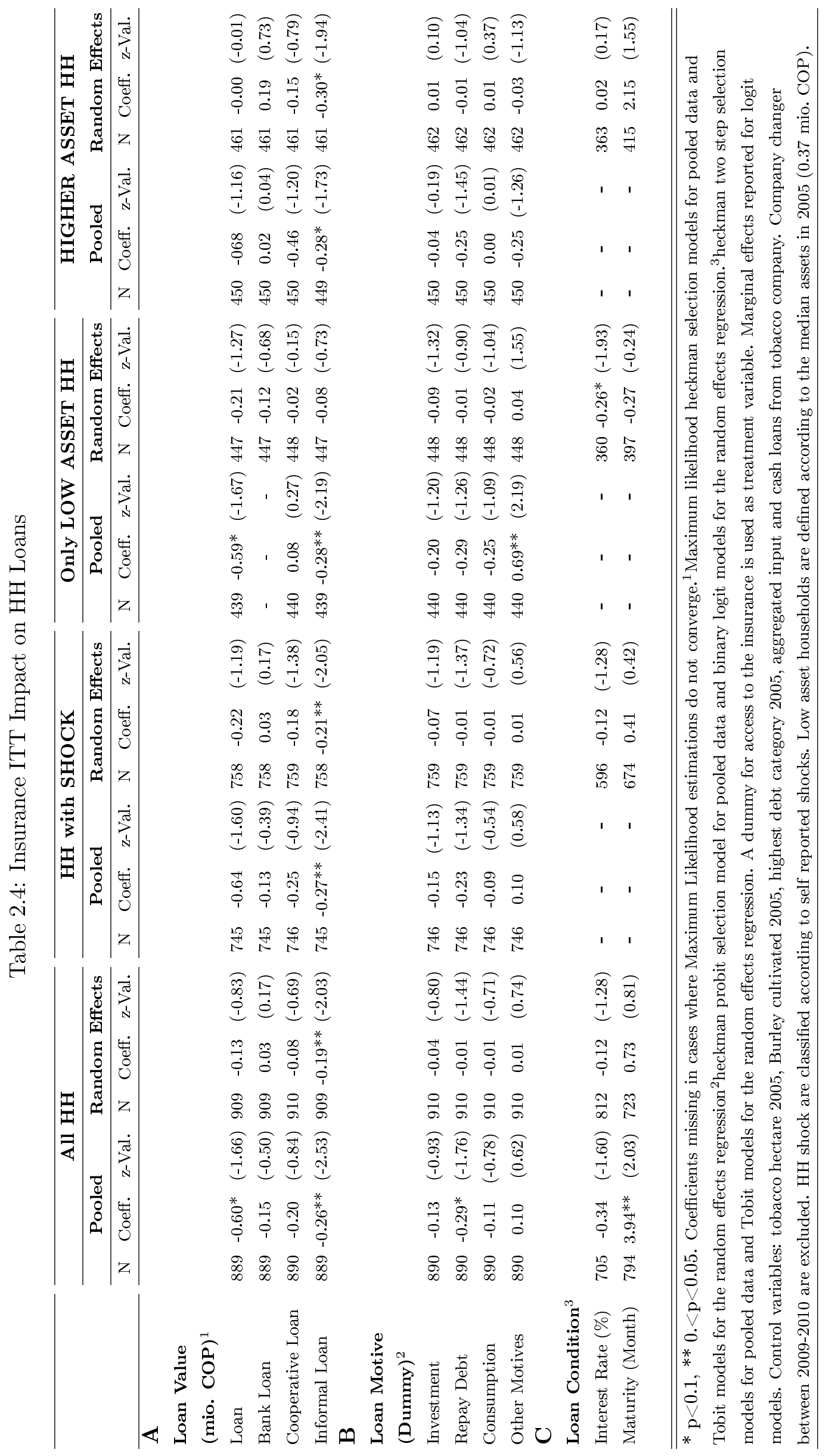


insurance has a modest negative effect on the total value of private loans, which is, however, only significant on the $10 \%$ level in the heckman selection model and not in the random effects model. Considering the source of funding, we find that the value of informal loans is significantly lower for participants who have access to the insurance program. This effect is consistent for the heckman selection model and the random effects Tobit model. The estimated Tobit coefficient suggests that access to the insurance reduced informal loans by about 200000 COP (approx. 100 US\$). The effect is similar in size to the average subsidy that every farmer with access to the insurance received from the public fund, the tobacco association and Protabaco ${ }^{16}$ Thus considering the complete premium including the share that was carried by the farmer, the effect on informal loans was on average smaller than the cost of the insurance. The coefficient is slightly larger when looking at the sub-sample of households that were affected by a shock, which could suggest that the insurance decreased the need for informal loans due to improved access to formal loans or less need for additional capital after shocks. Regarding the effect of access to the insurance on bank and comparative loans the coefficients signs are mostly negative but insignificant in all estimations. Furthermore, considering heterogeneous effects on poorer and more well off households the ITT coefficients on loan values are similar in size, however, the negative effects on the overall loan values and the informal loans are more salient for the poorer sub-group.

The results indicate that the insurance program decreased loans particularly from informal sources. But why did eligible households use less informal loans? To answer this question it is important to consider the motivation for loans. Panel B in Table 2.4 presents the results considering the reported motivations for the loan uptake. Descriptive statistics indicated that the principal motivation for loan uptake was to finance productive investments. However, the data suggest that motives varied depending on the sources of funding. While cooperative and bank loans were mainly used for productive loans, informal loans seemed to have more the character of "emergency" loans. They were less often used for investments than formal loans and were instead more often used to repay debts. The coefficients indicate that the program did not affect the use of loans for productive investments (see table 2.4). Regarding the likelihood to use loans to repay pending debts we find a modest negative effect, however, the coefficient

\footnotetext{
${ }^{16}$ Premiums were on average subsidized by $74 \%$, which equates to approximately 270000 COP weighted by an average of 1.25 hectares tobacco and $73 \%$ insurance adoption results in an average subsidy of around 250 000 COP per eligible farmer.
} 
is only significant for the whole sample and the heckman selection model. Changes in the likelihood to repay debts with loans could imply that the program decreased the vulnerability to debt traps for cases in which new credit had to be used to repay pending debts. Yet, the effect is not very salient, which might also be related to the lower bound effect of the ITT coefficient compared to the effect of actually being insured or more importantly being indemnified after suffering a shock. The likelihood to use loans to finance household's consumption is not significantly associated with the insurance. Lastly, the insurance program effect on loans for other purposes such as for example education, investments in the house, household shocks was positive and significant in the heckman selection model for poorer households but not significant otherwise. One disadvantage of our empirical approach is that we assume that error terms of the outcome variables are not correlated. However, loan motivations might be interdependent as using a loan for one purposes affects the likelihood to use a loan for another purpose 17 As robustness check we estimated models in which loan outcomes are estimated jointly in order to account for correlations of the error terms, which support the results of table 2.4 (see appendix).Panel C presents the estimated ITT coefficients on loan conditions. We test if access to the insurance led to better mean credit conditions approximated with the nominal interest rate and the credit maturity. In our sample, the average loan maturity was slightly below two years with a mean nominal interest rate of about 2 percent per month given that a household used a private loan. Generally, informal loans were associated with larger interest rates and lower maturities compared to formal loans. On average eligible farmers were charged lower interest rates and had larger maturities. The decrease in interest rates was stronger for the poorer sub-group whereas the positive effect on maturities was larger for the more well off sub-group. However, for the sub-group analysis the maximum likelihood estimations of the selection models do not converge so that only the tobit random effects coefficients are displayed in table 2.4

\section{Impact on Financial Assets}

Table 2.5 displays the ITT treatment coefficients on the financial asset variables. Marginal effects of the Multinomial Logit regression suggest that having access to the insurance reduced the likelihood of being in the lowest savings category by $11 \%$ (see table 2.5). The effect is

\footnotetext{
${ }^{17}$ About $10 \%$ reported multiple motivations per loan.
} 
larger when we focus on households that reported a shock. This points at a positive effect of the program on savings especially after being exposed to a shock. Moreover, the results hint at an effect that particularly benefited the savings of poorer households whereas it did not affect those in the more well of sub-group.

The estimation results do not suggest a clear program effect on the (log) value of household assets. However, if we exclude land property and only look at the value of liquid assets, we observe a positive and significant effect of the insurance program. This seems to support the theory that the insurance reduced the need to reduce household resources after shocks. This effect holds particularly true for the more well-off households, which is not surprising as there was little scope for an effect on low asset households.

The treatment effects do not show clear signs of a program effect on consumption. Looking at food and non-food consumption does not yield further insights. This could be due to a low elasticity of demand for food and due to ineligible households maintaining consumption levels by increasing debts and reducing savings.

Lastly, the results suggest that the insurance program had no significant effects on the household income per-capita, which could be related to the fact that the insurance was relatively new and that changes in the risk taking behavior might need some time and confidence in the insurance to evolve.

As Carter et al. (2007) note, climatic shocks can have long term impacts particularly on poorer households that might be derailed from what might have been a converging process otherwise. Therefore findings suggest that the insurance program improved households resilience to shocks and reduced their vulnerability to debt traps.

\section{Conclusion}

In this study we evaluate the impact of a traditional weather insurance program on small scale farmers producing tobacco in Santander, Colombia. We identify the impacts of the program exploring a natural experimental setup. The findings of the study indicate that access to the insurance generated some positive welfare effects for the beneficiaries. The results suggest that the insurance program tended to decrease households loans, leading them away from costly informal loans that are used to to repay debts and to deal with "emergencies". The insurance is also associated with increased savings and accumulation of liquid assets which can have 


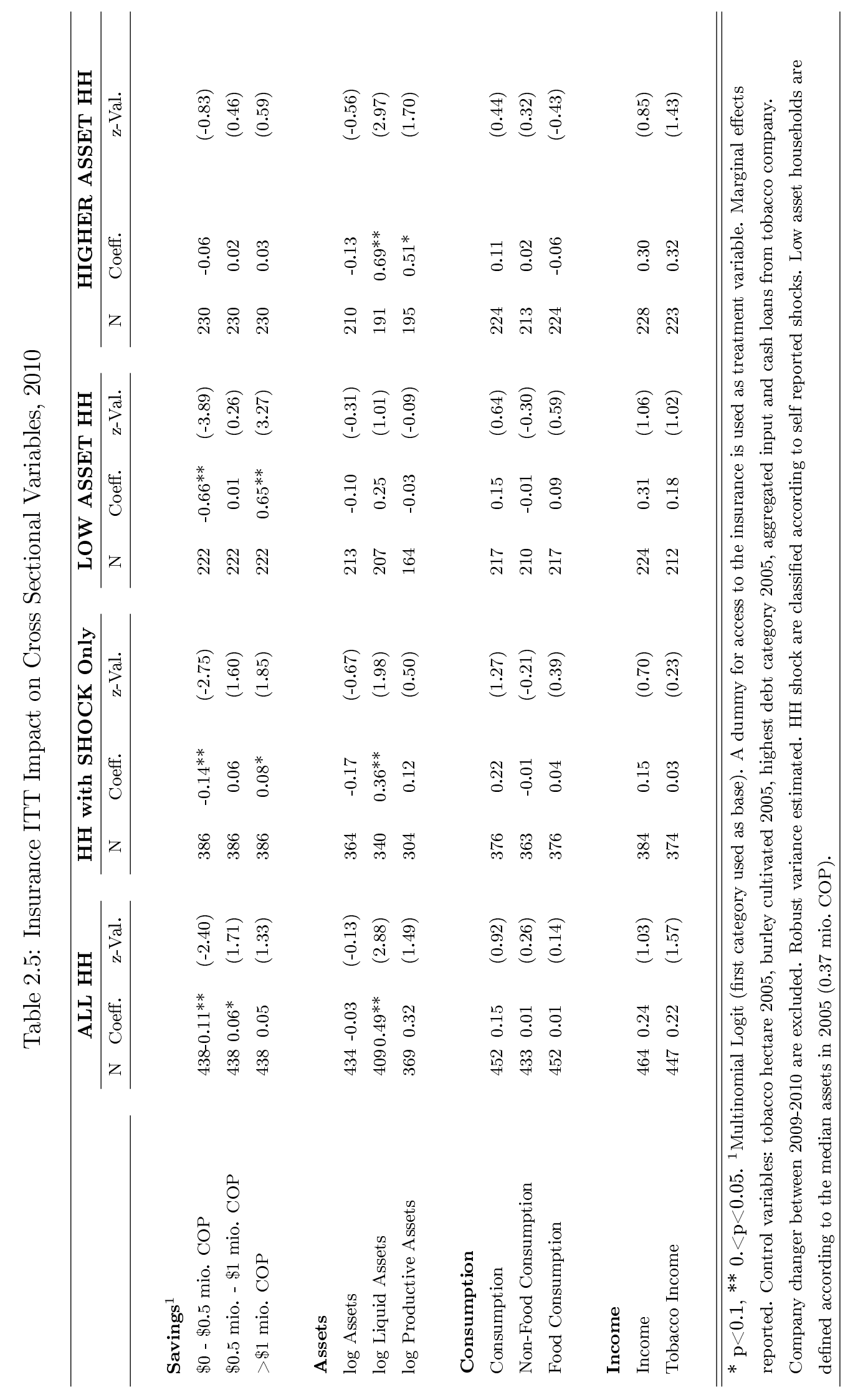


positive long term consequences. Yet, future research should focus on testing the long term impacts of the program.

The analysis of heterogeneous effects of the program by household level of wealth (value of assets) reveals that poorer households are the ones who benefit the most from the program in terms of an increased resilience to shocks. This suggest that agricultural insurance should set incentives to attract poorer farmers. Introducing a compulsory insurance program, supported with differentiated incentives to the poor could be an option. Alternatively, the implementation of less costly insurance products like index based insurance could help to improve access to the insurance by reducing the administration cost. This type of insurance could also help to reduce dissatisfaction with the insurance due to the inaccurate evaluation of the extend of damage. One aspect that is particularly weak on the current insurance program is that the evaluation of the extend of damage is done by experts who use their experience to estimate the expected return after a shock. This ad-hoc procedure seems to be very inaccurate. The use of index based insurance such as an area yield index could help to reduce that problem. A closer cooperation between the insurance company and tobacco companies could also contribute to improve this aspect as the tobacco company maintains historical records of the productivity of their farmers.

One of the limitations that the agricultural insurance faces is the dissatisfaction with the program. Farmers do not understand how insurances work and consider that they are entitled to a benefit independently of whether they are affected by shocks and the magnitude of the shock. Educational workshops would be required. 


\section{Appendix}

Table 2.7: Multivariate Probit and Seemingly Unrelated Regression of Insurance ITT Impact on HH Capitalization

\begin{tabular}{|c|c|c|c|c|c|c|c|c|c|c|c|c|}
\hline & \multirow{2}{*}{\multicolumn{3}{|c|}{$\frac{\text { ALL HH }}{\text { Pooled }}$}} & \multirow{2}{*}{\multicolumn{3}{|c|}{$\frac{\text { HH with SHOCK Only }}{\text { Pooled }}$}} & \multirow{2}{*}{\multicolumn{3}{|c|}{$\begin{array}{c}\text { LOW ASSET HH } \\
\text { Pooled } \\
\end{array}$}} & \multirow{2}{*}{\multicolumn{3}{|c|}{$\frac{\text { HIGH ASSET HH }}{\text { Pooled }}$}} \\
\hline & & & & & & & & & & & & \\
\hline & $\mathrm{N}$ & Coeff. & z-Val. & $\mathrm{N}$ & Coeff. & z-Val. & $\mathrm{N}$ & Coeff. & z-Val. & $\mathrm{N}$ & Coeff. & z-Val. \\
\hline \multicolumn{13}{|l|}{$\begin{array}{l}\text { Loan Size } \\
(\text { mio. COP })^{1}\end{array}$} \\
\hline Bank Loan & 908 & -0.08 & $(-0.48)$ & 757 & -0.08 & $(-0.43)$ & 447 & -0.28 & $(-1.64)$ & 461 & 0.14 & $(0.50)$ \\
\hline Cooperative Loan & 908 & -0.13 & $(-0.92)$ & 757 & -0.19 & $(-1.22)$ & 447 & 0.01 & $(0.08)$ & 461 & -0.20 & $(-0.89)$ \\
\hline Informal Loan & 908 & $-0.13^{* *}$ & $(-2.37)$ & 757 & $-0.15^{* *}$ & $(-2.33)$ & 447 & $-0.14 * *$ & $(-2.12)$ & 461 & -0.13 & $(-1.46)$ \\
\hline \multicolumn{13}{|l|}{$\begin{array}{l}\text { Loan Motive } \\
(\text { Dummy })^{2}\end{array}$} \\
\hline Investment & 910 & -0.07 & $(-0.67)$ & 759 & -0.13 & $(-1.17)$ & 448 & -0.22 & $(-1.46)$ & 462 & 0.05 & $(0.35)$ \\
\hline Repay Debt & 910 & $-0.24 *$ & $(-1.73)$ & 759 & -0.26 & $(-1.72)$ & 448 & -0.32 & $(-1.49)$ & 462 & -0.18 & $(-0.94)$ \\
\hline Consumption & 910 & -0.12 & $(-0.97)$ & 759 & -0.14 & $(-0.97)$ & 448 & $-0.34^{*}$ & $(-1.78)$ & 462 & 0.08 & $(0.44)$ \\
\hline Other Loan Motive & 910 & 0.10 & $(0.71)$ & 759 & 0.07 & $(0.47)$ & 448 & $0.59 *$ & $(2.34)$ & 462 & -0.25 & $(-1.38)$ \\
\hline \multicolumn{13}{|l|}{ Loan Condition ${ }^{1}$} \\
\hline Interest Rate (\%) & 668 & -0.12 & $(-1.02)$ & 550 & -0.13 & $(-1.01)$ & 333 & -0.18 & $(-1.28)$ & 335 & 0.02 & $(0.10)$ \\
\hline Maturity (Month) & 668 & 0.85 & $(0.72)$ & 550 & 1.02 & $(0.77)$ & 333 & -0.47 & $(-0.34)$ & 335 & $3.19^{*}$ & $(1.70)$ \\
\hline \multicolumn{13}{|c|}{$\begin{array}{l}{ }^{*} \mathrm{p}<0.1,{ }^{* *} 0 .<\mathrm{p}<0.05 .{ }^{1} \text { Seemingly unrelated regression. }{ }^{2} \text { Multivariate probit regression. Marginal } \\
\text { effects reported. Control variables: tobacco hectare } 2005 \text {, Burley cultivated } 2005 \text {, highest debt category } \\
2005 \text {, aggregated input and cash loans from tobacco company. Company changer between 2009-2010 ar } \\
\text { excluded. HH shock are classified according to self reported shocks. Low asset households are defined } \\
\text { according to the median assets in } 2005 \text { (0.37 mio. COP). }\end{array}$} \\
\hline
\end{tabular}




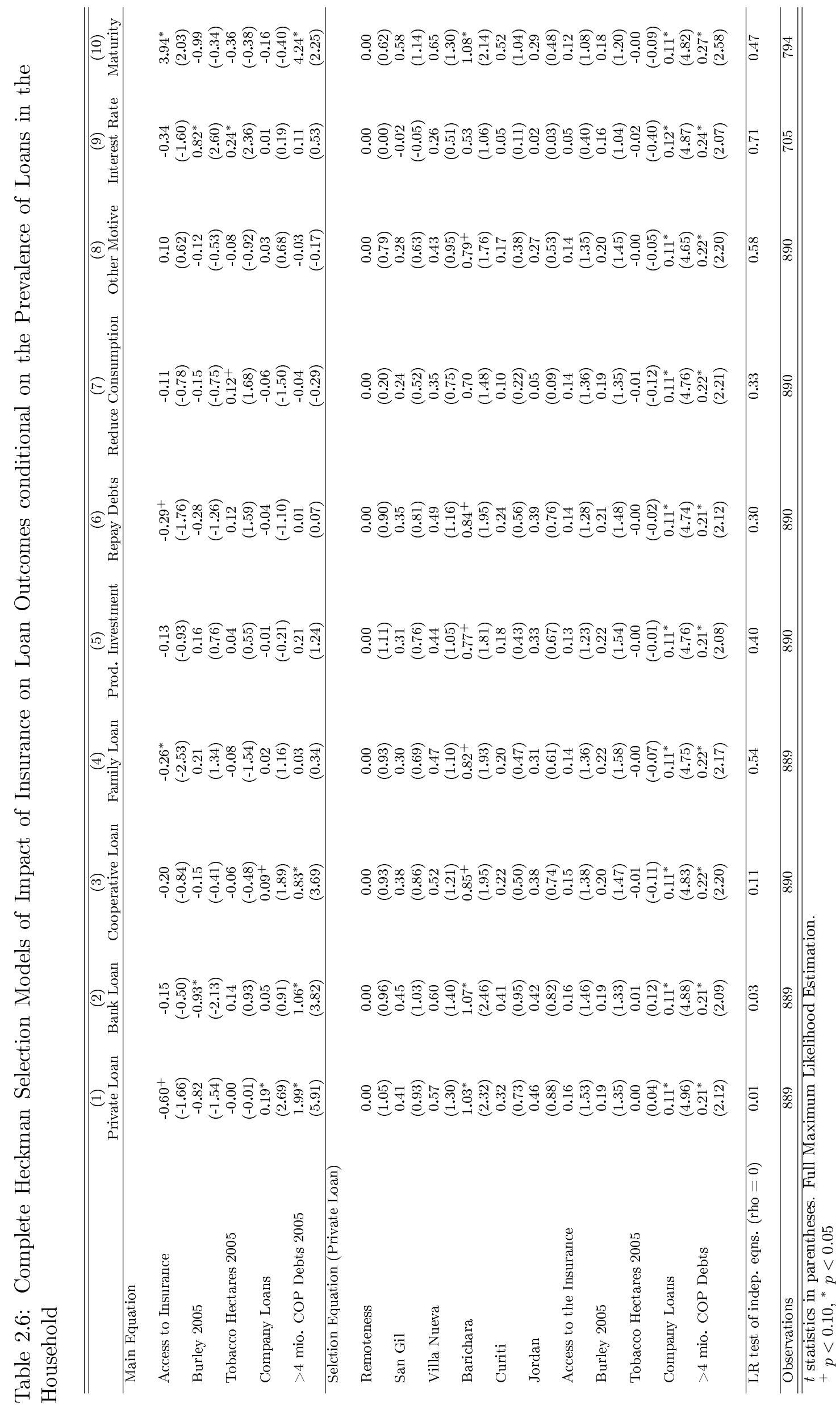


3.

\title{
Lucky for those who get it: Impact of Insurance Indemnifications on the Resilience to Shocks of Small Scale Farmers
}

\begin{abstract}
This paper explores the impacts of indemnity payments of a yield insurance on small scale tobacco farmers in Colombia. The analysis addresses three questions. First, who received indemnity payments? Secondly, were indemnities large enough to take effect on coping mechanisms? Thirdly, how did households use their indemnification payments? The analysis benefits from survey data that cover a period of severe climatic shocks. The identification strategy harnesses two features: first, out of two tobacco companies only one offered the insurance to their contract farmers and secondly, even among insured farmers a surprisingly large overlap in losses between indemnified and non-indemnified households can be observed. OLS and multivariate Probit models are estimated to quantify the indemnification impacts on coping strategies and the financial well being of households. The findings indicate that indemnified households were less likely to reduce their financial resources including assets and savings after shocks. Moreover, indemnified households reported significantly less loans in the aftermath of shocks.
\end{abstract}

\section{Introduction}

In this paper I investigate if indemnification payments from a yield insurance in Colombia helped small scale tobacco farmers to deal with income losses. More precisely, I examine how insurance payments affected coping strategies and the financial well-being of insured households in the aftermath of severe climatic shocks. On first sight it could seem obvious that a positive income shock helps households to deal with negative income shocks. However, this analysis addresses three questions. First, who received indemnity payments and were indemnities paid out consistently in this traditional insurance program? Secondly, were indemnities 
large enough to take a discernible effect on coping mechanisms? Thirdly, how did households use their indemnification payments?

The analyzed yield insurance covers weather related crop failures of farmers. Indemnification payments were triggered upon individual inspections of damages, which made payments dependent on the evaluation of an external inspector. The insurance was subsidized with up to $60 \%$ by the Colombian government who intended to reduce ex post emergency funds and to promote investment in the agricultural sector with the subsidy.

However, in 2010 and 2011 the weather phenomenon La Niña resulted in heavy rains and floods causing major damages that affected about 3 million Colombians and resulted in emergency relief programs summing up to about 400 million US\$ in humanitarian aid as many households were not able to cope with the losses themselves 11 In these cases where shocks drop assets below critical levels, households might be pushed onto a path leading to poverty, making recovery dependent on external help (Carter et al., 2007; Kovacevic and Pflug, 2011). Yet, providing efficient risk management tools could help households to reduce their vulnerability to poverty traps (World Bank, 2013). In the last decade innovations in the insurance sector have been a promising development giving poor households access to formal insurance (Dercon and Kirchberger, 2008; Churchill and Matul, 2012). The total number of microinsurance contracts sold in 2011 is estimated to be above 500 million covering different perils in the health, agricultural and life insurance sector (Churchill and Matul, 2012). Insurance indemnifications are expected to compensate for the losses reducing the need to apply costly coping strategies, which reduces the vulnerability to future shocks (Barnett and Skees, 2008, Heltberg et al., 2009). However, in the agricultural sector there is little empirical evidence in support of this relationship as indemnified and non-indemnified farmers cannot be compared in a straight forward way as they were differently exposed to shocks or comparisons suffer from self selection bias. Despite that, analysis in the health insurance sector analyzed how insurances affect coping mechanisms after health shocks. Dekker and Wilms (2010) describe for example a negative relationship of a micro health insurance in Uganda with out of pocket payments after illnesses supposedly related to the indemnification by the insurance, which decreased assets sales and debts.

Similar to insurance indemnifications, cash transfers and remittances can be regarded

\footnotetext{
${ }^{1} \mathrm{http:} / /$ www.colombiahumanitaria.gov.co (access 2.11.2013)
} 
as a positive income shock that contributes to the financial resources of households in the aftermath of shocks. De Janvry et al. 2006) examine how PROGRESA cash transfers served as a safety net. The authors report that transfers protected households from taking children out of school in response to shocks. In a similar way, Mohapatra et al. (2012) use propensity score matching with data from Pakistan and Ethiopia to show that remittances first of all increased when shocks occur in recipient households and consequently decreased the likelihood of asset sales as an ex-post coping strategy to shocks. In a previous study Dietrich and Ibanez (not published) analyzed the same insurance program using the same data set exploring the impacts on households loans and other financial variables. The results indicate a negative effect of the insurance on informal loans and a positive effect on savings and assets. Yet, it remains unclear whether the impacts were related to indemnification payments or through changes in risk attitudes or the credit worthiness. Therefore this study sheds more light on the specific impact channels of the insurance through indemnification payments after shocks.

Several recent studies have analyzed the impacts of microinsurances on productive decisions of farmers using RCTs (Cai et al., 2011; Cole et al., 2013; Mobarak and Rosenzweig, 2013). In contrast to these articles, this study is based on non-experimental data. Despite the many benefits of RCTs, there are also limitations. Best practice programs could be more likely to agree to be evaluated by RCTs compared to those that suffer from shortcomings resulting in self selection. Moreover, once programs know that they are being evaluated they might perform differently (Deaton, 2010). This study hints for example at implementation problems of the programs supporting the procedural burdens with yield insurances for small scale farmers.

This analysis focuses on tobacco contract farmers who are particularly vulnerable to shocks. In the research region most farmers do not own their land and almost all households earned less than the prescribed minimum wage..$^{2}$ Moreover, the productive risks are high so that farmers frequently have to deal with crop failures. For the analysis households were interviewed after a period of adverse climatic shocks that triggered indemnifications in several cases. The data cover self reported shocks and coping strategies as well as different aspects of households financial well being including loans, debts, savings, assets, expenses and income, which could be affected by households responses to shocks. The identification of the indemnity impacts

\footnotetext{
${ }^{2}$ About $91 \%$ of the households in our sample earned less income per adult household member than the prescribed minimum wage. The minimum wage is approx. 3 200US\$ per year compared to approx. 1500 US\$ income per adult in the research region.
} 
is based on two features. First, out of two very similar tobacco companies only one offered the insurance to their farmers, which is a requisite for receiving an indemnity. Secondly, even among insured households a considerable overlap of losses can be observed between indemnified and non-indemnified households, which allows to construct counterfactuals to indemnified households. A source for this loss overlap could be due to around $11 \%$ of insured households that claimed damages that were never inspected by the insurance company. The analysis of the determinants of indemnity payments suggest that these inconsistencies were not associated with household characteristics and seemed to be related to the limited verification capacities of the insurance company. OLS models including household fixed effects and multivariate probit models are estimated to quantify the indemnity impacts.

The results indicate that households that received an indemnity were less likely to reduce their financial resources after shocks. Furthermore, indemnified households were associated with lower loan values at the beginning of the next year, which could be related to a decreased need for emergency loans. The results suggest that despite the problems with the insurance those households that received an indemnification payment were better off after a period of severe climatic shocks. In addition, robustness checks that address endogeneity concerns and spill over effects of indemnities via informal transfers to other households support the findings.

The paper is organized as follows: section 2 presents a description of the insurance program. Section 3 describes the data and section 4 presents the methodological approach. In Section 5 to 7 the estimation result are discussed and in the last section I present concluding remarks.

\section{Background}

In 1993, the Colombian government started to create an institutional setting for agricultural insurances. A central instrument has been a public insurance fund that subsidizes climate insurances of farmers with up to $60 \%$ of the premium, which had a budget of about 31000 mio. COP (approx. 16 mio. US\$) in 2012. In 2004, the first insurance was offered to cotton farmers and was henceforth extended to several other crops. The details of the insurance specifications vary among crops and generally cover seven weather related events: excessive rain, flooding, hail, excessive wind, drought, erosion and pest. Currently only one company, MAPFRE, offers this type of insurance, which they lunched in 2007. The insurance is based on a yield insurance scheme in which indemnifications are paid after on site evaluations. 


\section{Insurance in the Tobacco Sector}

In Colombia about $0.4 \%$ of the cultivated area is dedicated to tobacco, which equates to around 14000 hectares. Santander, the research region, is the main tobacco producing department with about 3000 tobacco farmers. The mode of production is based on contract farming: prior to the cultivation the tobacco company negotiates contracts with the farmers setting the number and type of plants to be cultivated. Based on this contract, the company allocates credit in input material and cash that is repaid when the farmers hand in the cured tobacco leaves. There are up to two tobacco harvests per year. Most investments are made in the first harvest and only some farmers cultivate a second harvest that requires less investments and yields lower returns. The cultivation is very sensitive to climatic changes and the timing of the rain has strong impacts on the quantity and quality of the final harvest. At the same time loans to finance input materials constitute nearly half of the harvest value, which means that crop failures can lead to a reinforcing debt circle or loan defaults.

Two companies, Protabaco and Coltabaco, dominate the tobacco industry in Colombia. The special feature in this sector is that out of the two companies only Protabaco offered the insurance to their farmers. Hence, out of a very homogenous group of farmers only one part had access to the insurance, which was an essential condition for indemnities. Ultimately it was not clear why Coltabaco did not offer the insurance to their contract farmers and whether it would be offered in the future. However, several points could be listed. First, a wait and see strategy avoids the first mover cost of establishing the insurance. This includes for example the investments that Protabaco incurred in order to help to establish the insurance in the tobacco sector. Moreover, problems with the insurance could outweigh the benefits and waiting to see how the insurance performs before offering it to their farmers seems a reasonable second mover strategy.

The crop insurance in the tobacco sector was first offered in 2008. As the program was heavily subsidized by the public fund (60\%), the tobacco association (20\%) and the tobacco

company (6\%), insurance demand was high covering $78 \%$ of Protabaco farmers. Due to the subsidies, farmers only had to pay $14 \%$ of the premium plus taxes which summed up to be about 100000 COP (approx. 50 US\$) per hectare of Burley tobacco. 


\section{Insurance Indemnification}

The indemnification formula is based on estimated production cost, the yield and the historic yield. To avoid individual assessments, production costs per hectare are approximated by regional and tobacco variety specific means. The production cost $(c)$ includes input, labor and the renting cost after the plots have been established; risks associated with the transplantation of the plants or the curing phase are not covered. As a benchmark for the trigger value the mean historic yield per hectare $\left(h_{i}\right)$ of the last four years is used. The indemnification trigger value is defined as a drop of the current yield $\left(y_{i}\right)$ below $70 \%$ of the historic yield due to a weather shock ${ }^{3}$ In that case insured households are compensated for every lost kilo beneath the trigger value. The price per indemnified kilo is determined by the estimated production costs and the historic yield. Moreover, to reduce information asymmetry problems farmers have to carry a deductible of $15 \%$ of the estimated costs per hectare c. This results in the following formula to calculate the value of indemnification payments:

(1) Indemnification $=\left(0.7 * h_{i}-y_{i}\right) * \frac{c}{h_{i}}-0.15 * c$

In case of a shock, farmers contact a tobacco company official, who forwards the claim to the insurance company. Within eight days of receiving the report, the verification should take place. Independent inspectors assess how the final yield will be affected by the shock and thereby rely on their experience in the tobacco sector. If the plants died it is rather easy to determine the loss according to the historic yield and the mean production cost, but no clear formula exists for partial losses or quality decreases of the final yield. As losses often occur during the cultivation cycle it is difficult to foresee the impacts on the final output. Hence, some inconsistencies in the verification seem to be inevitable. Indemnifications are handed out to the farmer through the tobacco company at the end of the cultivation cycle jointly with the tobacco earnings and the tobacco company also uses the indemnifications to balance the farmer's debts with the company.

\section{Data and Descriptive Analysis}

Survey data were collected in the beginning of 2011 in the main tobacco producing department. For the sampling, focus was put on the tobacco production nucleus using producer lists of 2008

\footnotetext{
${ }^{3}$ The numbers change for other departments and the formula presented applies to tobacco farmers in Santander. In 2010 the production cost per hectare was estimated to 6.7 mio. COP for Burley tobacco in the research region.
} 
of both tobacco companies to randomly draw the households that were to be interviewed. In two waves 450 and 137 households were selected. In the second wave indemnified households were oversampled in order to get a sufficient amount of treated households $4^{4}$ Out of a total of 2242 tobacco farmers in the region, 468 households were interviewed including 264 insurance program participants.

The data include detailed information on household shocks in 2009 and 2010 covering the type of shock, the financial impacts on the household and how they responded to the shock. Moreover, the data cover loans, debts, savings, assets, expenses and income at the time of the survey. To shed more light on the comparability of farmers of both companies, questions on household characteristics were asked for the year 2005 hence before the program was implemented.

\section{Household Characteristics and Balance Table}

Table 3.1 depicts the descriptive statistics of pre-program characteristics and whether they were associated with 1) the tobacco companies, 2) households insurance status 3) households indemnification status.

Farmers cultivated about one hectare of tobacco in the main harvest and more than half of the households did not own their plots. About two thirds of the households in the sample produced for Protabaco while one third produced for Coltabaco and hence had no access to the insurance. Typically, farmers in the research region maintain long term relationships with their tobacco company and the fluctuation between both companies is fairly low. In the sample more than $90 \%$ of households that produced tobacco in 2005 still produced tobacco for the same company in 2010. Moreover, farmers of both companies are not spatially segregated and share the same neighborhoods being exposed to the same conditions. A more detailed description of the natural experimental set up can be found in chapter 2 where the effects of having access to the insurance on household loans and financial assets is analyzed. Yet, some differences in productive variables such as the type of tobacco and the input package between farmers of both companies can be observed, which are more likely to be driven by tobacco company demand differences rather than inherent differences of farmers (see column (1) of table 3.1.

\footnotetext{
${ }^{4}$ According to administrative data about $28 \%$ of the insured contracts in 2009 and 2010 were indemnified compared to $35 \%$ in the sample.
} 


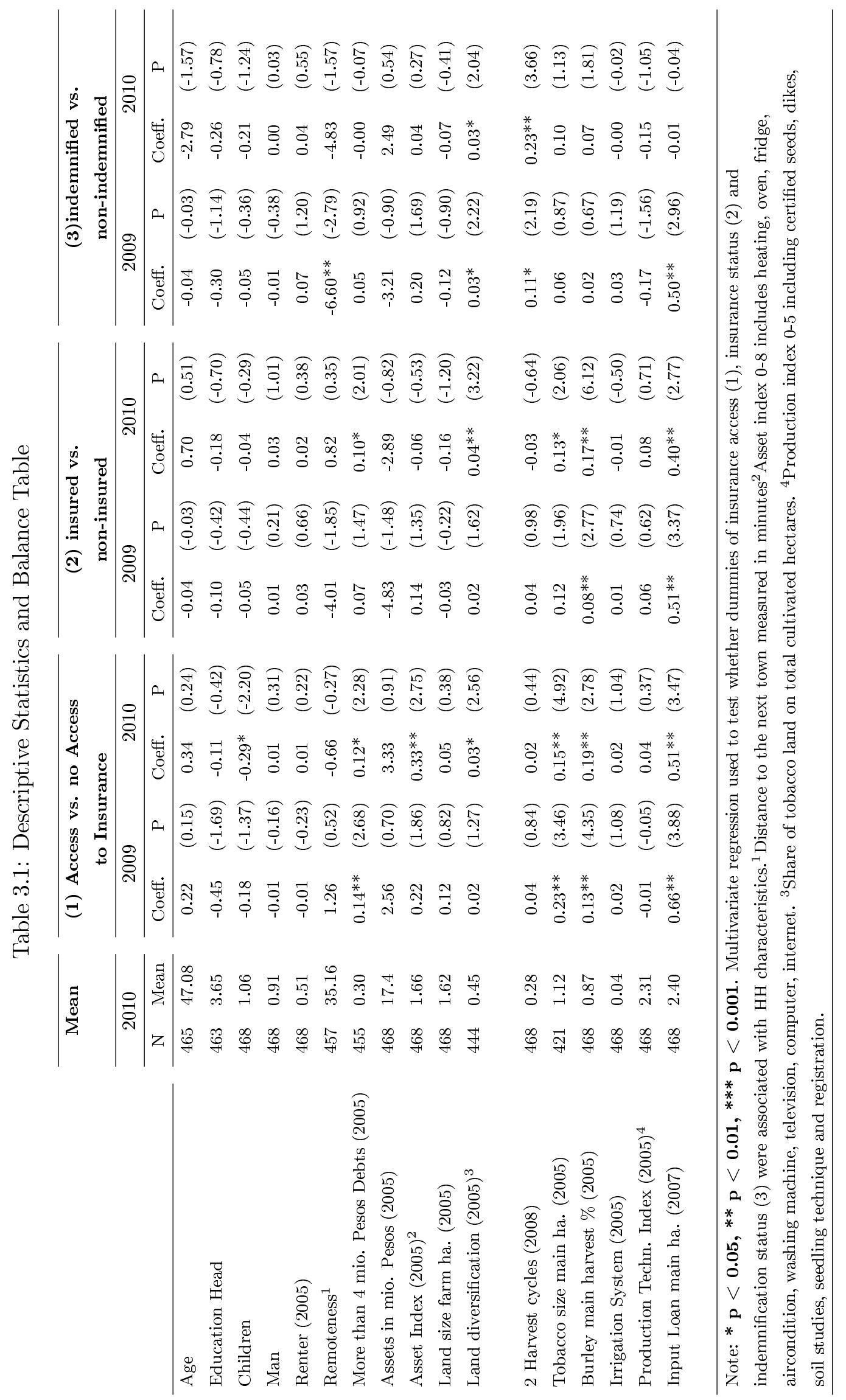


Furthermore, among the 313 Protabaco farmers in the sample about $62 \%$ purchased the insurance in 2009 and $85 \%$ in 2010. However, some regional differences in insurance adoption became evident. In some neighborhoods nearly all farmers adopted the insurance already in 2009 whereas in others the majority only adopted it in 2010, which could be related to different diffusion patterns of this relatively new product. Column 2 of the table 3.1 indicate that differences among insured and non-insured households in the sample are very similar to the company differences and do not hint at systematic differences between insured and non-insured households.

Most importantly, in the third column of table 3.1 differences in pre-program characteristics between indemnified and non-indemnified households are displayed, which constitute the treatment and control group for this analysis. Farmers of both groups were comparable in most aspects except the distance to the next town and the number of tobacco harvests. Differences in the number of harvests are not surprising as farmers that cultivate two harvest cycles instead of just one are more exposed to production risks and hence more likely to receive an indemnity. The difference in the distance to the next town could be related to a variation in the exposure to shocks in certain areas.

In the data set 124 households reported an insurance indemnification for 2009 and 61 for the year 2010, offering a fair amount of treated households. The average value per insurance payout summed up to 1.5 mio. COP (approx. $750 \mathrm{US} \$$ ) in 2009 compared to 0.5 mio. COP per payout in 2010. As in 2010 the second and less important harvest was affected, the indemnities were on average lower compared to 2009. Despite that more than $20 \%$ of the insured households claimed indemnification in 2009 and 2010 but were rejected. In cases where there was a claim, the average time until losses were verified exceeded the stipulated 8 days and took on average 18 days. Due to the covariance of shocks, farmers tended to make claims at the same time and thereby overwhelmed the verification capacities of the insurance company. In the data, $11 \%$ of the households that claimed indemnification reported that crop damages were never verified. These problems with the verification caused dissatisfaction among many program participants: $55 \%$ stated to be unsatisfied or very unsatisfied with the insurance and more than $65 \%$ reported little or no confidence in the insurance. The main complaint was that the insurance does not sufficiently pay out after losses (46\%), that they do not pay at all (18\%) and insufficient explanation of the insurance terms (18\%). On the other side, the tobacco 
company related verification problems to the low comprehension of insurance terms by the farmers.

\section{Climatic Shocks}

In the main harvest of 2009 the research region was struck by a major drought that led to significant crop failures and in 2010 an excess of rain caused considerable deficits in the second harvest cycle. Losses in these two years were exceptional and exceeded normal yield fluctuations markedly. Figure 3.1 displays the prevalence of self reported shocks from 2008 to 2010. For the year 2009 about $90 \%$ of the insurance program participants reported a shock, which only slightly decreased in 2010. This was mainly due to climatic events, as economic or health shocks were less important 5 The value of self reported losses for 2009 sums up to

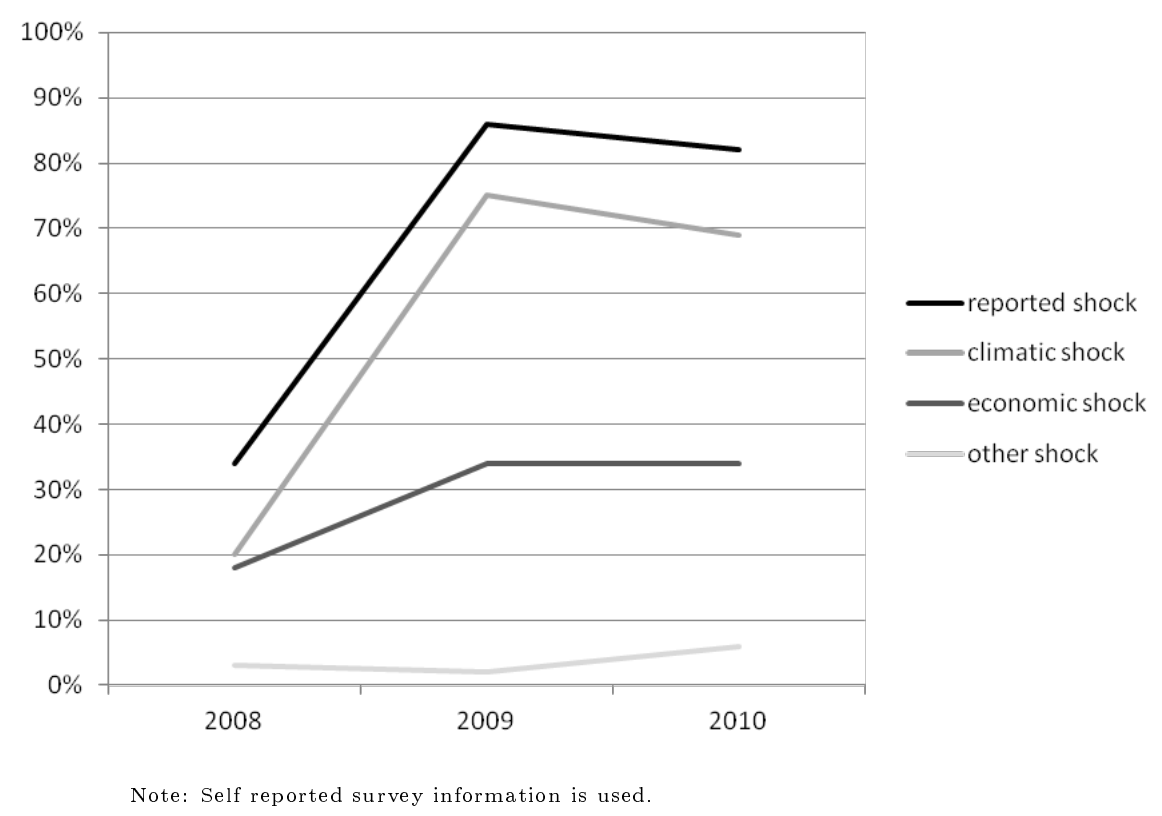

Figure 3.1: Prevalence of self reported Shocks

4.3 mio. COP (approx. 2 150US\$) and 3.6 mio. COP (approx. 1 800US\$) for 2010. This is quite substantial considering that the total household income in 2010 was about 9 mio. COP (approx. 4 500US\$).

In addition to observing a period of shocks, it is also important for the analysis to look at the distribution of losses. If all losses would be covered by the insurance than indemnifications would be perfectly determined among insured households. Figure 3.2 displays the kernel densities of losses. The left graph presents the loss distribution by indemnified and non-indemnified

\footnotetext{
${ }^{5}$ Economic shocks include job losses and non-farm business losses.
} 
households for the whole sample whereas the right graph only includes the subgroup of insured households that was eligible for indemnifications. In both graphs a shift to the right of indemnified households compared to non-indemnified becomes evident. This implies that households that received an insurance payment suffered on average larger losses. However, the difference is clearly not deterministic, which could have several reasons. Most importantly non-insured households were excluded from indemnifications resulting in non-indemnified losses. But also when looking at the subgroup of insured households the distribution remains similar. As the insurance only covers weather related tobacco losses, the overlap could source form losses that were not covered by the insurance. Lastly, the loss overlap could result from problems with the verification processes such as the $11 \%$ of claims that were never verified. Especially the right graph suggests that several insured households suffered significant losses that were not indemnified by the insurance. This is an interesting finding as it points out that the insurance smoothed losses only to a surprisingly low extend, despite the fact that the insurance covered the main risks of the main income source of these households.
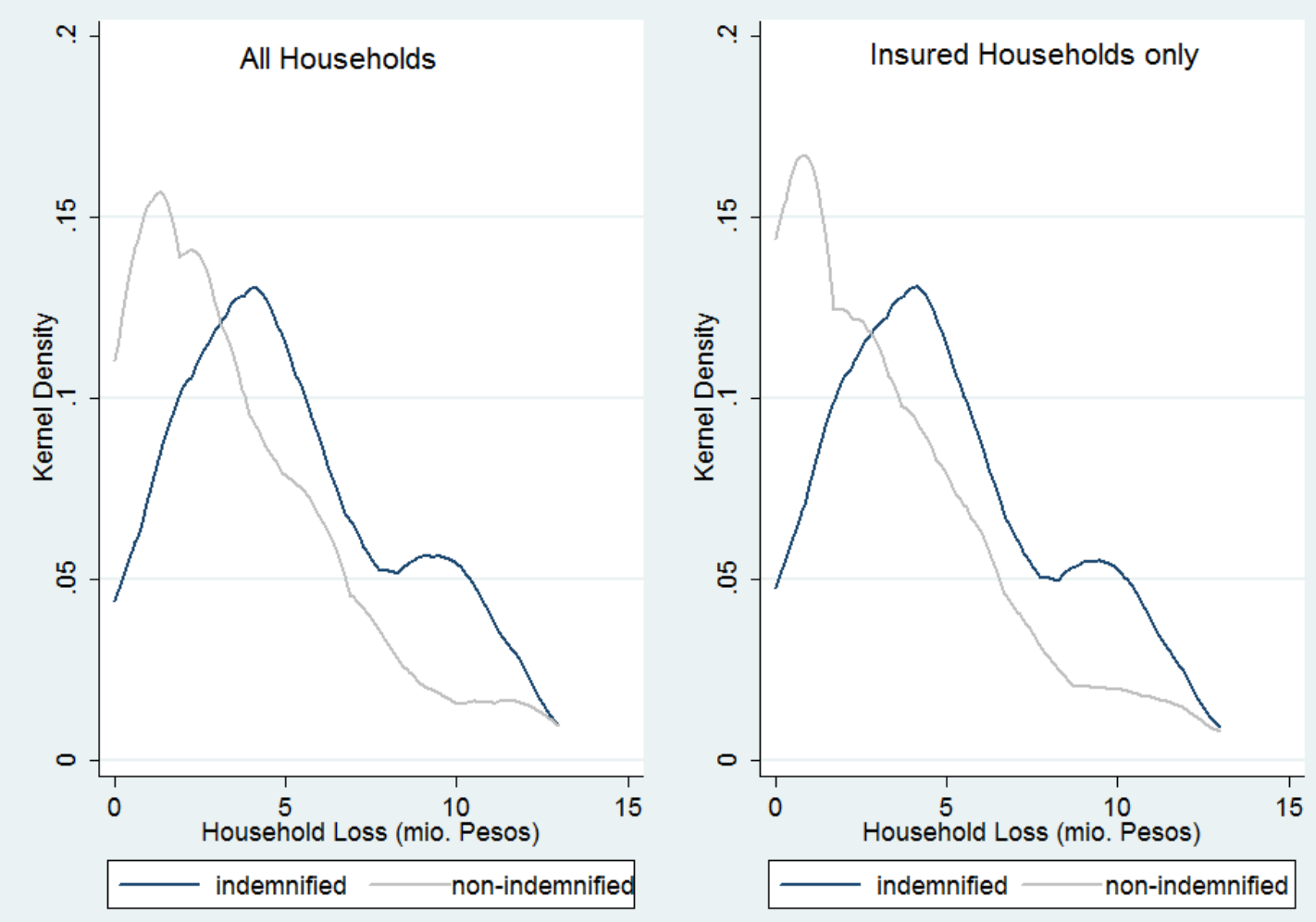

Note: epanechnikov kernel with "optimal" bandwidth are used. Data pooled for 2009 and 2010.

Figure 3.2: Overlap of Losses between indemnified and non-indemnified HH $(2009+2010)$ 


\section{Outcome Variable}

The data set offers information on households responses to shocks in 2009 and 2010. Coping strategies are classified into five categories, comprised of: no active strategy (minor losses, received indemnification; 47\%), loans (formal or informal and refinancing loans; 33\%), reduction of household resources (assets sales and savings; 18\%), reduction of expenses (6\%) and income diversification (second job, emigration, taking children out of school; 5\%). About 36\% of the indemnified households reported that they used the insurance payment as one of their main coping activities. Yet, ex post risk management often consists of a portfolio of actions (Skoufias, 2003). In about $24 \%$ of the cases households reported multiple coping strategies per shock. Table 3.2 displays the differences between indemnified and non-indemnified households in 2009 and 2010. This simple comparison shows a significantly higher likelihood to apply no active coping strategy for indemnified households in 2009 and a larger likelihood to use loans in response to shocks.

In addition to the dummy variables for coping strategies, the impact on households financial well being is analyzed, which can be regarded as the consequence of changes in coping strategies. Therefore data on loans, debts, savings, assets, consumption and incomes are considered. These variables are only available for the year 2010 except for loan data, which are also available for 2009. The average annual income per capita summed up to around 2.6 mio. COP (approx. 1300 US\$), 80\% of the households reported no or only minor savings and around $70 \%$ used a loan from formal or informal sources with an average value equivalent to the per capita household income in 2010 and only about half of it in 2009. The marked increase in loans from 2009 to 2010 might be result of the climatic losses and the need for capital in order to compensate for the losses of two consecutive years with adverse climatic events. 
Table 3.2: Descriptive Statistics of Outcome Variables

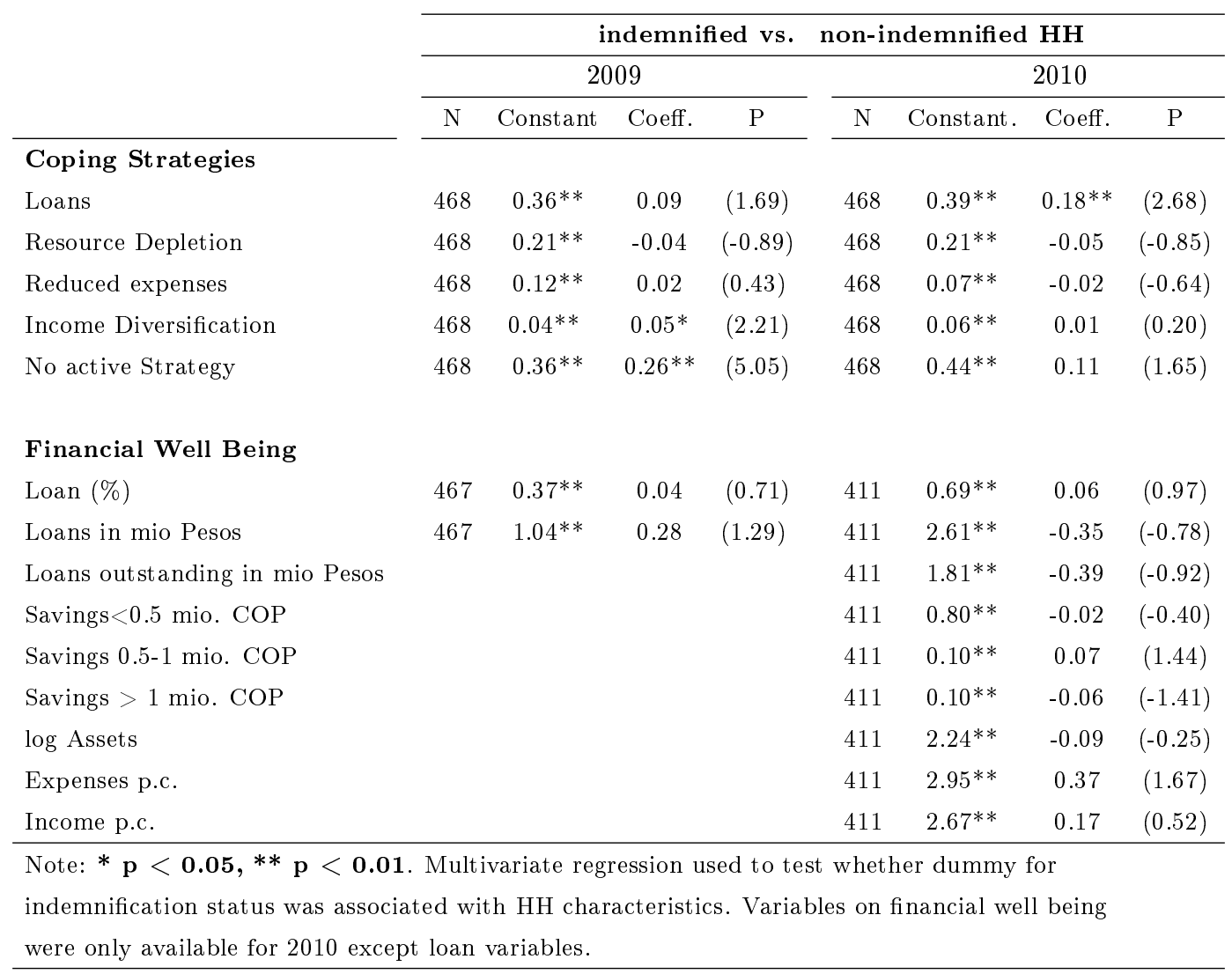

\section{Econometric Framework}

The data set consists of two groups of households out of which only one had access to the insurance. The decision to purchase the insurance was voluntary and not all household that had access to the insurance adopted it in the analyzed period. However, being insured is an essential requirement for receiving an indemnity after a shock. In order to quantify the indemnity impacts on coping strategies $\left(C_{i}\right)$, indemnified households $\left(I_{i 1}\right)$ are compared to non-indemnified households $\left(I_{i 0}\right)$. As indemnifications are only paid to the households that suffered a shock $\left(S_{i}\right)$, both, the treated and control groups need to be comparable in their shock exposure. Thus the average treatment effect of indemnifications can be presented as,

(2) $A T E=E\left[C_{1 i} \mid I_{i}=1, S_{i}=1\right]-E\left[C_{0 i} \mid I=0, S_{i}=1\right]$

\section{Estimation Procedure}

To test whether problems with the verification processes were systematic, I first explore the determinants of indemnity payments among insured households disregarding farmers that 
had no access or abstained from the insurance program. Thus I test if determinants besides the tobacco shocks made insurance customers more likely to receive indemnifications. Yet, in order to receive a payment the insured household needs to claim a loss, which could be affected by household characteristics such as for example the education level. Therefore I estimate Heckman selection models with the likelihood of a claim as selection equation and the indemnity status as outcome of the main equation. For the identification of the claim and indemnity equations, two sets of variables are incorporated that only affect the likelihood of claims but not the indemnity payments. First, shocks that were not covered by the insurance are assumed to increase the likelihood of claims but not the indemnity status 6 Secondly, dummies representing the tobacco company technician who consult farmers in their productive decisions and who are responsible to forward claims to the insurance company. $]^{7}$

In the second step the indemnity impacts on coping strategies and the financial well being are discussed including the whole sample of insured and uninsured farmers. All indemnified households were insured whereas non-indemnified households either produced for Coltabaco or they produced for Protabaco but did not buy the insurance. The crucial underlying assumption is that the coping strategies would be the same in the absence of indemnity payments. As mean losses of indemnified households exceed those of non-indemnified, losses are included as control variables in the estimations. Thus, by running OLS regressions to estimate the effect of indemnity payments on coping strategies the model can be expressed as follows:

(3) Coping Strategy $i=\beta_{0}+\beta_{1}$ Indemnity $_{i}+\beta_{2}$ Household Loss $_{i}+u_{i}$

As the decision to purchase the insurance was voluntary for Protabaco farmers unobserved confounders could bias the estimations. Therefore household fixed effects are included in the estimation whenever possible to rule out time invariant heterogeneity such as unobserved regional and company differences. Yet, one shortcoming of this models could be that different coping strategies interdepend on each other. In other words, applying one strategy affects the likelihood to apply another strategy. Thus I additionally present multivariate probit regression results to account for a possible correlation of error terms. Thereby the following equations are estimated jointly:

\footnotetext{
${ }^{6}$ Taking the low insurance education of farmers into account, suffering a shock that is not related to a climatic event is expected to increase the likelihood to make a claim without affecting the likelihood to get an indemnification payment.

${ }^{7}$ Households might be more likely to make a claim depending on characteristics of their tobacco company technician, which in return shouldn't affect the decision of the insurance inspectors to accept a claim.
} 
(4) $C_{i}^{\text {Loans }}=\beta_{0}+\beta_{1}$ Indemnity $_{i}+\beta_{2}$ Household Loss $_{i}+u_{1}$

(5) $C_{i}^{\text {Resources }}=\beta_{0}+\beta_{1}$ Indemnity $_{i}+\beta_{2}$ Household Loss $i+u_{2}$

(6) $C_{i}^{\text {Expenses }}=\beta_{0}+\beta_{1}$ Indemnity $_{i}+\beta_{2}$ Household Loss $_{i}+u_{3}$

(7) $C_{i}^{\text {Diversification }}=\beta_{0}+\beta_{1}$ Indemnity $_{i}+\beta_{2}$ Household Loss $_{i}+u_{4}$

(8) $C_{i}^{\text {NoactiveStr }}=\beta_{0}+\beta_{1}$ Indemnity $_{i}+\beta_{2}$ Household Loss $i+u_{5}$

where $u=\left(u_{1}, u_{2}, u_{3}, u_{4}, u_{5}\right)$ is an i.i.d. random variable with mean zero and orthogonal covariance matrix. Yet, a disadvantage of this approach is that the data have to be pooled and that they hence could suffer from serial correlation. For example, depleting household savings in 2009 rules out that savings were used in 2010 to cope with shocks. In the estimations a dummy for the indemnification status of the household is used as treatment variable and several control variables are included according to observed differences in the balance table 3.1 .

\section{Determinants of Indemnification Payments}

The Heckman estimation results are displayed in the first two columns of table 3.3. The results indicate that indemnification claims of insured households were -not suprisingly- affected by tobacco losses. Besides that households in certain areas and in the year 2009 were less likely to claim an indemnity. Controlling for the likelihood to make a claim, indemnifications were no longer affected by tobacco losses nor by household characteristics. Based on this model no significant selection processes via claims into indemnifications can be observed. Therefore columns 3-7 present OLS models on the determinants of claims and indemnities separately. The results support that household characteristics had no effect on the likelihood to be in-

demnified. Yet, more remote households and those that cultivated two tobacco cycles were more likely to be indemnified as already indicated in the balance table. Moreover, payments were significantly less likely to be reported for 2010 compared to 2009. As several households only insured the main harvest and the shock in 2010 occurred in the second harvest cycle, this could explain the negative coefficient of the year dummy.

Experience with past programs shows that individual monitoring of insurance contracts is one of the main burdens to traditional yield insurance for small scale farmers (Hazell et al. 
1986; Skees et al., 1999; Dercon and Kirchberger, 2008, Smith and Watts, 2009). The estimation results suggest that indemnification payments among insured households were mainly determined by exogenous shocks. However, the results still point at a considerable amount of randomness and some regional differences measured by the distance to the next town in the likelihood of being indemnified. 
Table 3.3: Determinants of claims and indemnifications, 2009-2010

\begin{tabular}{|c|c|c|c|c|c|c|c|}
\hline & $\begin{array}{c}(1) \\
\text { indemnity }\end{array}$ & $\begin{array}{c}(2) \\
\text { indemnity }\end{array}$ & $\begin{array}{c}(3) \\
\text { claim }\end{array}$ & $\begin{array}{c}(4) \\
\text { claim }\end{array}$ & $\begin{array}{c}(5) \\
\text { indemnity }\end{array}$ & $\begin{array}{c}6) \\
\text { indemnity }\end{array}$ & $\begin{array}{c}(7) \\
\text { indemnity }\end{array}$ \\
\hline Climatic Tobacco Loss & $\begin{array}{c}0.01 \\
(0.18)\end{array}$ & $\begin{array}{c}-0.00 \\
(-0.02)\end{array}$ & $\begin{array}{c}0.24^{* * *} \\
(5.61)\end{array}$ & $\begin{array}{c}0.65^{* * *} \\
(3.72)\end{array}$ & $\begin{array}{c}0.36^{* * *} \\
(5.20)\end{array}$ & $\begin{array}{l}0.46^{* *} \\
(2.59)\end{array}$ & $\begin{array}{c}0.37^{* * * *} \\
(5.20)\end{array}$ \\
\hline sq. Climatic Tobacco Loss & & & $\begin{array}{c}-0.01^{* *} \\
(-3.28)\end{array}$ & $\begin{array}{l}-0.04^{*} \\
(-2.23)\end{array}$ & $\begin{array}{c}-0.01^{* *} \\
(-2.96)\end{array}$ & $\begin{array}{l}-0.01 \\
(-0.75)\end{array}$ & $\begin{array}{c}-0.01^{* *} \\
(-3.01)\end{array}$ \\
\hline Uncovered Loss & & & $\begin{array}{c}-0.00 \\
(-1.26)\end{array}$ & & $\begin{array}{c}-0.00 \\
(-1.84)\end{array}$ & & $\begin{array}{l}-0.00^{*} \\
(-2.17)\end{array}$ \\
\hline sq. Uncovered Loss & & & $\begin{array}{c}0.00 \\
(1.59)\end{array}$ & & $\begin{array}{c}0.00 \\
(1.11)\end{array}$ & & $\begin{array}{c}0.00 \\
(1.44)\end{array}$ \\
\hline Remoteness & & & & & $\begin{array}{c}-0.02^{* *} \\
(-2.90)\end{array}$ & & \\
\hline Tobacco Land cultivated 2005 & & & & & $\begin{array}{c}-0.22 \\
(-1.65)\end{array}$ & & \\
\hline Harvest over two seasons & $\begin{array}{c}0.19 \\
(0.93)\end{array}$ & $\begin{array}{c}0.13 \\
(0.68)\end{array}$ & $\begin{array}{c}0.23 \\
(1.73)\end{array}$ & $\begin{array}{l}-1.00 \\
(-1.68)\end{array}$ & $\begin{array}{l}0.57^{*} \\
(2.32)\end{array}$ & $\begin{array}{c}-0.42 \\
(-0.77)\end{array}$ & $\begin{array}{l}0.60^{*} \\
(2.51)\end{array}$ \\
\hline Size main harvest 2010 & $\begin{array}{l}-0.15 \\
(-0.93)\end{array}$ & $\begin{array}{c}-0.07 \\
(-0.44)\end{array}$ & $\begin{array}{l}-0.22 \\
(-1.80)\end{array}$ & & & & $\begin{array}{c}-0.39 \\
(-1.79)\end{array}$ \\
\hline Education $\mathrm{HH}$ head & & $\begin{array}{c}0.05 \\
(1.06)\end{array}$ & $\begin{array}{l}-0.03 \\
(-1.14)\end{array}$ & & & & $\begin{array}{l}-0.04 \\
(-0.81)\end{array}$ \\
\hline Assets 2005 & & $\begin{array}{c}0.00 \\
(0.22)\end{array}$ & $\begin{array}{c}0.00 \\
(1.07)\end{array}$ & & & & $\begin{array}{c}0.00 \\
(0.89)\end{array}$ \\
\hline Land cultivated 2005 & & $\begin{array}{l}-0.08 \\
(-0.94)\end{array}$ & $\begin{array}{c}0.04 \\
(0.57)\end{array}$ & & & & $\begin{array}{c}0.03 \\
(0.28)\end{array}$ \\
\hline Renter 2005 & & $\begin{array}{c}0.41 \\
(1.81)\end{array}$ & $\begin{array}{c}0.00 \\
(0.01)\end{array}$ & & & & $\begin{array}{c}0.37 \\
(1.24)\end{array}$ \\
\hline Other land possesion status 2005 & & $\begin{array}{l}-0.05 \\
(-0.15)\end{array}$ & $\begin{array}{c}0.30 \\
(1.13)\end{array}$ & & & & $\begin{array}{c}0.34 \\
(0.75)\end{array}$ \\
\hline Highest Debts Category 2005 & & $\begin{array}{c}0.15 \\
(0.69)\end{array}$ & $\begin{array}{l}-0.21 \\
(-1.45)\end{array}$ & & & & $\begin{array}{c}-0.01 \\
(-0.04)\end{array}$ \\
\hline Children in $\mathrm{HH}$ & & $\begin{array}{c}0.04 \\
(0.39)\end{array}$ & $\begin{array}{l}-0.05 \\
(-0.76)\end{array}$ & & & & $\begin{array}{l}-0.02 \\
(-0.22)\end{array}$ \\
\hline HH Head Man & & $\begin{array}{c}0.26 \\
(0.82)\end{array}$ & $\begin{array}{c}0.06 \\
(0.24)\end{array}$ & & & & $\begin{array}{c}0.36 \\
(0.80)\end{array}$ \\
\hline Tobacco experience & & $\begin{array}{c}0.01 \\
(0.63)\end{array}$ & $\begin{array}{c}-0.00 \\
(-0.33)\end{array}$ & & & & $\begin{array}{c}-0.00 \\
(-0.05)\end{array}$ \\
\hline Year 2010 & $\begin{array}{c}-0.48 \\
(-1.40)\end{array}$ & $\begin{array}{c}-0.38 \\
(-1.20)\end{array}$ & $\begin{array}{c}-0.85^{* * *} \\
(-6.27)\end{array}$ & & $\begin{array}{c}-1.76^{* * *} \\
(-7.31) \\
\end{array}$ & & $\begin{array}{c}-1.74^{* * * *} \\
(-7.24)\end{array}$ \\
\hline HH Fixed Effects & no & no & no & yes & no & yes & no \\
\hline Selection Model Claim & & & & & & & \\
\hline Climatic Tobacco Loss & $\begin{array}{c}0.11^{* * * *} \\
(5.17)\end{array}$ & $\begin{array}{c}0.11^{* * *} \\
(5.18)\end{array}$ & & & & & \\
\hline Harvest over two seasons & $\begin{array}{c}0.21 \\
(1.45)\end{array}$ & $\begin{array}{c}0.22 \\
(1.55)\end{array}$ & & & & & \\
\hline Size main harvest 2010 & $\begin{array}{l}-0.14 \\
(-1.12)\end{array}$ & $\begin{array}{l}-0.15 \\
(-1.20)\end{array}$ & & & & & \\
\hline Tobacco experience (years) & $\begin{array}{l}-0.00 \\
(-0.13)\end{array}$ & $\begin{array}{l}-0.00 \\
(-0.24)\end{array}$ & & & & & \\
\hline Education Head & $\begin{array}{c}0.01 \\
(0.18)\end{array}$ & $\begin{array}{l}-0.00 \\
(-0.04)\end{array}$ & & & & & \\
\hline Assets 2005 & $\begin{array}{c}0.00 \\
(0.70)\end{array}$ & $\begin{array}{c}0.00 \\
(0.60)\end{array}$ & & & & & \\
\hline Land cultivated 2005 & $\begin{array}{l}-0.03 \\
(-0.49)\end{array}$ & $\begin{array}{c}-0.02 \\
(-0.28)\end{array}$ & & & & & \\
\hline Renter 2005 & $\begin{array}{c}-0.03 \\
(-0.15)\end{array}$ & $\begin{array}{c}-0.09 \\
(-0.56)\end{array}$ & & & & & \\
\hline No land title 2005 & $\begin{array}{c}0.21 \\
(0.84)\end{array}$ & $\begin{array}{c}0.21 \\
(0.84)\end{array}$ & & & & & \\
\hline Highest debt category 2005 & $\begin{array}{l}-0.15 \\
(-1.00)\end{array}$ & $\begin{array}{l}-0.17 \\
(-1.13)\end{array}$ & & & & & \\
\hline Children in $\mathrm{HH}$ & $\begin{array}{l}-0.04 \\
(-0.70)\end{array}$ & $\begin{array}{l}-0.05 \\
(-0.73)\end{array}$ & & & & & \\
\hline Man & $\begin{array}{l}-0.06 \\
(-0.23)\end{array}$ & $\begin{array}{l}-0.12 \\
(-0.46)\end{array}$ & & & & & \\
\hline Uncovered loss & $\begin{array}{c}0.06 \\
(0.45)\end{array}$ & $\begin{array}{c}0.06 \\
(0.45)\end{array}$ & & & & & \\
\hline Area 1 & $\begin{array}{c}0.10 \\
(0.31)\end{array}$ & $\begin{array}{c}0.10 \\
(0.32)\end{array}$ & & & & & \\
\hline Area 2 & $\begin{array}{l}0.72^{* *} \\
(2.66)\end{array}$ & $\begin{array}{c}0.71^{* *} \\
(2.66)\end{array}$ & & & & & \\
\hline Area 3 & $\begin{array}{c}0.98^{* * * *} \\
(3.98)\end{array}$ & $\begin{array}{c}0.97^{* * *} \\
(4.00)\end{array}$ & & & & & \\
\hline Area 4 & $\begin{array}{l}-4.49 \\
(-0.01)\end{array}$ & $\begin{array}{c}-4.71 \\
(-0.00)\end{array}$ & & & & & \\
\hline Area 5 & $\begin{array}{c}0.20 \\
(0.62)\end{array}$ & $\begin{array}{c}0.20 \\
(0.63)\end{array}$ & & & & & \\
\hline Area 6 & $\begin{array}{c}-0.01 \\
(-0.02)\end{array}$ & $\begin{array}{c}0.03 \\
(0.06)\end{array}$ & & & & & \\
\hline Area 7 & $\begin{array}{c}0.26 \\
(1.00)\end{array}$ & $\begin{array}{c}0.28 \\
(1.09)\end{array}$ & & & & & \\
\hline Other area & $\begin{array}{l}0.71^{* * *} \\
(3.15)\end{array}$ & $\begin{array}{c}0.71^{* * * *} \\
(3.32)\end{array}$ & & & & & \\
\hline Year 2010 & $\begin{array}{c}-0.88^{* * *} \\
(-6.38)\end{array}$ & $\begin{array}{c}-0.88^{* * *} \\
(-6.37)\end{array}$ & & & & & \\
\hline LR-Test $($ rho $=0)$ & P. $>\operatorname{chi} 2=0.27$ & P. $>\operatorname{chi} 2=0.12$ & & & & & \\
\hline Observations & 435 & 435 & 435 & 180 & 441 & 182 & 435 \\
\hline Pseudo $R^{2}$ & 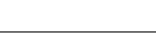 & & 0.170 & 0.249 & 0.203 & 0.220 & 0.192 \\
\hline
\end{tabular}




\section{Indemnification Impact on Coping Strategies}

Table 3.4 displays the estimation results where column 1-5 refer to logit fixed effects models and column 6 to 10 to multivariate probit models. The treatment coefficients indicate that households that received an indemnity were significantly less likely to report an active coping strategy supposedly as they could use the payments to mitigate the consequences of the shock. This suggests that indemnities contributed significantly to the financial resources affecting the choice of coping strategies. Moreover, receiving an indemnification was negatively and significantly associated with liquidation of household resources such as assets or savings in response to shocks. The effect is significant on the $1 \%$ level for the logit fixed effects and the multivariate probit models. Marginal effects suggest that households that received an insurance payment were $17 \%$ less likely to have liquidated resources after shocks than non-indemnified households. Using loans as coping strategies is positively associated with indemnification payments, but the effects is not statistically significant. Similarly, the treatment coefficient on expense reductions is insignificant. However, a dummy as outcome variables might not capture small changes and "hidden" transitions to lower consumption levels after shocks. Lastly, regarding changes in income diversification after shocks no clear impacts of indemnifications can be observed, which might be related to the low prevalence of positive responses $(6 \%)$.

\section{Indemnification Impact on Financial Well-Being}

As data on the the financial well being are only available for 2010, standard OLS estimations as described in equation (3) are used to quantify the indemnification effects (see table 3.5. Only information on loan outcome are available for 2009 and 2010 allowing to estimate fixed effects.

Normally farmers use loans to finance upcoming harvests, for instance by buying seeds and fertilizer for non-tobacco crops or by supplementing the tobacco company's input package with their own investments. The results suggest that indemnity payments were negatively but insignificantly associated with the likelihood of a household loan. Despite that looking at loan

values indicates that indemnification decreased them significantly by about 1.3 mio. COP (approx. 650 US\$). The results could imply that non-indemnified households increased loan volumes to cope with shocks but they did not take up a loan solely to compensate for losses. This could also explain why this effect did not become evident when looking at self reported 


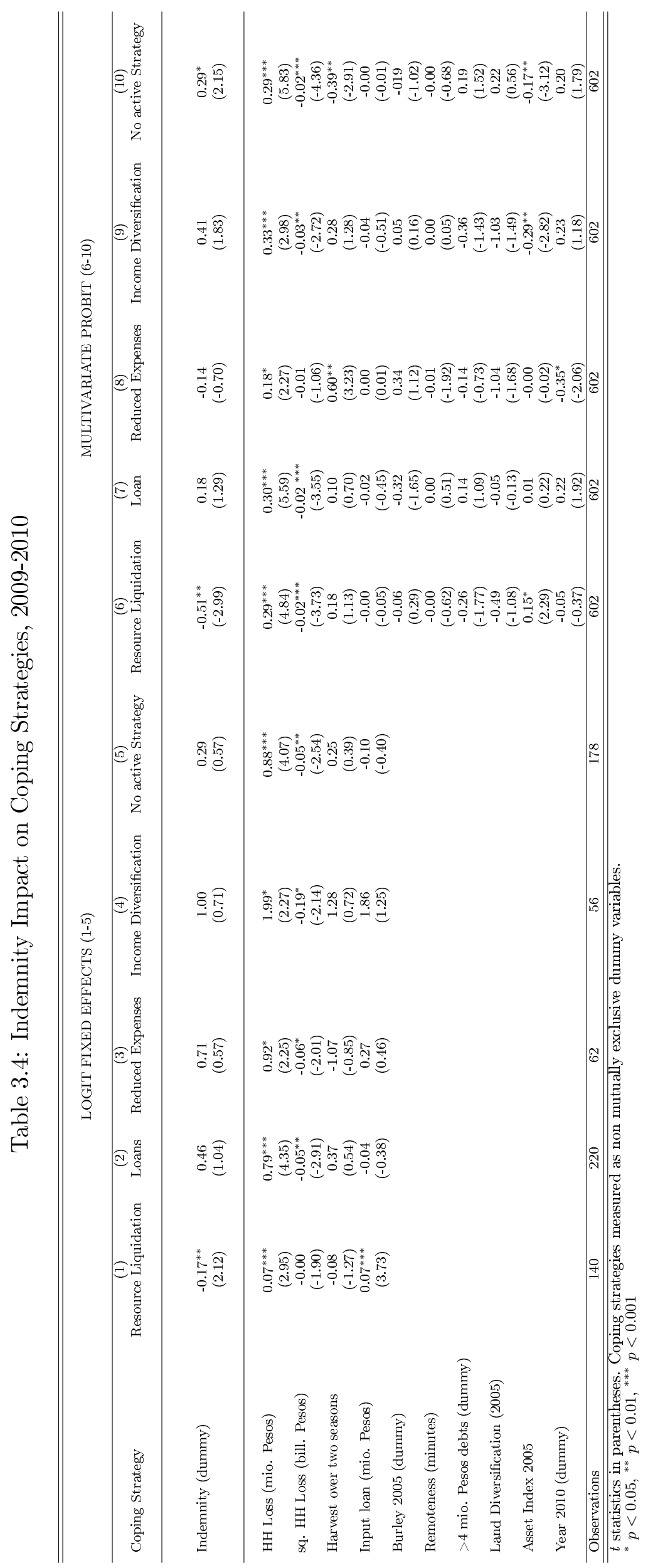




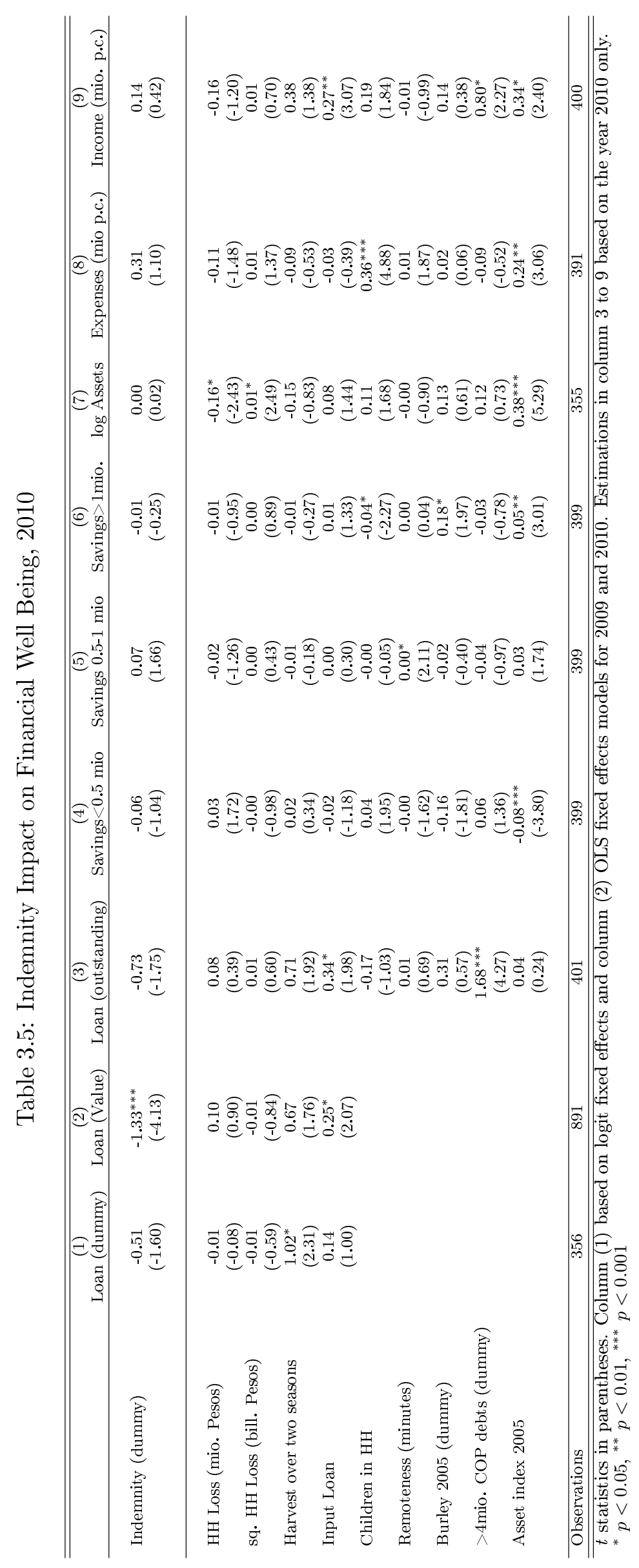


coping strategies. As a consequence of lower loan volumes, the amount of outstanding debts in the beginning of 2011 was on tendency lower for indemnified households, yet, the coefficient is only significant on the $10 \%$ level. Having less debts after shocks could have important consequences particularly for capital constrained households as loans to compensate for losses crowd out capital for productive purposes.

In column 4 to 7 the indemnity impacts on savings and assets are analyzed. Household savings were reported in three categories ranging from 0 to more than 1 mio. COP (approx. 500 US\$). Estimating multinomial logit models does not show any clear indemnification impacts on these saving categories. Similarly, no clear indemnification impacts on (log) liquid assets become evident. As many households had problem assigning values to their assets especially for their land property, I focus on liquid assets only. Nonetheless the variance in responses is still high and indemnification effects could have become absorbed by these inaccuracies.

Furthermore, the data offer information on consumption per capita. The indemnity coefficient sign is positive but not significant. This could suggest that non-indemnified households maintained consumption levels and were able to compensate for losses using for example loans.

Lastly, as insurance payments can be regarded as a positive income shock, indemnities should increase incomes. The estimated indemnity coefficient is positive but the effect is not significantly different from zero. This could be due to the relative small indemnity values in 2010 compared to the total household incomes. On average the insurance indemnification summed up to about $5 \%$ of the average household income. Despite that, the indemnities in 2009 represented about $15 \%$ of the average household income as in this year the main harvest cycle was affected by a shock resulting in larger payments. But as income information is only available for 2010 these payments are not regarded in this estimation.

\section{Robustness Checks}

As with most non-experimental evaluation set ups, concerns about the comparability of treated and non-treated subjects might call results into questions. In this section I present several robustness checks that aim to address some of these concerns. Table 3.6 displays the treatment coefficients of three alternative estimation models. One concern is related to the fact that the decision to buy the insurance was voluntary, which could lead to self selection and unobserved heterogeneity between indemnified and non-indemnified households. As robustness check I 
estimate the indemnity impact on the sub-group of insured households, hence only those who were eligible for indemnity payments. In the presence of an endogeneity bias we would expect that the results on this sub-sample deviate from the previous findings. However, the results are fairly similar and support the negative effect of indemnity payments on resource liquidation, the likelihood of applying an active coping strategy and the value of loans. Despite that an increased likelihood of expense reduction for indemnified households becomes evident. However, in contrast to the previously discussed logit models, these results rely on linear OLS models because of convergence problems due to the drop in observations

Another bias could evolve from systematic differences in self reported losses. Insured household might for example be more aware of their losses or non-indemnified households could strategically misreport losses for example to justify their discontent with the insurance. Besides the survey data, Protabaco provided company information for the analysis on all harvests from 2007 to 2010 including data on the cultivation size, yield, price of all of their contracts. The data allow to match the administrative information and the survey data for 140 insured households that participated in the first interview wave. 8 These data can be used to classify tobacco shocks according to the indemnification formula (1) of the insurance program. Hence, if the tobacco yield of a farmer drops below $70 \%$ of her historic yield (plus a $15 \%$ deductible) the household is classified as having suffered a tobacco shock. As historic yield I use the administrative data on 2007 and 2008 hence a period with normal yield fluctuations.9 Column 2 of table 3.6 displays the effect of indemnities using this administrative measure of tobacco shocks. Despite the drop in observation, the effects are in line with the previous results, which speaks against a bias through self reported loss reports.

Lastly, I test for spill over effects of indemnities via transfers to non-indemnified neighbors or family members, which could have led to an underestimation of the indemnity impacts. Therefore I analyze whether households were more likely to lend money to other households after being indemnified. Informal transfers were rather uncommon in the research region and were only reported by about $2 \%$ in the sample. In the first line of column (3) a dummy for informal transfers is used and the second line refers to the value of these transfers, which

\footnotetext{
${ }^{8}$ Attrition due to company changes and production stops is below $9 \%$ between 2007 and 2010 in the records. The administrative data offer information on each contract whereas the survey captures household information that could comprise several contracts. To exclude that a household used several contracts at the same time or cultivated also for another tobacco company, I use survey production information in order to identify them.

${ }^{9}$ In case historic information is not available, the municipality mean is used to proxy the historic yield as this is the general insurance company procedure.
} 
Table 3.6: Treatment Coefficients of Robustness Checks on the Impact of Indemnity Payments on HH Coping Strategies and Financial Well Being

\begin{tabular}{|c|c|c|c|c|c|c|c|c|c|}
\hline & \multicolumn{3}{|c|}{ (1) Insured HH only } & \multicolumn{3}{|c|}{$\begin{array}{l}\text { (2) administrative data to } \\
\text { measure shocks among } \\
\text { insured HH }\end{array}$} & \multicolumn{3}{|c|}{ (3) Whole Sample } \\
\hline & $\mathrm{N}$ & Coeff. & z-Val. & $\mathrm{N}$ & Coeff. & z-Val. & $\mathrm{N}$ & Coeff. & z-Val. \\
\hline \multicolumn{10}{|l|}{ Coping Strategies } \\
\hline Loans & 365 & 0.05 & $(0.78)$ & 133 & 0.11 & $(0.68)$ & & & \\
\hline Resource Depletion & 365 & $-0.15^{* *}$ & $(-2.69)$ & 133 & $-0.30^{*}$ & $(-2.52)$ & & & \\
\hline Reduced expenses & 365 & $0.07^{*}$ & $(2.27)$ & 133 & 0.02 & $(0.71)$ & & & \\
\hline Income Diversification & 365 & 0.01 & $(0.28)$ & 133 & 0.01 & $(0.22)$ & & & \\
\hline No active Strategy & 365 & 0.07 & $(1.14)$ & 133 & 0.25 & $(1.87)$ & & & \\
\hline \multicolumn{10}{|l|}{ Financial Well Being } \\
\hline Loan (dummy) & 136 & -0.83 & $(-1.83)$ & 46 & -2.49 & $(-1.76)$ & & & \\
\hline Loan (value) & 466 & $-1.56^{* *}$ & $(-3.67)$ & 171 & $-3.00^{* *}$ & $(-3.09)$ & & & \\
\hline Loan (outstanding) & 265 & -0.84 & $(-1.73)$ & 93 & -0.37 & $(-0.86)$ & & & \\
\hline Savings $<0.5$ mio. & 263 & -0.06 & $(-0.93)$ & 110 & -0.06 & $(-0.45)$ & & & \\
\hline Savings $0.5-1$ mio & 263 & 0.09 & $(1.94)$ & 110 & 0.10 & $(1.16)$ & & & \\
\hline Savings $>1$ mio. & 263 & -0.03 & $(-0.54)$ & 110 & -0.04 & $(-0.46)$ & & & \\
\hline (log) Assets & 236 & 0.11 & $(0.48)$ & 96 & -0.13 & $(-0.31)$ & & & \\
\hline Expenses (mio p.c.) & 260 & 0.34 & $(1.16)$ & 96 & 0.16 & $(0.53)$ & & & \\
\hline Income (mio. p.c.) & 265 & 0.21 & $(0.56)$ & 102 & -0.21 & $(-0.41)$ & & & \\
\hline \multicolumn{10}{|l|}{ Transfers to other $\mathbf{H H}$} \\
\hline Informal Loan (dummy) & & & & & & & 892 & -0.01 & $(-0.54)$ \\
\hline Informal Loan (value) & & & & & & & 892 & 4410.84 & $(0.13)$ \\
\hline \multicolumn{10}{|c|}{ Note: Only treatment coefficients are displayed. Coping Strategy impact in column 1 and 2 based on } \\
\hline \multicolumn{10}{|c|}{$\begin{array}{l}\text { linear fixed effects models. Linear fixed effects coefficients in }(3) \text { refer to transfers that households made to } \\
\text { other households in the year they were indemnified or not. Control variables: losses, sq. losses, harvests, } \\
\text { input loan, children, remoteness, burley } 2005,>4 \text { mio. debts, asset index } 2005 \text {. }\end{array}$} \\
\hline
\end{tabular}

summed on average up to 1.3 million COP (approx. 650\$US). The coefficients suggest that indemnity payments had no effect on informal transfers and hence do not hint at spill over effects of indemnities through solidarity networks.

\section{Conclusion}

This study investigates the impacts of indemnities of a yield insurance for small scale tobacco farmers after a period of severe climatic shocks that affected the well-being of many households profoundly. The special feature in the tobacco sector is that out of two nearly identical tobacco companies only one offered the insurance to their contract farmers and hence only one part was eligible for indemnity payments. The data suggest that several insured households suffered considerable losses that were not indemnified. There was a considerable overlap of losses between indemnified and non-indemnified insured households, which indicates a surpris- 
ingly low income smoothing effect of the insurance. However, those households that received an indemnification benefited significantly in the aftermath of shocks. Fixed effects and multivariate probit models are estimated to quantify the indemnity impacts. The results indicate that receiving an insurance compensation was associated with a $17 \%$ decrease in the likelihood of household resource reductions in response to shocks. Moreover, indemnified households reported significantly lower loans values than non-indemnified households. The findings imply that the indemnification payments contributed significantly to the household means allowing them to abstain from resource reductions and emergency credit as ex post coping strategies. However, the results also point out the problems of individual loss verifications, confirming the problems with yield insurances for small holder farmers. 


\title{
Impacts of Agricultural Insurances on the Production of Small Holder Farmers in Colombia田
}

\begin{abstract}
Small holder farmers often invest less than the marginal productivity and marginal cost would suggest. Agricultural insurance is expected to reduce these inefficiencies encouraging a more risk taking behavior. In this paper we investigate the impacts of an agricultural insurance for small scale farmers on household loans and the farm production. We focus on a yield insurance for tobacco farmers in Colombia that covers climatic shocks. The insurance program was recently launched and insurance adoption constantly increased. However, we observe spatial differences in the diffusion of the insurance that we use to identify the insurance effects. The data for the analysis were collected in household surveys including 301 households with access to the insurance. Household fixed effects controlling for past and current shock exposure are estimated to quantify the insurance impacts. Surprisingly, we do not find effects of the insurance on credit access nor on productivity. Problems with the implementation of the insurance program could have undermined trust in the program explaining this finding.
\end{abstract}

\section{Introduction}

Risks are a major impediment for small holder farmers to increasing production investments (World Bank, 2013). Two burdens come into play (Boucher and Guirkinger, 2008): firstly, small scale farmers typically have limited access to capital, which is required to finance investments if own resources do not suffice. Secondly, risks hamper the decision to take up loans despite having access to capital. This includes for example the fear of loosing collateral after loan defaults. The assets that serve as collateral often form the basis of farm

\footnotetext{
${ }^{\dagger}$ Joint work with Marcela Ibanez
} 
incomes as for instance the farm land and loosing these assets would deteriorate livelihoods significantly. Therefore, despite high marginal returns to investments, the risk of failures and catastrophic consequences impedes investments (Boucher and Guirkinger, 2008). Insurances for small holder farmers have found increasing attention in the last decade as a tool to mitigate these risk barriers (Churchill and Matul, 2012)

In this paper we investigate how adopting an agricultural insurance affected loans and farm output of small scale farmers in Colombia. The analyzed yield insurance covers weather related losses in which damages are verified individually. To identify the impacts of the program we explore differences in the diffusion of the insurance over time. In the analysis we estimate fixed effects models controlling for household's exposure to covariate shocks in the current and past year.

Capital is an integral component of agricultural production decisions. Capital constrained farmers might not be able to allocate the optimal amount of inputs to the production leading to inefficiencies in the cultivation (Hazarika and Alwang, 2003, Guirkinger and Boucher, 2008). Agricultural insurance could help to reduce these inefficiencies: insurance indemnification payments compensate for losses after crop failures and increases the resilience to shocks. Thus loan defaults become less likely, which could encourage investments. Moreover, from the capital supply side, a reduced default risk increases the creditworthiness and facilitates access to credit. The investments could in return enhance productivity and quality of the farm output (e.g. Gine and Yang (2009); Cai et al. (2011)). In addition, insured households might concentrate on higher yielding and more risky crops rather than engaging in income diversification strategies (Skees, 1999, Fuchs and Wolff, 2011).

To test the risk reduction effects of the insurance on household loans and farm output, we focus on tobacco farmers. The effect in this sector is particularly interesting as these farmers face an array of climatic risks. However, at the same time the cultivation requires significant investments in input materials and underinvestment result in production inefficiencies. Since 2008 tobacco farmers have access to a yield insurance program subsidized by the Colombian government. The insurance covers the main production risks that include excessive rain, floods, hail, excessive wind, drought, erosion and pest. The analysis benefits from a rich data set that covers outcome variables of the year 2009 and 2010. This allows us to quantify the effects using fixed effect models, which control for time invariant unobserved heterogeneity. 
The literature on the relationship of insurance and risk taking behavior has been explored experimentally. For example in a framed field experiment in Ethiopia, Hill and Viceisza (2012) find a positive effect of insurances on fertilizer use. In contrast, Gine and Yang (2009) find that rainfall insurance led to a $13 \%$ decrease in credit take up for high yield seeds compared to the control group. However, lab experiments of this type have been criticized due to its limitations to study actual decisions (Levitt and List, 2007).

More recently the results of several randomized controlled trials contributed to the understanding of the link between insurance and production farm output. For example Cai et al. (2011) implemented a randomized controlled trial in China where they vary the incentives for participation in an insurance program. They show that insurance participation was associated with increases in farmers' sow production. Similar evidence is provided by Cole et al. (2013) from India. They find that farmers who purchased rainfall insurance increased investments in agricultural inputs and invested more in high return, high risk crops. They argue that by reducing the volatility of returns, insurance makes investments in risky activities more attractive. Our analysis is complementary to this work. Yet, instead of just focusing on production outcomes we test how insurance affected financial access, which can be considered the first step to production investments and changes in production outcomes. Using a detailed catalog of questions to classify credit constraints, Guirkinger and Boucher (2008) show that removing these barriers could increase production output by $26 \%$ among Peruvian farmers. Similarly, Hazarika and Alwang (2003) analyze the effect of access to credit on tobacco farmers in Malawi. The authors find a modestly positive relationship of loans and the tobacco cost efficiency.

Our findings indicate that adoption of the insurance was not clearly related to increased financial access. We also do not find significant effects of the insurance on production outcomes. This could be due to the fact that the insurance program suffered from inconsistencies in the verification of damages (see chapter 3). These shortcomings might have caused the relatively low trust in the program and farmers did not rely on the risk reducing effect of the insurance.

The paper is organized as follows. Section 2 provides a description of the agricultural insurance program. Section 3 and 4 present the data and the methodological approach used to identify the impacts of the program. Section 5 discusses the estimation results and in the last section we conclude. 


\section{Background}

Agricultural insurances in Colombia started in 2004. By 2010 about 10000 polices were sold covering about 42000 hectares.1] The Colombian government has been an important contributor to the establishment of the insurance. A public insurance fund with a value of approximately 18 million US\$ (2011) subsidized up to $60 \%$ of the insurance premium. The Colombian government followed two main objectives. Firstly, to reduce the need for emergency relief programs after catastrophic weather shocks (see chapter 3). Secondly, to promote investments in the rural sector and to foster the adoption of more efficient production technologies.

The insurance covers crop failures related to excessive rain, flooding, hail, excessive wind, drought, erosion and pest. The underlying insurance scheme triggers indemnity payments upon individual field verifications of damages. Attempts to implement index based insurance failed due to the lack of weather stations.

Among the products covered by the insurance program, tobacco is particularly interesting as it is mainly produced by small scale farmers. Among our sample of producers, the average size of the tobacco plot was about 1 hectare. These farmers are moreover limited in their access to credit. Only about half of the households reported to be able to obtain a bank loan of 4 million. COP (approx. 2000 US $\$$ or less than half the annual household income) to finance an emergency expenditure. Therefore an analysis on the risk reduction effects associated with insurances on household loans and farm output seems particularly interesting in the tobacco sector. Besides that, the tobacco production is very sensitive to shocks. Administrative tobacco records of the years 2007 to 2010 suggest strong fluctuation of tobacco yields in the research region. The mean tobacco productivity reached about 1700 kilos per hectare but varied by more than 350 kilo or $20 \%$ in this four year period. In the first semester of 2009, unusual low levels of rain affected the region lowering productivity by $25 \%$. Moreover, in the second semester of 2010, the region was exposed to excessive rains.

The production of tobacco is dominated by two tobacco companies, which both operate using contract farming modes: the companies negotiate contracts with the farmers on the cultivation size and the type of tobacco to be produced. Depending on the size and tobacco

\footnotetext{
${ }^{1}$ The covered crops included are cotton, banana, maize, rice, sorghum, potato, onions, forestry, peanuts and tobacco.
} 
type, farmers receive credit in input material in standardized packages and cash from the company that they repay when they hand in the cured tobacco leaves at the end of the cultivation cycle.

\section{Insurance in the Tobacco Sector}

The agricultural insurance was introduced in 2008 in the tobacco sector. One of the two tobacco companies offered the insurance to their contract farmers (see Chapter 2). In some departments as Huila the take up of the insurance was mandatory. Yet in Santander, our research area, the insurance was voluntary. Farmers could freely decide to purchase the insurance when they signed the contract for the next tobacco harvest. No administrative efforts had to be made by the farmers and the complete communication with the insurance company could be carried out through the tobacco company. Tobacco company officials acted as intermediaries between the farmer and the insurance company. The insurance premium added up to $6.85 \%$ of the estimated production costs of 6.7 million COP per hectare ${ }^{2}$ However, the premium was subsidized with $86 \%$ by different sources including the public fund $(60 \%)$, the tobacco association (20\%) and the tobacco company (6\%). Thus, farmers only had to pay $14 \%$ of the insurance premium plus the value added taxes (16\%), which amounts to approximately 100000 Pesos (approx. 50 US\$) per hectare of Burley tobacco.

Indemnification payments were triggered if the tobacco yield, $y_{i}$, dropped below $70 \%$ of the historic yield, $h_{i}$ due to a weather related event. The historic yield represents the average output of the last four production years. In case of a damage the insurance compensated for (estimated) production cost $c$. In case of a shock a deductible of $15 \%$ of the estimated costs had to be carried by the insured. This results in the following formula to assess the value of indemnity payments:

$$
\text { Indemnification }=\left(0.7 * h_{i}-y_{i}\right) * \frac{c}{h_{i}}-0,15 * c
$$

In case of a loss, the inspection should take place within eight days after receiving the claim. The independent insurance inspector has to assess how the shock will affect the final yield and determine base on that the value of the indemnification to be paid. As shocks often strike during the cultivation cycle it is difficult for the inspectors to estimate the impacts on the final output. Therefore inconsistencies in the verification procedures seem inevitable

\footnotetext{
${ }^{2}$ This figure refers to Burley tobacco in 2010.
} 
(see Chapter 3). These problems with the verification procedure resulted in a low confidence: about two thirds in our sample reported having little or no confidence in the insurance.

In case an indemnification is triggered, the farmer receives the payment from the tobacco company at the end of the cultivation cycle jointly with the tobacco earnings. The tobacco company moreover used indemnifications to balance the farmers debts with the company.

\section{Data}

For the evaluation of the program, we conducted surveys with tobacco producers in Santander, Colombia. Out of 2242 tobacco farmers in the research region, 587 were randomly selected to be interviewed. Insured and indemnified households were oversampled to get a sufficient amount of treated farmers for the analysis $3^{3}$ Out of this sample, 306 farmers produced for Protabaco, the company that adopted the agricultural insurance program and the rest of the farmers produced for Coltabaco. Chapter 2 of this dissertation presents a complementary analysis of the impacts of the program exploring company differences while in this paper temporal differences in the program participation are explored.

The surveys were carried out in four municipalities: San Gil, Barichara, Villa Nueva and Curiti. The data set includes information on social-demographics, household characteristics, income, expenditures, capital, use of the farm land and experiences with insurances. Furthermore, the data contain retrospective information for the years 2009 and 2010 on household loans and the tobacco production. As tobacco is the main income source and delivered in packages of 100 kilos, farmers had little problems to recall production information of the last two years. Therefore we dispose of panel data regarding loans and production outcomes that we explore in the analysis. Moreover, to check the comparability of treated and control groups, we asked several questions on household characteristics in 2005 when the insurance program was not yet implemented.

In addition to the survey data Protabaco, the insured company, allowed us access to production information on all of their tobacco contracts in the research region. Using these production information, we construct a measure for covariate losses on the neighborhood level. A more detailed description of this measure and descriptive results are presented in the next sections.

\footnotetext{
${ }^{3}$ We use probability weights in the estimations.
} 


\section{Descriptive Analysis}

Table 4.1 presents descriptive information on pre-program characteristics of households with access to the insurance. Farmers in the sample have on average more than 20 years of experience with tobacco, which they cultivated on 1.4 hectares in the main and second harvest 2005. Only about one third of the farmers owned their plots and households reported assets worth 17.8 million COP Pesos (approx. 9000 US\$), which was mainly due to land property.

Comparing household characteristics of 2005 for insured and non-insured farmers, we find that they were very similar. Except, insured farmers were more likely to produce Burley tobacco and cultivated a larger fraction of their land than non-insured farmers. Moreover we find some geographical differences reflected in the distance to the next town.

Table 4.1: Descriptive Statistics and Company Differences

\begin{tabular}{|c|c|c|c|c|c|c|}
\hline & \multicolumn{2}{|c|}{ Descriptive } & \multicolumn{2}{|c|}{$\begin{array}{c}\text { insured vs. } \\
\text { non-insured } 2009\end{array}$} & \multicolumn{2}{|c|}{$\begin{array}{c}\text { insured vs. } \\
\text { non-insured } 2010\end{array}$} \\
\hline & $\mathrm{N}$ & Mean & Diff. & t-Test & Diff. & t-Test \\
\hline Age & 300 & 47.0 & 0.21 & $(0.14)$ & 2.45 & $(1.24)$ \\
\hline Education $\mathrm{h}$ head & 299 & 3.66 & 0.16 & $(0.58)$ & 0.01 & $(0.04)$ \\
\hline Remoteness & 294 & 35.1 & $-5.34 *$ & $(-2.11)$ & -1.16 & $(-0.34)$ \\
\hline Memberships in associations & 301 & 0.65 & -0.12 & $(-1.31)$ & 0.10 & $(0.81)$ \\
\hline Sex household head & 301 & 0.91 & 0.02 & $(0.67)$ & 0.07 & $(1.61)$ \\
\hline Rooms 2005 & 298 & 2.76 & 0.10 & $(0.63)$ & -0.33 & $(-1.61)$ \\
\hline Children & 301 & 1.00 & 0.06 & $(0.43)$ & 0.03 & $(0.14)$ \\
\hline Renter 2005 & 301 & 0.33 & 0.15 & $(0.62)$ & -0.10 & $(-0.32)$ \\
\hline Owner 2005 & 301 & 0.34 & -0.13 & $(-0.51)$ & -0.06 & $(-0.19)$ \\
\hline Highest debt category 2005 & 294 & 0.34 & -0.00 & $(-0.07)$ & 0.07 & $(0.86)$ \\
\hline Assets 2005 (mil. Pesos) & 301 & 17.8 & -7.19 & $(-1.87)$ & -4.66 & $(-0.90)$ \\
\hline Asset-index 2005 & 301 & 1.72 & 0.05 & $(0.35)$ & 0.27 & $(-1.59)$ \\
\hline Value livestock (mil. Pesos) & 259 & 1.15 & 0.02 & $(0.06)$ & -0.38 & $(-0.96)$ \\
\hline Experience Tobacco & 298 & 22.6 & 0.87 & $(0.57)$ & -1.09 & $(-0.54)$ \\
\hline Burley main harvest 2005 & 301 & 0.93 & 0.00 & $(0.14)$ & $0.12^{* *}$ & $(2.88)$ \\
\hline Prod. Technology 2005 & 301 & 2.63 & 0.07 & $(0.57)$ & 0.03 & $(0.17)$ \\
\hline Irrigation System 2005 & 301 & 0.04 & 0.55 & $(0.82)$ & -0.77 & $(-1.10)$ \\
\hline Hectares cultivated 2005 & 294 & 1.78 & -0.10 & $(-0.64)$ & -0.13 & $(-0.65)$ \\
\hline Tobacco hectare 2005 & 286 & 1.45 & -0.00 & $(-0.02)$ & 0.19 & $(1.18)$ \\
\hline Land diversification 2005 & 294 & 0.45 & 0.02 & $(1.26)$ & $0.05^{*}$ & $(2.28)$ \\
\hline
\end{tabular}




\section{Insurance Diffusion and covariate Shocks}

Since the launch in 2008, insurance adoption has constantly increased. Our data suggest that insurance take up has risen from $18 \%$ in 2008 to $64 \%$ and $85 \%$ in 2009 and 2010. However, this increase was stronger in some neighborhoods compared to others. Table 4.2 presents the insurance adoption rate between 2008 and 2010 by neighborhoods. The data suggest that insurance take up increased on tendency but with marked differences among neighborhoods. In several neighborhoods the insurance adoption in 2010 was well below the sample average of $85 \%$.

The differences at the neighborhood level could be explained by differences in the exposure to past shocks and the expectation of future shocks (Sarris et al., 2006, Cabas, 2008, Chantarat et al., 2009). For example Karlan et al. (2012) show that farmers that suffered a shock in the previous year were more likely to expect a shock in the next year and were hence more likely to purchase insurance. However, measuring the exposure to shocks is not easy. Weather related information in the area is scarce and self-reported information on shock exposure could be biased by the insurance. Being insured could make farmers more aware of weather related events and moreover, insured household might have an strategic motive to over-report losses with the aim of receiving additional compensations. To avoid these problems, we use production records of the tobacco company to define tobacco losses at the neighborhood level. In neighborhoods (veredas), 40 to more than 100 households are exposed to very similar climatic conditions. Hence, farmers' own productivity has only a marginal effect on the neighborhood mean. In the analysis we define shocks as mean productivity changes in 2009 and 2010 compared to the baseline year 2007. Since no climatic shocks hampered the tobacco cultivation in 2007, this baseline can be considered as a "normal" year. Positive values reflect positive shocks and negative values describe tobacco losses compared to the baseline year 2007 .

Table 4.2 presents the exposure to covariate tobacco losses defined with the administrative data. In 2009 tobacco losses were highest, exceeding $1000 \mathrm{~kg} / \mathrm{ha}$ in the main harvest in two neighborhoods. This is quite substantial considering that the mean productivity totals in about $1700 \mathrm{~kg} / \mathrm{ha}$. Losses in 2009 can be attributed to a drought that caused severe damages and led to substantial losses. Yet, in 2010 the main harvest was not exposed to covariate shocks, which resulted in modest productivity increases compared to 2007. Despite that, in 2010 the second harvest cycle was adversely affected by excessive rains. However, in this 
analysis we only focus on the first harvest cycle, which is households most important yield. The t-Test result support the relationship of insurance demand and past shocks. The exposure to covariate shocks in the past year was positively associated with the insurance uptake in 2009 and $2010(\operatorname{Pr}(\mathrm{T}>\mathrm{t})=0.081)$.

To summarize, we find spatial differences in insurance take up over time that we will explore in the analysis. The exposure to tobacco shocks, which we can measure on the neighborhood level using precise administrative data, could have driven these differences.

Table 4.2: Insurance adoption and HH shocks (\%) by neighborhoods

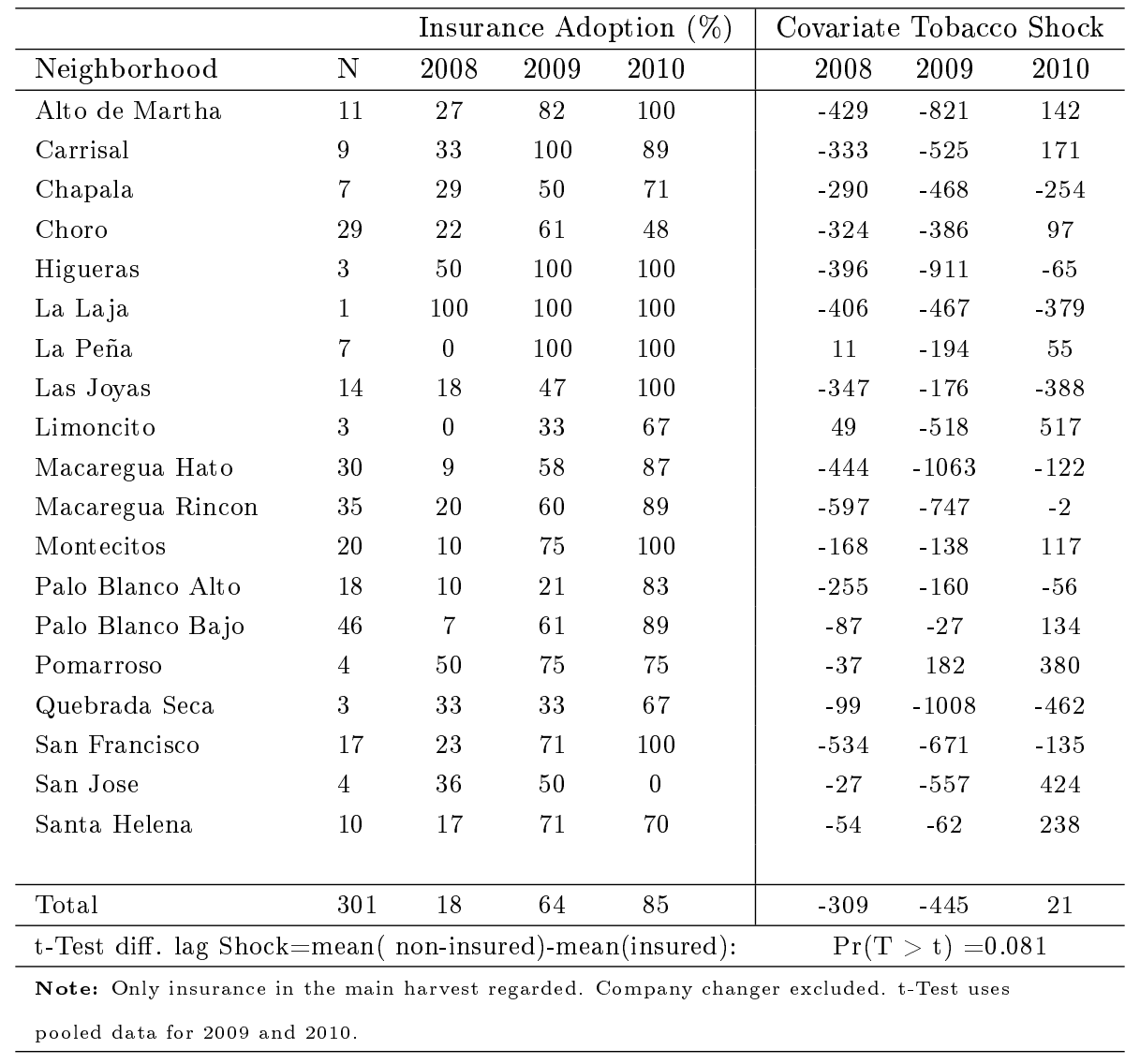

\section{Methodology}

Purchasing the insurance could be endogenous to loans and production output. Unobserved characteristics could affect both, the decision to adopt the insurance and outcome variables, leading to biased estimates. Panel data methods can be used to rule out bias from time invariant unobserved heterogeneity. Estimating individual fixed effects (FE) the subject means are subtracted from the observed variables, so that time invariant fixed effects drop out of the 
estimation. This model can be formulated as:

(4) $Y_{i t}-\bar{Y}_{i}=\beta_{1}\left(T_{i t}-\bar{T}_{i}\right)+\beta_{2}\left(Z_{i t}-\bar{Z}_{i}\right)+\left(\epsilon_{i}-\epsilon_{i}\right)+\left(u_{i t}-\bar{u}_{i}\right)$

where $T$ denotes a variable for the treatment status, $Z$ describes time variant covariates and $\epsilon$ reflects time invariant fixed effects that are canceled out in the estimation. The coefficient $\beta_{1}$ measures the average treatment effect on the outcome $Y_{i t}$. To account for time variant confounds we control for the past and current exposure to shocks using our measure of covariate shocks.

\section{Results}

In the analysis we estimate the insurance impact on two sets of outcome variables. First, we look at the impact on household loans. Secondly, we explore the impacts on the tobacco output.

\section{Insurance Impact on Household Capital}

The survey offers detailed information on all household sources of loans. This includes tobacco company credit as well as loans from other sources, which we will refer to as private loans throughout the analysis. Table 4.3 displays the estimation results of the fixed effects models. In the first column the total household loans are used as dependent variable, in columns 2-4 we look at tobacco company loans and columns 5-8 present the impacts on private loans.

Households that adopted the insurance were not associated with significantly higher loans. However, loans were positively associated with shocks. Yet, including interaction terms of the insurance status and the exposure to covariate shocks does not indicate that the insurance affected loans differently after shocks (not reported). Regarding loans from the tobacco company a positive relation can be observed. Farmers that adopted the insurance had significantly larger company loans particularly in input material. Regarding the interpretation of the results reversed causality concerns should be regarded. Farmers might have adopted the insurance in order to obtain higher contract volumes with the tobacco company. Tobacco company executives emphasized that the decision to purchase the insurance was completely voluntary and farmers were not urged to buy the insurance. However, to account for increases in company loans we include them as controls in the following regressions.

Regarding private loans no clear effects can be observed. Bank loans were positively asso- 
ciated with the insurance whereas the cooperative and informal loan coefficients are negative. Yet, the effects are not significant and hence do not hint at increases in private loans after adopting the insurance.

The estimation results do not support the theory that risk reductions with the insurance increase loans in order to finance investments. This could be due to low confidence in the insurance. Changes in the risk taking behavior would require that farmers trust in the risk reduction effect of the insurance and also that banks trust the insurance.

Table 4.3: Fixed Effect Estimations on Insurance Impacts on HH loans, 2009-2010

\begin{tabular}{|c|c|c|c|c|c|c|c|c|}
\hline & \multirow[b]{2}{*}{$\begin{array}{c}(1) \\
\text { Total HH Loans }\end{array}$} & \multicolumn{3}{|c|}{ COMPANY LOANS (2-4) } & \multicolumn{4}{|c|}{ PRIVATE LOANS (5-8) } \\
\hline & & $\begin{array}{c}(2) \\
\text { Company Loans }\end{array}$ & $\begin{array}{c}(3) \\
\text { Cash } \\
\end{array}$ & $\begin{array}{c}(4) \\
\text { Input }\end{array}$ & $\begin{array}{c}(5) \\
\text { Private Loans }\end{array}$ & $\begin{array}{c}(6) \\
\text { Bank }\end{array}$ & $\begin{array}{c}(7) \\
\text { Cooperative }\end{array}$ & $\begin{array}{c}(8) \\
\text { Informal }\end{array}$ \\
\hline Insurance & $\begin{array}{c}0.50 \\
(0.91)\end{array}$ & $\begin{array}{l}0.66^{*} \\
(2.43)\end{array}$ & $\begin{array}{c}0.19 \\
(1.40)\end{array}$ & $\begin{array}{l}0.47^{*} \\
(2.21)\end{array}$ & $\begin{array}{c}-0.20 \\
(-0.39)\end{array}$ & $\begin{array}{c}0.30 \\
(1.05)\end{array}$ & $\begin{array}{c}-0.43 \\
(-1.10)\end{array}$ & $\begin{array}{l}-0.07 \\
(-0.65)\end{array}$ \\
\hline \multicolumn{9}{|l|}{ Controls } \\
\hline 2 Harvests & $\begin{array}{l}2.14^{*} \\
(3.63)\end{array}$ & $\begin{array}{l}1.17^{*} \\
(3.79)\end{array}$ & $\begin{array}{l}0.32^{*} \\
(2.57)\end{array}$ & $\begin{array}{l}0.85^{*} \\
(3.61)\end{array}$ & $\begin{array}{c}0.89 \\
(1.54)\end{array}$ & $\begin{array}{c}0.75 \\
(1.45)\end{array}$ & $\begin{array}{c}0.20 \\
(0.42)\end{array}$ & $\begin{array}{l}-0.06 \\
(-0.43)\end{array}$ \\
\hline Covariate Shock & $\begin{array}{l}0.39^{*} \\
(4.55)\end{array}$ & $\begin{array}{c}0.02 \\
(0.59)\end{array}$ & $\begin{array}{c}-0.01 \\
(-0.69)\end{array}$ & $\begin{array}{c}0.03 \\
(1.24)\end{array}$ & $\begin{array}{l}0.37^{*} \\
(4.50)\end{array}$ & $\begin{array}{l}0.19^{*} \\
(2.86)\end{array}$ & $\begin{array}{l}0.15^{*} \\
(2.59)\end{array}$ & $\begin{array}{l}0.03^{+} \\
(1.84)\end{array}$ \\
\hline lag Covariate Shock & $\begin{array}{l}0.34^{+} \\
(1.78)\end{array}$ & $\begin{array}{c}0.03 \\
(0.43)\end{array}$ & $\begin{array}{l}-0.02 \\
(-0.83)\end{array}$ & $\begin{array}{c}0.05 \\
(1.04)\end{array}$ & $\begin{array}{l}0.31^{+} \\
(1.74)\end{array}$ & $\begin{array}{c}0.23 \\
(1.50)\end{array}$ & $\begin{array}{c}0.05 \\
(0.37)\end{array}$ & $\begin{array}{c}0.02 \\
(0.81)\end{array}$ \\
\hline Company Loan & & & & & $\begin{array}{c}0.06 \\
(0.39) \\
\end{array}$ & $\begin{array}{c}0.16 \\
(1.12)\end{array}$ & $\begin{array}{c}-0.10 \\
(-1.21)\end{array}$ & $\begin{array}{c}0.00 \\
(0.14)\end{array}$ \\
\hline Observations & 521 & 521 & 521 & 521 & 521 & 521 & 521 & 521 \\
\hline$R^{2}$ & 0.197 & 0.137 & 0.054 & 0.124 & 0.163 & 0.099 & 0.086 & 0.024 \\
\hline
\end{tabular}

\section{Insurance Impact on the Tobacco Production}

In this section we analyze if the insurance affected the farm output in the main harvest. We consider the tobacco productivity and price per kilo to test for changes related to efficiency increases. Moreover, the total yield and harvest value are considered to test for changes in production expansions. In the estimations we control for households' capital and, in addition, we include interaction terms of the insurance status and loans to test whether loans had a different effect in combination with the insurance.

The estimation results do not point at insurance effect on the tobacco productivity (see Table 4.3. The coefficients on productivity, harvest value, yield and price are insignificant. The interaction terms of insurance and loans does not suggest that loans were differently used by insured households. We find that total loans had a positive, but insignificant effect on 
productivity. Input loans from the tobacco company affect production outcomes positively. An increase of 1 million. COP in input loans was associated with an increase of only 0.68 million COP in the harvest value and hence, yielded on average negative returns. The effect of private loans is lower compared to input loans due to the fact that private loans were not only invested in the tobacco production but also used for other purposes.

Therefore the results do not support the theory of production increases related to the insurance. Moreover, the results do not indicate input inefficiencies as additional inputs did not yield positive returns.

Table 4.4: Fixed Effect on Insurance Impacts on Farm Output, 2009-2010

\begin{tabular}{|c|c|c|c|c|c|c|c|c|}
\hline & $\begin{array}{c}(1) \\
\text { Productivity }\end{array}$ & $\begin{array}{c}(2) \\
\text { Productivity }\end{array}$ & $\begin{array}{c}(3) \\
\text { Harvest Value }\end{array}$ & $\begin{array}{c}(4) \\
\text { Harvest Value }\end{array}$ & $\begin{array}{c}(5) \\
\text { Yield }\end{array}$ & $\begin{array}{c}(6) \\
\text { Yield }\end{array}$ & $\begin{array}{c}(7) \\
\text { Price }\end{array}$ & $\begin{array}{c}(8) \\
\text { Price }\end{array}$ \\
\hline Insurance & $\begin{array}{c}0.79 \\
(0.01)\end{array}$ & $\begin{array}{l}-65.07 \\
(-0.31)\end{array}$ & $\begin{array}{l}-0.25 \\
(-0.34)\end{array}$ & $\begin{array}{l}-0.58 \\
(-0.49)\end{array}$ & $\begin{array}{c}-214.12 \\
(-1.17)\end{array}$ & $\begin{array}{c}-227.76 \\
(-0.81)\end{array}$ & $\begin{array}{l}95.07 \\
(0.82)\end{array}$ & $\begin{array}{l}-3.35 \\
(-0.02)\end{array}$ \\
\hline Insurance*Loans & & $\begin{array}{l}11.03 \\
(0.30)\end{array}$ & & $\begin{array}{c}0.09 \\
(0.36)\end{array}$ & & $\begin{array}{c}9.27 \\
(0.16)\end{array}$ & & $\begin{array}{l}14.60 \\
(0.95)\end{array}$ \\
\hline \multicolumn{9}{|l|}{ Controls } \\
\hline Loans & & $\begin{array}{l}14.31 \\
(0.36)\end{array}$ & & $\begin{array}{c}0.17 \\
(0.66)\end{array}$ & & $\begin{array}{l}26.52 \\
(0.46)\end{array}$ & & $\begin{array}{l}15.44 \\
(1.07)\end{array}$ \\
\hline Private Loans & $\begin{array}{l}19.88 \\
(1.09)\end{array}$ & & $\begin{array}{c}0.15 \\
(1.40)\end{array}$ & & $\begin{array}{l}16.68 \\
(0.84)\end{array}$ & & $\begin{array}{l}27.68^{*} \\
(2.54)\end{array}$ & \\
\hline Input Loan & $\begin{array}{l}37.36 \\
(1.43)\end{array}$ & & $\begin{array}{l}0.68^{*} \\
(2.34)\end{array}$ & & $\begin{array}{c}122.29^{+} \\
(1.87)\end{array}$ & & $\begin{array}{l}20.02 \\
(0.65)\end{array}$ & \\
\hline Covariate Shock & $\begin{array}{l}32.65^{*} \\
(2.05)\end{array}$ & $\begin{array}{l}32.24^{*} \\
(2.04)\end{array}$ & $\begin{array}{l}0.26^{*} \\
(2.66)\end{array}$ & $\begin{array}{l}0.24^{*} \\
(2.44)\end{array}$ & $\begin{array}{c}64.47^{*} \\
(2.91)\end{array}$ & $\begin{array}{l}60.85^{*} \\
(2.73)\end{array}$ & $\begin{array}{r}37.60^{+} \\
(1.84)\end{array}$ & $\begin{array}{r}37.35^{+} \\
(1.83)\end{array}$ \\
\hline lag Covariate Shock & $\begin{array}{l}-46.55 \\
(-1.41) \\
(-1.41)\end{array}$ & $\begin{array}{l}-46.89 \\
(-1.44) \\
(-1.44)\end{array}$ & $\begin{array}{c}-0.25 \\
(-1.19) \\
(-1.19)\end{array}$ & $\begin{array}{c}-0.25 \\
(-1.19) \\
(-1.19)\end{array}$ & $\begin{array}{c}-2.90 \\
(-0.06) \\
(-0.06)\end{array}$ & $\begin{array}{c}-2.96 \\
(-0.07) \\
(-0.07)\end{array}$ & $\begin{array}{c}10.13 \\
(0.28) \\
(0.28)\end{array}$ & $\begin{array}{c}7.68 \\
(0.21) \\
(0.21)\end{array}$ \\
\hline Observations & 506 & 506 & 504 & 504 & 512 & 512 & 509 & 509 \\
\hline$R^{2}$ & 0.189 & 0.192 & 0.271 & 0.271 & 0.201 & 0.193 & 0.090 & 0.094 \\
\hline
\end{tabular}

\section{Conclusion}

Small holder farmers often invest less than the marginal productivity and marginal costs would suggest, which is often related to capital and risk constraints. Agricultural insurances are expected to be a powerful tool to reduce these inefficiencies. In this study we analyze whether agricultural insurances for small holder farmers with few liquid resources take effect on farm capitalization and production. For the analysis we benefit from survey data on 2009 and 2010 and spatial differences in the insurance take up of this newly introduced product. As the insurance adoption was voluntary we estimate household fixed effects to address concerns 
with unobserved heterogeneity that control for the exposure to covariate shocks in the current and past year. Our findings do not support the predicted impact of risk reductions associated with insurances on loans and farm output. Adopting the insurance was not clearly related to loans from banks, cooperatives or informal sources. Moreover, we do not find insurance impacts on the tobacco production. Despite that, increases in loans had a positive effect on production outcomes, though the returns to additional input material do not hint at input allocation inefficiencies. The absence of insurance impacts on loans and production outcomes could be due to the fact that the insurance program has had several problems that resulted in a low confidence in the program. Therefore farmers did not rely on the risk reducing effect of the insurance and maintained their mode of operations. Thus, the impacts might only unfold after the insurance is well established and farmers have experienced risk reductions related to the insurance. 


\title{
A Blessing in Disguise? On the Development of Social Ties $\dagger^{\dagger}$
}

\begin{abstract}
Despite the high human and economic cost of natural disasters and wars, it has been argued that extreme shocks can trigger positive processes of institutional change. However, the empirical evidence is mixed suggesting that in some cases shocks promote the development of social capital while in other cases it has the opposite effect. Which characteristics of shocks trigger social development? In this article we investigate the effects of the structure of shocks on social ties. The hypothesis is based on the assumption that repeated interaction of individuals promotes the development of social ties. Carried over to the context of informal insurance networks this suggests that successful collaboration after shocks increases social ties of its members. To measure the impact of shocks on social cohesion a three stage design is used. In the first stage social ties are measured using the Ring-Test of Social Value Orientation. The second stage is a repeated solidarity game in which a negative shock can destroy the income that participant had generated in a real effort task. In cases of a shock, non-affected participants decide whether to help affected participants. In the third stage a slightly modified version of the previous Ring-Test of Social Value Orientation is repeated, which allows to measure social ties of subjects before and after the treatments. The findings show that more frequent shocks strengthened social ties. However, the covariance of shocks reduced social ties compared to idiosyncratic shocks.
\end{abstract}

\section{Introduction}

Extreme disasters can overwhelm the capacities of states and drag whole regions into poverty. Between 1988 and 2011 damages from disasters in low and lower middle income countries added up to $127 \%$ of their GDP (World Bank, 2013). Thereby households in poor areas are most vulnerable to shocks. Between 1970 and 2008, 95\% of all deaths from natural disasters were registered for developing countries, which is not only related to a population imbalance

\footnotetext{
${ }^{\dagger}$ Joint work with Marcela Ibanez and Stephan Klasen
} 
but also due to differences in the capacity of states, communities and households to handle risks (Field et al., 2012).

Despite the high human and economic cost of natural disasters and wars, it has been argued that extreme shocks can trigger positive processes of institutional change (Cramer, 2006). However, the empirical evidence is mixed suggesting that in some cases shocks promote the development of social capital while in other cases it even has the opposite effect. For instance, Carter and Castillo (2005) find that areas that were more heavily affected by hurricane Mitch in Honduras exhibited higher levels of trust. Similarly, Voors et al. (2012) find that exposure to conflict was associated with higher levels of altruism in Burundi. Moreover, Bellows and Miguel (2006, 2009) and Blattman (2009) find evidence that areas that were more severely affected by civil war in Sierra Leone and Uganda have higher levels of political mobilization and participation in community groups. On the other side, Cassar et al. (2012) show that this is not the case in Tajikistan. Furthermore, De Luca and Verpoorten $(2012)$ exemplify that in Uganda civil conflict decreased general trust and increased ethnic identity. So why is it that disasters result sometimes in higher levels of social capital and at other times not? Which conditions favor the development of social change? One burden to identify the factors of shocks that trigger social cohesion is that disasters are typically accompanied by other confounders. For example the simultaneous effect of shocks on wealth and social cohesion does not allow to draw conclusions on the underlying drivers of social cohesion. Moreover, cross sectional data have to rely on ex post measures of social capital that could be incomplete.

The objective of this paper is to understand the channels by which disasters can trigger social development. In particular, we explore the idea that having the opportunity to help fosters social cohesion. Using a laboratory experiment, we test for an array of factors that can affect the development of social ties. To measure the impact of shocks on social cohesion we used a three stage design similar to van Dijk et al. (2002). In the first stage we measured social ties using the Ring-Test of Social Value Orientation (Liebrand, 1984). Participants of the experiment were randomly matched and had to decide how to distribute their income between themselves and another anonymous participant. The second stage was a repeated solidarity game in which a negative shock could destroy the income that participants had generated in a real effort task. When this happened, non-affected participants decided whether they wanted to transfer a fix amount to the affected participant. We use a between subject design 
in which we varied: i) the number of times or frequency to which each participant is exposed to a negative shock; ii) the value of the endowment that is lost due to the negative shock; iii) the number of participants in the social network that is affected at a given moment; iv) the proportion of the endowment that can be transferred to help those affected by the shock. By varying these four factors we can control for wealth and distributional effects that would result from having a different number of participants affected or a different number of participants helping. In the third stage the Ring-Test was repeated, except that groups were formed between participants from the same solidarity networks. The comparison of the measure of social ties between the first and third stage allows us to quantify the impacts of the treatments on social cohesion in solidarity networks using a difference in differences approach.

The experiments were conducted in the computer lab of the Universidad Nacional in Medellin, Colombia, with 540 students. Colombia has been exposed to a large range of shocks in the last decades. On one hand the ongoing civil conflict that has caused displacements of nearly 6 million people and cost the life of more than 177000 civilians between 1958 and 2012.1 On the other hand several natural disasters, such as excessive rains, inundations and storms related to the weather phenomenon El Niño, have affected about $10 \%$ or 4 million Colombians between 2000 and 2009 2 Moreover, the IPCC forecasts an increase in the frequency of extreme weather events in this region due to climatic changes that will further increase the exposure to risks (Field et al., 2012). Despite some insurance programs that specifically address the poor households, especially the most vulnerable have to rely on informal insurance mechanisms to manage risks (see Chapter 1 to 3 ). Thus, the analysis seems particularly relevant in the Colombian context.

The findings of our study support the hypothesis that having the opportunity to help fosters social ties. We find that the frequency of the shocks increased the degree of altruism significantly and that covariate shocks resulted in lower social tie developments compared to idiosyncratic shocks. Interestingly, the analysis on heterogeneous effects indicates that more individualistic participants were rewarding collaboration in the network stronger compared to participants with more altruistic value orientations.

The rest of the paper is organized as follows: Section 2 and 3 outline the experimental design and procedures. Section 4 presents the results and the last section concludes.

\footnotetext{
${ }^{1} \mathrm{http}: / /$ www.centrodememoriahistorica.gov.co (access 1.11.2013)

${ }^{2}$ http://www.emdat.be/result-country-profile (access 1.11.2013)
} 


\section{Experimental Design}

We use a three stage experimental design similar to van Dijk et al. (2002). In the following we describe each of these stages in detail.

\section{First Stage}

In the first stage we randomly matched session participants in groups of two. Participants did not know the identity of the other person in the group but they knew that it was another session participant. These groups remained constant throughout the first stage. In this stage participants had to state their preferences in the Ring-Test of Social Value Orientation (Liebrand, 1984). This test is widely used in the field of psychology, but has also been applied in several economic studies (e.g. Liebrand (1984); Sonnemans et al. (2006); Rose (2007); Sutter et al. (2010)). In the test, participants were confronted with a series of 32 choices be-

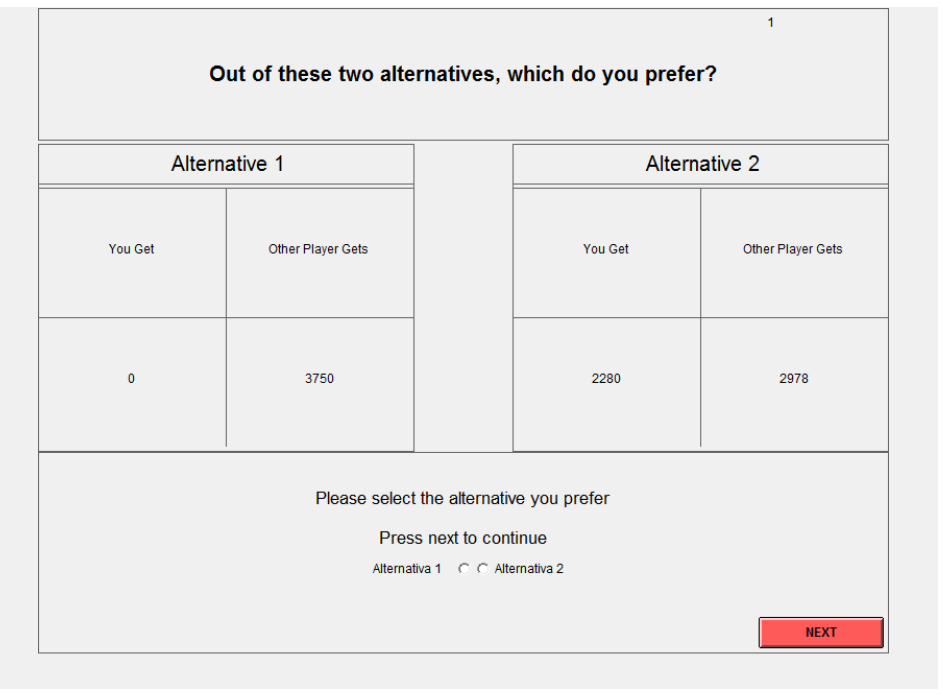

Figure 4.1: Ring-Test Screen

tween own-other payoff combinations. Each payoff combination allocates a positive or negative amount of money to the decision maker herself and to the participant whom the individual is matched with. To better illustrate the test, figure 4.1 displays a screen shot of one of the 32 decisions.

In a coordinate system, the payoff for the other $(\mathrm{O})$ can be measured on the vertical axis and the amount of money allocated to herself $(\mathrm{S})$ on the horizontal axis. Each of the 32 combinations of payoffs for the other $(\mathrm{O})$ and oneself $(\mathrm{S})$ fulfills the equation $O^{2}+S^{2}=500^{2}$. A complete list of all 32 payout questions is displayed in table 4.1 . The responses to these 32 
questions can be summed up and displayed as a vector in a circle. Therefore subject's preferred other and own values of the 32 decisions are aggregated, which yields a vector in the O-S coordinate system as illustrated in figure 4.2 . The angle of this vector in the coordinate system reflects the degree of altruism. An angle of $0^{\circ}$ describes for example a purely individualistic subject whereas $90^{\circ}$ denotes an altruistic participant. Intermediate positive values indicate cooperativeness while negative values indicate competitiveness in which participants are willing to forgo own payments to decrease the payment of others. Figure 4.2 displays the possible RingTest outcomes using the classification of altruistic, cooperative, individualistic and competitive preferences according to Liebrand (1984). As some participants stated angles below $-67.5^{\circ}$ we added an additional category that we call envious group, as these players have a high preference to reducing the payment of the other participant.

The consistency of responses is measured by the length of the vector. A vector of 0 length would for example describe perfectly contradicting responses along the 32 decisions. The set

Table 4.1: Ring-Test Value Combinations

\begin{tabular}{|c|c|c|c|c|c|}
\hline \multicolumn{2}{|c|}{ Order } & \multicolumn{2}{|c|}{ Alternative 1} & \multicolumn{2}{|c|}{ Alternative2 } \\
\hline 1st stage & 3rd stage & own & other & own & other \\
\hline 1 & 32 & 0 & 3750 & 2280 & 2978 \\
\hline 2 & 4 & -2978 & -2280 & -3248 & -1875 \\
\hline 3 & 30 & -2655 & 2655 & -2280 & 2978 \\
\hline 4 & 2 & 2655 & 2655 & 2978 & 2280 \\
\hline 5 & 13 & 3750 & 0 & 3720 & -488 \\
\hline 6 & 14 & -3248 & 1875 & -2978 & 2280 \\
\hline 7 & 31 & 0 & -3750 & -2280 & -2978 \\
\hline 8 & 15 & -3465 & -1433 & -3623 & -968 \\
\hline 9 & 16 & 3623 & 968 & 3720 & 488 \\
\hline 10 & 24 & 3720 & 488 & 3750 & 0 \\
\hline 11 & 9 & 2655 & -2655 & 2280 & -2978 \\
\hline 12 & 25 & 3720 & -488 & 3623 & -968 \\
\hline 13 & 28 & 2280 & -2978 & 0 & -3750 \\
\hline 14 & 10 & -2280 & 2978 & 0 & 3750 \\
\hline 15 & 22 & 3248 & 1875 & 3465 & 1433 \\
\hline 16 & 8 & 2978 & -2280 & 2655 & -2655 \\
\hline 17 & 7 & -3623 & 968 & -3465 & 1433 \\
\hline 18 & 17 & -2655 & -2655 & -2978 & -2280 \\
\hline 19 & 23 & -3750 & 0 & -3720 & 488 \\
\hline 20 & 18 & -2978 & 2280 & -2655 & 2655 \\
\hline 21 & 1 & 3248 & -1875 & 2978 & -2280 \\
\hline 22 & 6 & 3623 & -968 & 3465 & -1433 \\
\hline 23 & 26 & 3465 & -1433 & 3248 & -1875 \\
\hline 24 & 29 & 2978 & 2280 & 3248 & 1875 \\
\hline 25 & 11 & -3720 & -488 & -3750 & 0 \\
\hline 26 & 12 & -3720 & 488 & -3623 & 968 \\
\hline 27 & 21 & -3623 & -968 & -3720 & -488 \\
\hline 28 & 20 & -3248 & -1875 & -3465 & -1433 \\
\hline 29 & 5 & 2280 & 2978 & 2655 & 2655 \\
\hline 30 & 3 & 3465 & 1433 & 3623 & 968 \\
\hline 31 & 27 & -3465 & 1433 & -3248 & 1875 \\
\hline 32 & 19 & 228 & -2978 & -2655 & -2655 \\
\hline
\end{tabular}

of values were adopted from van Dijk et al. (2002) and multiplied by 7.5 to be transformed to 


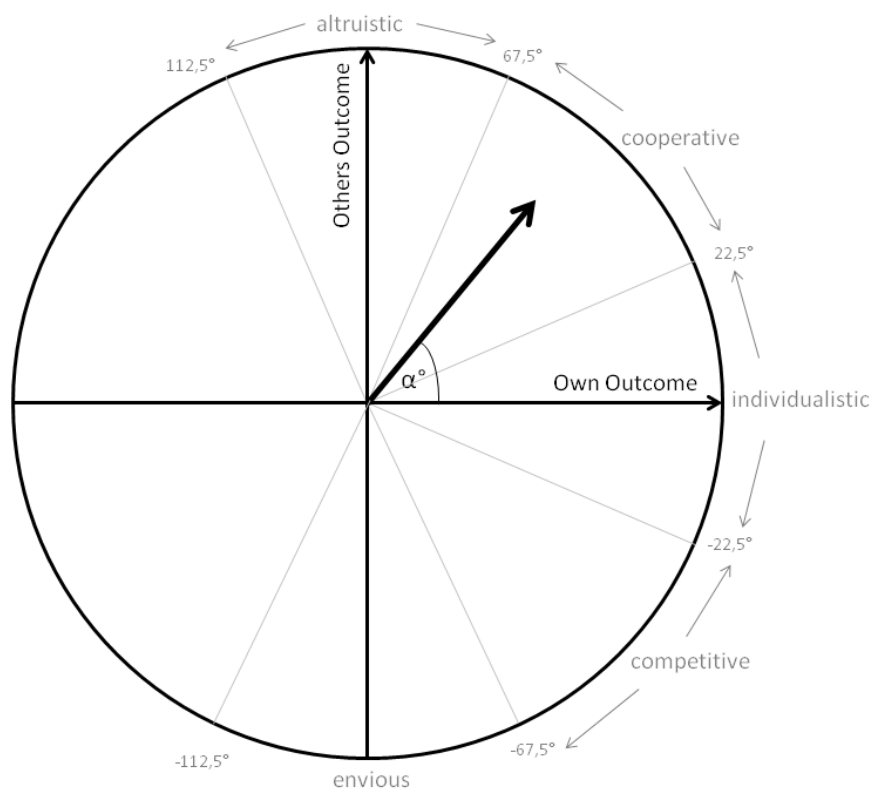

Note: Classification adopted from Liebrand (1984)

Figure 4.2: Ring-Test Example

Colombian Pesos (COP). The multiplier was adjusted to conform with the usual payout levels in the research lab. At the end of the third stage, one decision was randomly selected for the payment. Hence, participants received their payout corresponding to their own decision and the decision of the other player.

\section{Second Stage}

The second stage combined a repeated solidarity game and a real effort task. Solidarity networks of three participants were randomly formed and kept fixed over 9 periods. Participants didn't know their network partner nor could they communicate with them. In order to decrease "house money effects" in the solidarity game, we implemented a modified version of the Gill and Prowse (2012) real effort game. Participants were presented a screen with 15 sliders. Each slider was positioned at zero and could be moved up to 100. The task consisted in positioning the sliders in 50 using the mouse. The slider could be moved as many times as wanted. A number to the right of the bar indicated the position of the slider while on the top of the screen participants could see the chronometer and the number of sliders correctly positioned (Figure 4.6 in the appendix presents a screen shot of this task). We included one trial round to familiarize participants with the task and thereafter started the experiment. They had 
45 seconds to position as many sliders as possible and received a fix income of $15000 \mathrm{COP}$ (approx $\$$ US 9) regardless of their actual performance.

In order to replicate the risks to which individuals are exposed in daily life, we explained that the participant and the other network members could lose their income. However, the risk of losing the income was exogenous and did not depend on the performance in the real effort task. In case subjects were hit by a shock they got to see a red lightning on the screen. Otherwise a green check indicated that they were not affected in this period. If a shock occurred, a predefined loss was subtracted from the income. After the realization of the shock, a summary table informed participants about the number of affected members in the network, the value of the loss and the income after the loss. If someone in the network suffered a shock, a transfer period was started in which unaffected network members had to decide whether to transfer a predefined amount from their income to the affected network members. In cases where two players were hit by a shock, transfers of the third network member were allocated in equal shares to the two affected members. In the last step they were informed about the transfer decisions of their network members and their earning in that period. Participants only received the aggregated information of the transfer decisions of their network partners so that they could not identify who had helped them. The game lasted for 9 periods, which always had the same sequence: First, the real effort task was played and participants received an income. Second, risks were realized or not and lastly, solidarity decisions were taken. In the experiment we varied the conditions under which shocks happened, yet, subjects received no information on the allocation process of shocks. Moreover, in order to avoid income effects that would result from playing the game repeatedly, earnings were not carried over to the next period. Instead, one random period was selected for the final payment.

\section{Treatments}

We are interested in investigating how the exposure to shocks affected the development of social ties. In particular, in the experiment we exogenously varied the frequency and covariate structure of shocks. Thus, we allowed that each member in the network is hit once or twice by a shock in the 9 periods of the game. Moreover, we allowed shocks to be idiosyncratic or covariate. In the first case, only one participant was affected at a given moment while in treatments with covariate shocks two participants were affected simultaneously. Varying 
only these two dimensions would lead to differences in two aspects. First, higher frequency of shocks would result in higher losses and hence wealth differences. Second, as we increased the covariance of the shocks and allowed two members to be affected simultaneously in one period, the number of members in the solidarity network who could help was reduced. Hence, this could result in differences in wealth distributions after shocks. Therefore, in the experiment we also varied the size of shocks and the value of the (fixed) transfer. We allowed that subjects loose either the complete or half of their income and that the fixed transfer is either one third or one sixth of the income. In total we ran 12 treatments with different combinations of the following 4 dimensions: 1) frequency of the shocks where subjects suffer 1 or 2 shocks over the nine periods, 2) shocks size where either half or the entire income is lost, 3) fixed transfer size where either $\frac{1}{3}$ or $\frac{1}{6}$ of income can be transferred, 4) covariate structure of the shock where 1 or 2 members are affected simultaneously by a shock. Table 4.2 presents a summary of the implemented treatments. Treatments 1 to 4 refer to idiosyncratic shocks when players Table 4.2: Summary of Treatments

\begin{tabular}{|c|c|c|c|c|c|c|}
\hline \multicolumn{2}{|c|}{ Treatment } & $\begin{array}{c}\text { Shocks per } \\
\text { Subject }\end{array}$ & $\begin{array}{c}\text { Loss } \\
\text { (Share of } \\
\text { Endowment) } \\
\end{array}$ & $\begin{array}{c}\text { Transfer } \\
\text { (Share of } \\
\text { Endowment) } \\
\end{array}$ & $\begin{array}{c}\text { Covariance } \\
\text { (2 Shocks at the } \\
\text { same time) }\end{array}$ & $\begin{array}{c}\text { Matching 3rd } \\
\text { Period }\end{array}$ \\
\hline \multirow{4}{*}{ I 1} & 1 & 1 & 1 & 0.17 & 0 & network \\
\hline & 2 & 1 & 0.5 & 0.17 & 0 & network \\
\hline & 3 & 1 & 1 & 0.33 & 0 & network \\
\hline & 4 & 1 & 0.5 & 0.33 & 0 & network \\
\hline \multirow{4}{*}{ I 2} & 5 & 2 & 1 & 0.33 & 0 & network \\
\hline & 6 & 2 & 0.5 & 0.17 & 0 & network \\
\hline & 7 & 2 & 0.5 & 0.33 & 0 & network \\
\hline & 8 & 2 & 1 & 0.17 & 0 & network \\
\hline \multirow{4}{*}{$\mathrm{C}$} & 9 & 2 & 1 & 0.33 & 1 & network \\
\hline & 10 & 2 & 0.5 & 0.17 & 1 & network \\
\hline & 11 & 2 & 1 & 0.17 & 1 & network \\
\hline & 12 & 2 & 0.5 & 0.33 & 1 & network \\
\hline \multirow{3}{*}{ Control } & 13 & 2 & 0.5 & 0.17 & 0 & session \\
\hline & 14 & 1 & 1 & 0.33 & 0 & session \\
\hline & 15 & 1 & 0.5 & 0.33 & 0 & \\
\hline
\end{tabular}

are affected once. We call this group of treatments I1 to differentiate them from treatments 5 to 8 where participants were affected twice, which we denote I2. Treatments 9 to 12 refer to covariate shocks where each participant is affected twice, which we call treatments C. Furthermore, to examine whether increases in social ties where related to matching differences in the third stage, we conducted 3 sessions were we kept the matching constant as we will 
describe in more detail in the next section. We refer to these treatments as Control.

In order to keep sessions comparable, we predefined the shock combinations for all network members and only randomized the position of subjects within the networks. For example, subjects on the first network position always suffered a shock in the fifth period whereas the player on the second position was hit in period 8. Figure 4.3 presents the shock combinations for all treatments. This way of allocating shocks allows us to have full control over the frequency and timing of the shocks and ensures comparability of the sessions.

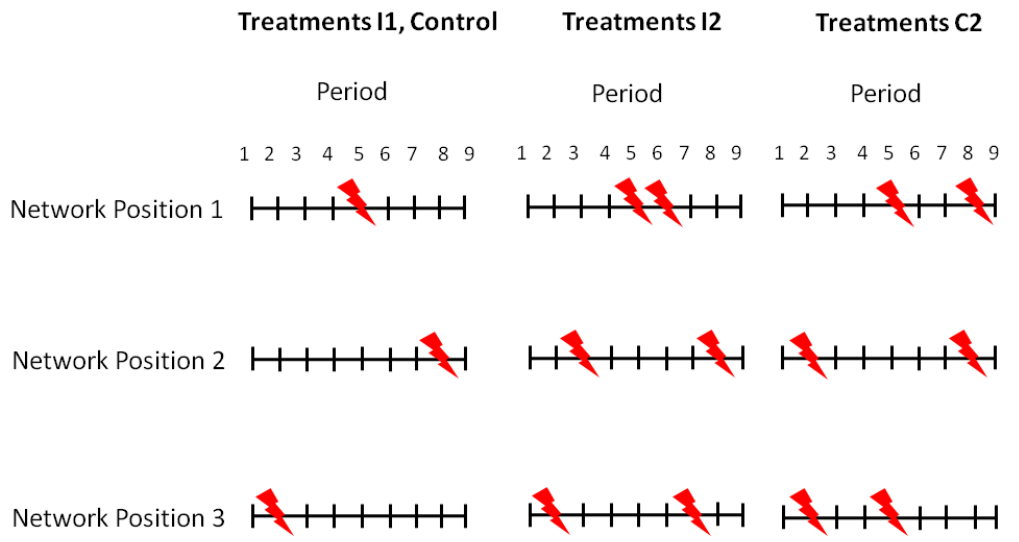

Figure 4.3: Shock Timing within Networks

\section{Third Stage}

In the last stage the Ring-Test of Social Value Orientation is repeated. In contrast to the first stage, subjects were not matched with a random participant in the session but with a member of their solidarity network of the second stage of the experiment. We included the same combinations of payments as in the first stage, though in a different order. As before, one decision was selected for each participant for the final payment. The difference in the matching process between the first and third stage allows us to analyze how altruism changes when directed towards a network member in stead of a random participant. In other words, it enables us to analyze how social ties change when directed to a network partner instead of a random participant. Yet, we implemented the Control treatments in which participants were also matched with another random participant in the third stage. This allows to test whether 
the development of social ties is different for network members compared to random session participants. Hence, we can examine whether experience during the solidarity game affected the social value orientation in the third step.

Developments in social ties can be described by changes in the angle of the vectors of the Ring-Test of Social Value Orientation. Therefore the larger the raise in the angle from the first to the third stage, the higher the level of social cohesion in networks. As we exogenously varied the conditions under which solidarity can occur, we can draw causal interpretation on the effect on the development of social ties, our measure of social cohesion.

\section{Experimental Procedures}

The experiments were conducted between February and March 2013 in a computer lab of the Universidad Nacional de Colombia, Sede Medellin. We chose to run the experiments at a university as opposed to running field experiments in rural communities in order to avoid already existing social relations of participants. The university offered the possibility to invite students from different faculties that did not know each other and hence did not bring any pre-existing social ties into the experiment. Therefore nearly $70 \%$ of the participants reported not having any friends in their session. Participants were recruited via a mass email that informed students in the university about the experiment. Those willing to participate were randomly allocated to an experimental session of 18 participants. Thereby we kept the share of male/female and student subjects balanced within sessions. Upon arrival, participants were randomly assigned to workstations in separated cubicles. The experiments were entirely computerized using z-tree software (Fischbacher, 2007). After four pilot sessions, we ran 30 sessions with a total of 540 experiment participants. The instructions for the experiment were presented on the computer screens and examples and test questions were asked to ensure understanding of the tasks. Payments were handed out individually after completing a questionnaire that took about 10 minutes. On average the experimental sessions lasted 1.5 hours and the average payment was 17000 COP (approx. 10 US\$) including a show up fee of 5000 COP. 


\section{Results}

Before discussing the econometric analysis we first present descriptive findings of the different experiment stages.

\section{Ring Test of Social Value Orientation}

We find a high degree of consistency in the responses to the Ring-Test of Social Value Orientation. Only four observations in the first stage are below the consistency exclusion criterion used by Sonnemans et al. (2006) $]^{3}$ In addition to that, we restrict the analysis to observations that lie in the angle range of $-112.5^{\circ}$ to $112.5^{\circ}$ of the circle to avoid responses related to confusion or misunderstandings.

Table 4.3 presents the results of the Ring-Test of Social Value Orientation in the first and third stage. We find that in both stages, the average level of social ties is relatively low. The mean angle of the vector that resulted from summing up preferred own-other allocations over the 32 decisions is around $5^{\circ}$ and $11^{\circ}$ in the first and third stage, which corresponds to individualistic preferences according to Liebrand (1984). In case subjects were matched with a random session participant in the third step instead of a network member, the implied angle of the distributional vector is not significantly different between the first and third stage (rank sum test Prob. $>|z|=0.481)$. However looking at the whole sample, we find that the angle increased significantly by about $4^{\circ}$ in the third stage (rank sum test Prob. $>|z|=0.039$ ).

The second part of Table 4.3 presents the distribution of participants according to their degree of altruism. Subjects are classified in four categories according to the implied angle of the social tie vector (See figure 4.2 ). The data show that $46 \%$ of the participants were individualistic in the first stage, which increased to $58 \%$ in the third stage. The second most common group with almost one third were cooperative players, hence players who were willing to give up some of their income to increase the income of the other player. Furthermore, about $17 \%$ of the participants were competitive in the first stage. Once that participants have interacted in the solidarity network in the second experiment stage, we see that the fraction of competitive participants decreased while individualistic participants increased. The more extreme groups of envious and altruistic participants were markedly smaller. In both groups

\footnotetext{
${ }^{3}$ The authors exclude observations with a consistency below 600 . Random responses would result on average in a consistency of 500 .
} 
we see a decrease in the third stage, which could be related to learning effects. Surprisingly, we find that the fraction of cooperative players decreases in treatments I2 and C2. This could be related to bad experience in the solidarity network of the second stage. However, the econometric analysis will shed more light on this question.

Table 4.3: Social Tie Angle in 1st and 3rd Stage by Treatments

\begin{tabular}{|c|c|c|c|c|c|c|c|c|c|c|}
\hline & \multicolumn{2}{|c|}{ Total } & \multicolumn{2}{|c|}{ I1 } & \multicolumn{2}{|c|}{ I2 } & \multicolumn{2}{|c|}{$\mathrm{C2}$} & \multicolumn{2}{|c|}{ Control } \\
\hline & $1 \mathrm{st}$ & $3 \mathrm{rd}$ & $1 \mathrm{st}$ & $3 \mathrm{rd}$ & $1 \mathrm{st}$ & $3 \mathrm{rd}$ & $1 \mathrm{st}$ & $3 \mathrm{rd}$ & $1 \mathrm{st}$ & $3 \mathrm{rd}$ \\
\hline Angle & $5^{\circ}$ & $11^{\circ}$ & $10^{\circ}$ & $15^{\circ}$ & $1^{\circ}$ & $9^{\circ}$ & $10^{\circ}$ & $12^{\circ}$ & $-2^{\circ}$ & $5^{\circ}$ \\
\hline $\mathrm{N}$ & \multicolumn{2}{|c|}{1062} & \multicolumn{2}{|c|}{425} & \multicolumn{2}{|c|}{392} & \multicolumn{2}{|c|}{140} & \multicolumn{2}{|c|}{105} \\
\hline \multirow{3}{*}{ Diff. $($ Prob $>|z|)$} & \multicolumn{2}{|c|}{0.039} & \multicolumn{2}{|c|}{0.093} & \multicolumn{2}{|c|}{0.068} & \multicolumn{2}{|c|}{0.794} & \multicolumn{2}{|c|}{0.481} \\
\hline & \multicolumn{2}{|c|}{ Total } & \multicolumn{2}{|c|}{ I1 } & \multicolumn{2}{|c|}{ I2 } & \multicolumn{2}{|c|}{ C2 } & \multicolumn{2}{|c|}{ Control } \\
\hline & $1 \mathrm{st}$ & $3 \mathrm{rd}$ & $1 \mathrm{st}$ & $3 \mathrm{rd}$ & $1 \mathrm{st}$ & $3 \mathrm{rd}$ & $1 \mathrm{st}$ & $3 \mathrm{rd}$ & $1 \mathrm{st}$ & $3 \mathrm{rd}$ \\
\hline \multicolumn{11}{|l|}{ Altruistic } \\
\hline Percentage & $2 \%$ & $1 \%$ & $3 \%$ & $2 \%$ & $1 \%$ & $0 \%$ & $0 \%$ & $0 \%$ & $2 \%$ & $0 \%$ \\
\hline Angle & $77^{\circ}$ & $81^{\circ}$ & $78^{\circ}$ & $81^{\circ}$ & $77^{\circ}$ & - & - & - & $74^{\circ}$ & - \\
\hline \multicolumn{11}{|l|}{ Cooperative } \\
\hline Percentage & $30 \%$ & $30 \%$ & $30 \%$ & $37 \%$ & $29 \%$ & $25 \%$ & $38 \%$ & $30 \%$ & $24 \%$ & $22 \%$ \\
\hline Angle & $37^{\circ}$ & $38^{\circ}$ & $38^{\circ}$ & $36^{\circ}$ & $37^{\circ}$ & $40^{\circ}$ & $39^{\circ}$ & $35^{\circ}$ & $41^{\circ}$ & $38^{\circ}$ \\
\hline \multicolumn{11}{|l|}{ Individualistic } \\
\hline Percentage & $46 \%$ & $58 \%$ & $49 \%$ & $55 \%$ & $43 \%$ & $61 \%$ & $47 \%$ & $59 \%$ & $44 \%$ & $59 \%$ \\
\hline Angle & $4^{\circ}$ & $6^{\circ}$ & $4^{\circ}$ & $5^{\circ}$ & $3^{\circ}$ & $6^{\circ}$ & $9^{\circ}$ & $8^{\circ}$ & $1^{\circ}$ & $3^{\circ}$ \\
\hline \multicolumn{11}{|l|}{ Competitive } \\
\hline Percentage $\%$ & $17 \%$ & $10 \%$ & $15 \%$ & $6 \%$ & $22 \%$ & $13 \%$ & $11 \%$ & $9 \%$ & $20 \%$ & $17 \%$ \\
\hline Angle & $-40^{\circ}$ & $-37^{\circ}$ & $-39^{\circ}$ & $-41^{\circ}$ & $-40^{\circ}$ & $-33^{\circ}$ & $-48^{\circ}$ & $-38^{\circ}$ & $-40^{\circ}$ & $-38^{\circ}$ \\
\hline \multicolumn{11}{|l|}{ Envious } \\
\hline Percentage $\%$ & $3 \%$ & $1 \%$ & $1 \%$ & $0 \%$ & $5 \%$ & $1 \%$ & $3 \%$ & $1 \%$ & $6 \%$ & $0 \%$ \\
\hline Angle & $-86^{\circ}$ & $-75^{\circ}$ & $-88^{\circ}$ & - & $-83^{\circ}$ & $-78^{\circ}$ & $-88^{\circ}$ & $-70^{\circ}$ & $-91^{\circ}$ & - \\
\hline
\end{tabular}

\section{Solidarity Game}

Despite the fixed payment in the real effort game, participants showed a high motivation to solve the task. On average, they managed to position 5 sliders correctly and as expected, over time, they improved their performance significantly ${ }^{4}$

Moreover, we find a high degree of solidarity in the game. In $75 \%$ of the cases participants that were affected by a shock received help from the network. Yet, not all members in the group collaborated and when two people had the option to help, in only $33 \%$ of the cases both

\footnotetext{
${ }^{4}$ The average of correctly positioned slides improved steadily and in the 9th period subjects solved 1.15 slides more compared to the first period (Wilcoxon rank sum test Prob $>|z|=0.00$ ).
} 
transferred income to the affected member. Given that participants had the possibility to help the network, they decided to transfer part of their income in about half of the times.

In the analysis we refer to collaboration as the share of times network members decided to help when given the chance. The decision to collaborate was highly correlated with the group average (correlation=0.74). Figure 4.4 displays the collaboration by transfer periods. Shocks and thus transfer periods were predefined in periods 2, 5 and 8 in I1, C2 and Control treatments. Additionally we included shocks in periods 3, 6, 7 in I2 treatments. Surprisingly, we find that collaboration was not constant over rounds. Collaboration was highest in the fifth period and similar in the transfer period at the beginning and end of the game. This could be related to an observant attitude at the beginning and an unraveling of cooperation at the end where help cannot be reciprocated anymore. Furthermore, in the covariate treatment about $70 \%$ decided to help the two affected network members compared to only $55 \%$ in the idiosyncratic treatments. This could be due to the fact that in the covariance treatment, the third person is the only one who can help and cannot free ride on the help of others. In treatments where participants suffered two idiosyncratic shocks, subjects had 4 chances to help, in treatments with one idiosyncratic shocks they had two chances and in the covariate shock treatments participants only had one period in which they could interact with affected network members.

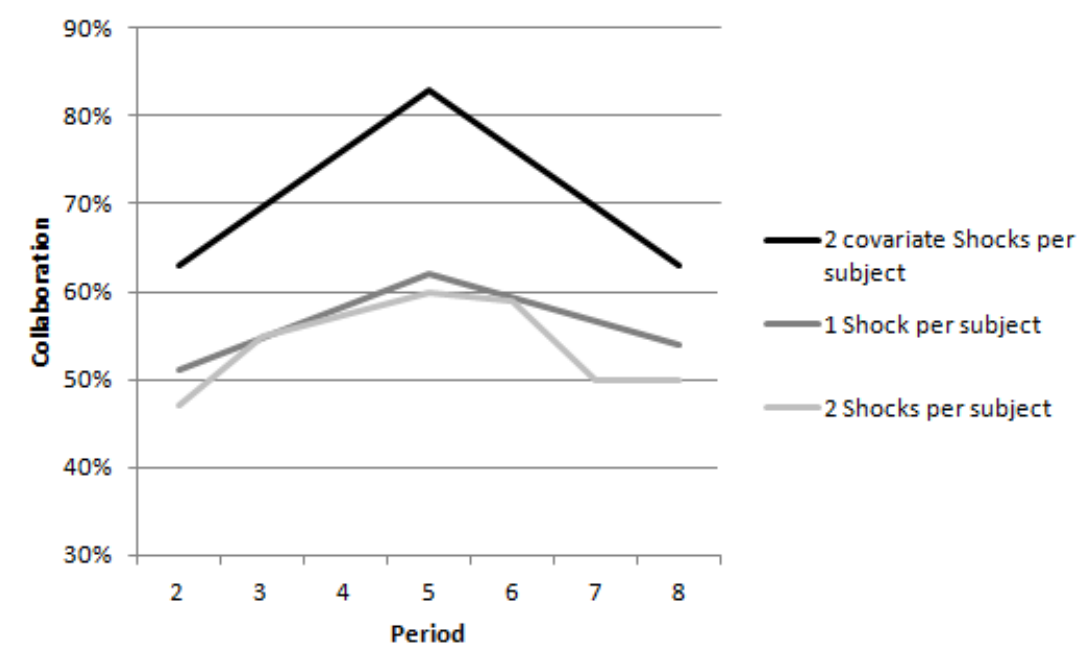

Note: Collaboration denotes the mean share network members decided to help affected members.

Figure 4.4: Network Collaboration by Period

Moreover, collaboration in the network was sensitive to the size of the shock and the 
transfer: if shocks led to complete losses of the endowment, subjects collaborated in $60 \%$ of the cases compared to $53 \%$ when they only lost half of the endowment (rank sum Prob. >

$|z|=0.033)$. As the value of the transfer increased from $\frac{1}{3}$ to $\frac{1}{6}$ of the income, collaboration decreased from $64 \%$ to $49 \%$ (rank sum Prob. $>|z|=0.000$ ).

\section{Econometric Analysis}

To quantify the impact of the frequency and covariate structure of the shock on social cohesion, we estimate the following fixed effects model.

$$
D D_{i t}=\beta_{1}\left(T_{i t}-\bar{T}_{i}\right)+\beta_{2}\left(Z_{i t}-\bar{Z}_{i}\right)+\left(\epsilon_{i}-\epsilon_{i}\right)+\left(u_{i t}-\bar{u}_{i}\right)
$$

Where $D D$ refers to our experimental measure of social ties, $i$ refers to each participant, $\mathrm{t}$ to the implied angle in the first and third stage of the game, $T$ denotes the treatment status, $Z$ time variant covariates and $\epsilon$ reflects the time invariant fixed effects. This model is equivalent to a difference in difference estimation in a two period settings (Khandker et al. 2010). In the treatments we consider the impact of frequency of the shocks and the covariate structure of the shocks. We control for the shock and transfer sizes in order to account for wealth and distribution effects.

In the analysis we focus on social ties on the individual and solidarity network level. On first thought, the solidarity network level seems to be appropriate to measure social cohesion. For example, informal insurance networks rely on mutual social ties and in case ties are only unilateral, solidarity is not reciprocated and collaboration is not sustainable. On the other hand, mean changes on the group level could result from heterogeneous effects on the individual level. Certain aspects as for example the timing of shocks in the solidarity game could cause differences in social tie changes on the individual level. Therefore we present the estimation results on the network and the individual level. Definitions of all variables that are included in the estimations can be found in table 4.9 in the appendix.

\section{Impact of the Frequency of Shocks}

Table 4.5 displays the fixed effects estimation on the network (column 1-3) and individual (column 4-7) level. We consider treatments when shocks are idiosyncratic and not more than one network member was hit by a shock in a given period (I1 and I2). As treatment variable we use a dummy with the value of zero if subjects suffered one shock and the value of one 
if subject suffered two shocks in the solidarity game. The results suggest that suffering two shocks compared to one shock led to significantly higher social ties. This finding is robust regardless of whether we analyze it on the network or the individual level. The size of the effect of more frequent shocks is slightly larger on the network level and reflects a more than $5^{\circ}$ increase of the angle in the ring compared to sessions with one shock only. This effect size is considerable and nearly as large as the mean social tie angle of the first stage.

The coefficient signs moreover indicate that larger shocks tended to affect social ties positively, whereas the transfer size had a negative effect. However, the effects are not significant. Surprisingly the network collaboration had no effect on the development of social ties. Similarly, the effect of the number of egoistic freeriders that never helped and compliers that always helped had no significant effect on the development of social ties. This suggest that social tie increases were not very sensitive to the performance of the interaction but rather influenced by the repeated possibility to interact.

In the last column we include the net help, which describes the balance of help received minus help given to other members. The variable enters with a positive and significant coefficient. This points out that subjects stated stronger social ties in the third stage if they were net beneficiaries of the solidarity network. Yet, the positive shock frequency effect remains and interaction terms of help received and the frequency of shocks do not indicate any heterogeneous effects (results not reported). The positive effect could be due to the fact that net beneficiaries of the network reciprocated part of their net earnings of the solidarity game in the third stage.

\section{Impact of Covariance of Shocks}

Table 4.5 presents the results for social tie changes in case of covariate shocks. Therefore we consider only treatments in which each subject suffered two shocks in the solidarity game (I2 and $\mathrm{C} 2$ ). Our treatment variable is zero if only one member of the network is affected at a given period and one if two members of the network are affected simultaneously in a period. The estimation results indicate that as more members in the network were affected by a negative shock, the development of social ties is slower. The effect size ranges from $-5^{\circ}$ to $-10^{\circ}$ compared to idiosyncratic shocks. The effect is similar in size on the individual and network level. As in the previous estimations, net beneficiaries of the network stated stronger social ties 
Table 4.4: Fixed Effect Estimation of Frequency of Shocks Effects on Social Ties

\begin{tabular}{lccccccc}
\hline \hline & \multicolumn{1}{c}{ NETWORK LEVEL $(1-3)$} & \multicolumn{4}{c}{ INDIVIDUAL LEVEL (4-7) } \\
\hline & $(1)$ & $(2)$ & $(3)$ & $(4)$ & $(5)$ & $(6)$ & $(7)$ \\
\hline \multirow{3}{*}{ Shock Frequency } & $5.58^{*}$ & $5.63^{*}$ & 5.36 & $4.31^{* *}$ & $3.91^{*}$ & $4.35^{* *}$ & $3.98^{*}$ \\
& $(1.77)$ & $(1.80)$ & $(1.64)$ & $(2.08)$ & $(1.86)$ & $(2.09)$ & $(1.83)$ \\
& & & & & & &
\end{tabular}

CONTROL VARIABLES

\begin{tabular}{|c|c|c|c|c|c|c|c|}
\hline Shock Size & $\begin{array}{c}0.49 \\
(1.50)\end{array}$ & $\begin{array}{c}0.20 \\
(0.53)\end{array}$ & $\begin{array}{c}0.45 \\
(1.24)\end{array}$ & $\begin{array}{c}0.41 \\
(1.46)\end{array}$ & $\begin{array}{c}0.27 \\
(0.84)\end{array}$ & $\begin{array}{c}0.35 \\
(1.15)\end{array}$ & $\begin{array}{c}0.26 \\
(0.82)\end{array}$ \\
\hline Tansfer Size & $\begin{array}{l}-0.21 \\
(-0.21)\end{array}$ & $\begin{array}{l}-0.33 \\
(-0.34)\end{array}$ & $\begin{array}{c}0.38 \\
(0.34)\end{array}$ & $\begin{array}{l}-1.31 \\
(-1.56)\end{array}$ & $\begin{array}{l}-1.32 \\
(-1.57)\end{array}$ & $\begin{array}{l}-0.84 \\
(-0.91)\end{array}$ & $\begin{array}{l}-1.43 \\
(-1.63)\end{array}$ \\
\hline Network Collaboration & & $\begin{array}{c}6.94 \\
(1.34)\end{array}$ & & & $\begin{array}{c}4.29 \\
(1.05)\end{array}$ & & $\begin{array}{c}3.68 \\
(0.86)\end{array}$ \\
\hline Network Freerider & & & $\begin{array}{l}-2.71 \\
(-1.17)\end{array}$ & & & $\begin{array}{c}-2.29 \\
(-1.29)\end{array}$ & \\
\hline Network Complier & & & $\begin{array}{c}-0.02 \\
(-0.01)\end{array}$ & & & $\begin{array}{c}0.27 \\
(0.20)\end{array}$ & \\
\hline Shock Timing & & & & & & & $\begin{array}{c}0.05 \\
(0.03)\end{array}$ \\
\hline Network Wealth Equality & & & & & & & $\begin{array}{c}1.60 \\
(0.62)\end{array}$ \\
\hline Net Help Received & & & & & & & $\begin{array}{l}2.51^{* *} \\
(2.26)\end{array}$ \\
\hline$N$ & 276 & 276 & 276 & 817 & 817 & 817 & 817 \\
\hline$R^{2}$ & 0.163 & 0.174 & 0.173 & 0.073 & 0.075 & 0.078 & 0.088 \\
\hline
\end{tabular}

t $t$ statistics in parentheses. Observation with consistency $<600$, Control and C2 excluded.

${ }^{*} p<0.10,{ }^{* *} p<0.05,{ }^{* * *} p<0.01$

in the third stage. Moreover, the effect size increases after controlling for network collaboration or the number of freeriders and compliers in the networks. That suggests, that the increased collaboration in covariate treatments slightly dampened the negative covariance effect. As in the covariate case only one subject could help the two affected members, there was either full collaboration or none. In contrast, the idiosyncratic treatment allows for intermediate collaboration (one member helps and one withholds). Confronted with these more extreme strategies, subjects were on average more likely to cooperate in the covariate treatment. Yet, networks without any cooperation were also more often observed 5 Therefore, increases in the network collaboration after covariate shocks cannot fully compensate for the negative effect of the reduction in the number of chances to interact.

An alternative to the separate analysis of the frequency and covariance of shocks is to

\footnotetext{
${ }^{5}$ The number of subjects that never helped in the covariate case sums up to $31 \%$ which is nearly twice the size compared to the idiosyncratic case (rank sum Prob $>|z|=0.028$ ). On the other side, the remaining $69 \%$ in covariate case helped whenever they could (one time vs four times idiosyncratic case) compared to $23 \%$ in the idiosyncratic case (rank sum Prob $>|z|=0.000$ ).
} 
Table 4.5: Fixed Effect Estimation of Social Tie Effect of Covariance of Shocks

\begin{tabular}{|c|c|c|c|c|c|c|c|}
\hline & \multicolumn{3}{|c|}{ NETWORK LEVEL (1-3) } & \multicolumn{4}{|c|}{ INDIVIDUAL LEVEL (4-7) } \\
\hline & $(1)$ & $(2)$ & $(3)$ & $(4)$ & $(5)$ & $(6)$ & $(7)$ \\
\hline Shock Covariance & $\begin{array}{c}-4.86 \\
(-1.57)\end{array}$ & $\begin{array}{l}-5.47^{*} \\
(-1.69)\end{array}$ & $\begin{array}{c}-9.33^{* *} \\
(-2.19)\end{array}$ & $\begin{array}{c}-4.56 \\
(-1.41)\end{array}$ & $\begin{array}{c}-5.42 \\
(-1.61)\end{array}$ & $\begin{array}{c}-9.94^{* *} \\
(-2.23)\end{array}$ & $\begin{array}{l}-6.15^{*} \\
(-1.83)\end{array}$ \\
\hline CONTROL VARIABLES & & & & & & & \\
\hline Shock Size & $\begin{array}{c}0.32 \\
(0.88)\end{array}$ & $\begin{array}{c}0.01 \\
(0.03)\end{array}$ & $\begin{array}{c}0.13 \\
(0.35)\end{array}$ & $\begin{array}{c}0.36 \\
(1.26)\end{array}$ & $\begin{array}{c}0.22 \\
(0.69)\end{array}$ & $\begin{array}{c}0.21 \\
(0.70)\end{array}$ & $\begin{array}{l}-0.01 \\
(-0.04)\end{array}$ \\
\hline Transfer Size & $\begin{array}{c}1.31 \\
(1.15)\end{array}$ & $\begin{array}{c}0.95 \\
(0.82)\end{array}$ & $\begin{array}{c}0.80 \\
(0.68)\end{array}$ & $\begin{array}{c}0.85 \\
(0.96)\end{array}$ & $\begin{array}{c}0.71 \\
(0.78)\end{array}$ & $\begin{array}{c}0.41 \\
(0.45)\end{array}$ & $\begin{array}{c}-0.09 \\
(-0.10)\end{array}$ \\
\hline Network Collaboration & & $\begin{array}{c}9.88 \\
(1.64)\end{array}$ & & & $\begin{array}{c}4.28 \\
(0.90)\end{array}$ & & $\begin{array}{c}1.57 \\
(0.32)\end{array}$ \\
\hline Network Freerider & & & $\begin{array}{c}3.83 \\
(1.44)\end{array}$ & & & $\begin{array}{c}3.40 \\
(1.65)\end{array}$ & \\
\hline Network Complier & & & $\begin{array}{c}3.47 \\
(1.53)\end{array}$ & & & $\begin{array}{c}2.66 \\
(1.52)\end{array}$ & \\
\hline Shock Timing & & & & & & & $\begin{array}{l}3.47^{* *} \\
(2.23)\end{array}$ \\
\hline Network Wealth Equality & & & & & & & $\begin{array}{c}1.73 \\
(0.57)\end{array}$ \\
\hline Net Help Received & & & & & & & $\begin{array}{l}2.15^{*} \\
(1.84)\end{array}$ \\
\hline$N$ & 180 & 180 & 180 & 532 & 532 & 532 & 532 \\
\hline$R^{2}$ & 0.164 & 0.189 & 0.192 & 0.075 & 0.078 & 0.087 & 0.104 \\
\hline
\end{tabular}

use the number of chances to interact with network members as treatment variable (see table 4.8 in the appendix). Thereby potential effects of the covariate structure besides the lower number of chances to help can be explored. Including chances to help besides the dummy for the covariance of shocks in the estimations shows that opportunities to help significantly increased social ties. Besides that, the covariance had no significant effect. This could imply that beyond the limited possibility to interact after covariate shocks, there were no further factors of the covariate structure that hampered the development of social ties.

\section{Heterogeneous Impacts by first Stage Social Tie Categories}

To test whether the results were driven by the social tie levels of the first stage, we estimate the effects separately for altruistic, cooperative, individualistic, competitive and envious participants according to the first stage Ring-Test. Table 4.4 displays the estimation results for the frequency of shocks. As we break the sample into the five categories the number of observation in each estimation decreases and we only look at the effects on the individual level. Especially 
Table 4.6: Fixed Effects Estimation of Shock Frequency Effect by 1st Stage Categories

\begin{tabular}{cccccc}
\hline \hline & $\begin{array}{c}(1) \\
\text { altruistic }\end{array}$ & $\begin{array}{c}(2) \\
\text { cooperative }\end{array}$ & $\begin{array}{c}(3) \\
\text { individualistic }\end{array}$ & $\begin{array}{c}(4) \\
\text { competitive }\end{array}$ & $\begin{array}{c}(5) \\
\text { envious }\end{array}$ \\
\hline \multirow{2}{*}{ Shock Frequency } & & & & & \\
& -10.36 & -4.56 & 1.70 & 2.15 & 18.08 \\
& $(-0.33)$ & $(-1.40)$ & $(0.81)$ & $(0.45)$ & $(0.94)$
\end{tabular}

CONTROL VARIABLES

\begin{tabular}{lccccc} 
Shock Size & 0.79 & -0.15 & -0.07 & 0.69 & -4.85 \\
& $(0.22)$ & $(-0.33)$ & $(-0.23)$ & $(0.98)$ & $(-0.90)$ \\
Transfer Size & 0.00 & -0.49 & -0.06 & -0.70 & 12.91 \\
& $()$. & $(-0.41)$ & $(-0.08)$ & $(-0.36)$ & $(1.13)$ \\
Network Solidarity & -42.56 & 6.89 & $8.56^{* *}$ & $35.64^{* * *}$ & 24.51 \\
& $(-0.93)$ & $(1.09)$ & $(2.11)$ & $(3.59)$ & $(0.63)$ \\
Net Help Received & 13.82 & 0.74 & -0.77 & 0.08 & -5.44 \\
& $(0.40)$ & $(0.43)$ & $(-0.69)$ & $(0.03)$ & $(-0.52)$ \\
\hline$N$ & 16 & 242 & 378 & 150 & 24 \\
$R^{2}$ & 0.774 & 0.129 & 0.124 & 0.626 & 0.744 \\
\hline \hline
\end{tabular}

Observation with consistency $<600, \mathrm{C} 2$ and Control sessions excluded.

$t$ statistics in parentheses

${ }^{*} p<0.10,{ }^{* *} p<0.05,{ }^{* * *} p<0.01$

for the "extreme" groups of altruistic and envious participants the number of observations is below 30 . The coefficients indicate that the effect of the shock frequency increases the lower the initial social tie level. Cooperative subjects rather tended to decrease social ties after suffering two shocks whereas the coefficient turns positive for more individualistic participants. This implies that the positive effect of more frequent shocks was rather driven by individualistic, competitive or envious participants. This is interesting as one could have expected that more solidarious participants would be more sensitive to interaction compared to individualistic or competitive ones that care more about increasing their own benefits. However, the shock frequency coefficients are not significant using these subsamples. Another interesting finding is that cooperation in the network had a large and significant effect for individualistic and competitive participants whereas it had no effect on the group of cooperative participants. This implies that more altruistic participants were reacting less to collaboration in the solidarity game. One explanation for the difference in the sensitivity to collaboration could source from the expectations of participants on the network behavior. More individualistic subjects might have been positively surprised when they experienced network collaboration, which they expressed in a more altruistic value orientation in the third stage. In contrast, more altruistic participants expected networks to help and hence did not reward collaboration in the third stage. 
Table 4.7: Fixed Effects Estimation of Covariance Effect by 1st Stage Categories

\begin{tabular}{|c|c|c|c|c|c|}
\hline & $\begin{array}{c}(1) \\
\text { altruistic }\end{array}$ & $\begin{array}{c}(2) \\
\text { cooperative }\end{array}$ & $\begin{array}{c}(3) \\
\text { individualistic }\end{array}$ & $\begin{array}{c}(4) \\
\text { competitive }\end{array}$ & $\begin{array}{c}(5) \\
\text { envious }\end{array}$ \\
\hline Shock Covariance & - & $\begin{array}{c}4.28 \\
(0.94)\end{array}$ & $\begin{array}{c}-8.74^{* *} \\
(-2.31)\end{array}$ & $\begin{array}{c}-6.39 \\
(-0.73)\end{array}$ & $\begin{array}{l}16.23 \\
(0.68)\end{array}$ \\
\hline \multicolumn{6}{|c|}{ CONTROL VARIABLES } \\
\hline Shock Size & - & $\begin{array}{l}-0.49 \\
(-0.99)\end{array}$ & $\begin{array}{c}-0.38 \\
(-1.11)\end{array}$ & $\begin{array}{c}0.85 \\
(1.25)\end{array}$ & $\begin{array}{l}-2.76 \\
(-0.57)\end{array}$ \\
\hline Transfer Size & - & $\begin{array}{l}-0.48 \\
(-0.36)\end{array}$ & $\begin{array}{c}1.45 \\
(1.51)\end{array}$ & $\begin{array}{c}3.16 \\
(1.42)\end{array}$ & $\begin{array}{l}16.79 \\
(1.50)\end{array}$ \\
\hline Network Solidarity & - & $\begin{array}{c}2.07 \\
(0.31)\end{array}$ & $\begin{array}{l}10.89^{*} \\
(1.97)\end{array}$ & $\begin{array}{l}13.86 \\
(1.40)\end{array}$ & $\begin{array}{c}1.76 \\
(0.05)\end{array}$ \\
\hline Net Help Received & - & $\begin{array}{c}0.73 \\
(0.36) \\
\end{array}$ & $\begin{array}{l}-1.51 \\
(-1.19)\end{array}$ & $\begin{array}{c}1.08 \\
(0.46)\end{array}$ & $\begin{array}{l}-9.14 \\
(-1.03)\end{array}$ \\
\hline$N$ & - & 169 & 238 & 102 & 21 \\
\hline$R^{2}$ & & 0.096 & 0.122 & 0.633 & 0.826 \\
\hline
\end{tabular}

The findings on the heterogeneous effects on the covariate shock structure are very similar. Table 4.7 presents the estimation results for which we consider treatments $\mathrm{I} 2$ and $\mathrm{C} 2$. The number of observation is lower for these treatments compared to the frequency estimations. The negative effect of the covariate structure of shocks can only be observed for individualistic, competitive and envious participants, while the coefficient sign is positive for cooperative participants. As in the frequency estimations, network collaboration had stronger effects on less altruistic participants.

\section{Conclusion}

In this study we analyze how the frequency and covariance of shocks affect the development of social ties in informal networks. Our hypothesis is that collaboration after shocks strengthens social ties of network members. This analysis is the first to examine this relationship and particularly relevant in the prospect of climate change. The frequency of extreme weather events is expected to increase, which puts especially those households at risk that do not have access to formal insurances (Samson et al., 2011; Heltberg et al., 2009). However, the development of social ties in communities could promote adoption processes after shocks and hence reduce the vulnerability to future shocks.

For the analysis we ran laboratory experiments with students of the Universidad Nacional 
in Medellin, Colombia. The experiments includes a pre and post test of social ties that allows to quantify how treatments in the solidarity game affected the development of social ties. The findings indicate a positive effect of more frequent shocks on social ties and a negative effect of the covariance of shocks. Surprisingly, the effect gets stronger the more individualistic the participant were in the the pre test, which could be related to lower expectations on the network collaboration.

The results could have important implications for adoption processes to shocks. Communities with stronger social ties are better endowed to engage in collective action as for example the construction of dams in flood prone areas or the reforestation to avoid desertification of community farmland, which reduces the risk of future shocks. Moreover, in case shocks strike, communities with stronger social ties are more likely to collaborate leading to more efficient informal insurance mechanisms. Therefore successful collaboration after shocks could accelerate adoption processes to mitigate risks of future shocks. However, the results also suggest that chances to interact drive the development of social ties, which means that covariate shocks -like most climate shocks- have a lower self enforcing effect on social ties than idiosyncratic shocks. Despite that, this self enforcing effect of social ties holds for informal insurance networks and interaction in formal agreements is expected to result in lower social tie increases Molm et al., 2009). That raises the question whether introducing formal insurances in communities that rely on informal insurance networks could lead to slower processes of social cohesion. 


\section{Appendix}

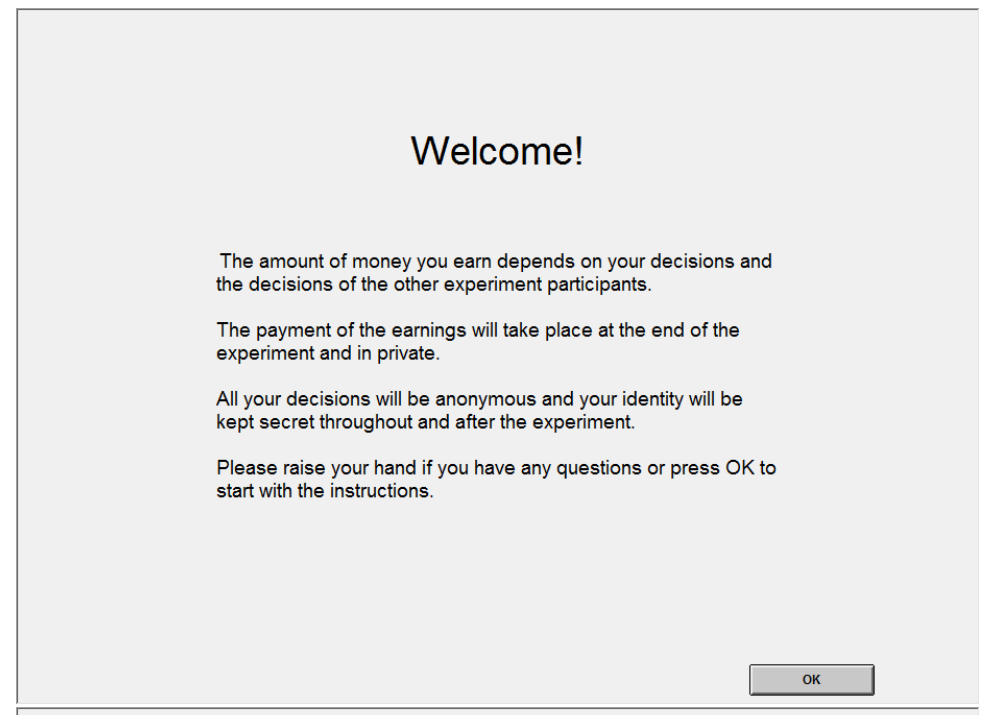

Part 1

In this part of the experiment you will be confronted with two options on payments for yourself and another anonymous participant. Nor you nor the other player knows with whom he partnered up. It is you task to decide, which of the two option you prefer.

You don't know with whom you are playing, but you will always play with the same person.

At the same time another participant has to decide between two payment options for him and payments for you.

You will be confronted with 32 of those decisions each with different value combinations. For the final payment we will select one random decision at the end of the experiment.

For an example please press next.

Figure 4.5: Experiment Introduction Screens 


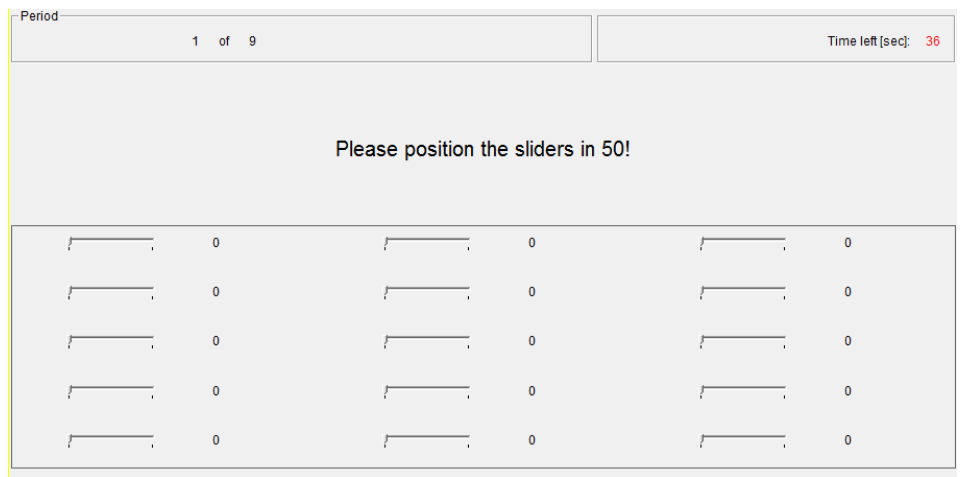

Figure 4.6: Endowment Task Screen

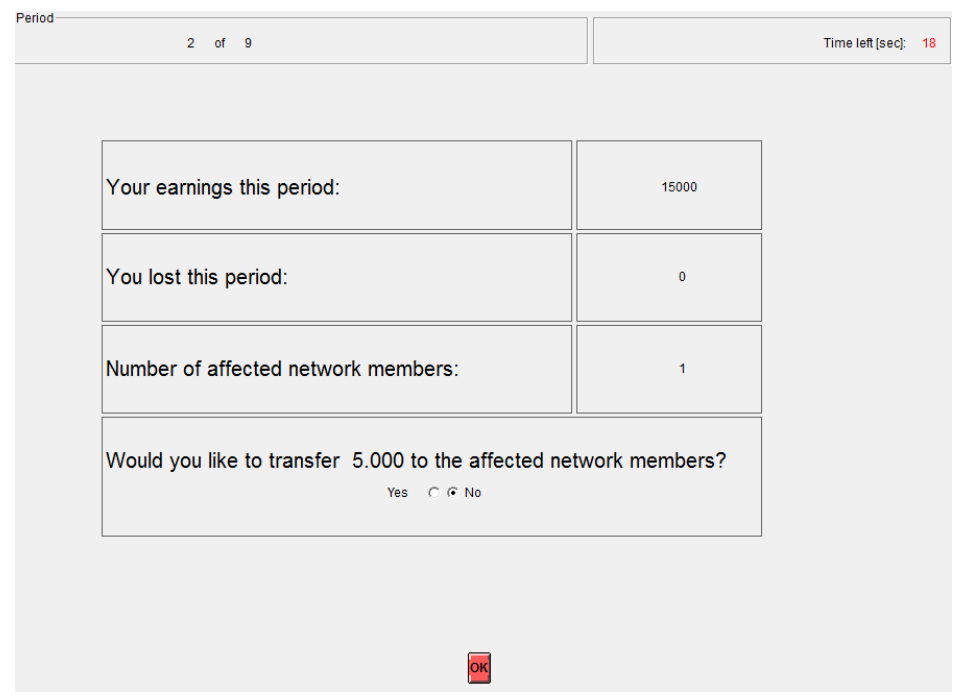

Figure 4.7: Transfer Decision Screen 
Table 4.8: Fixed Effect Estimation of Social Tie Effect of Chances to help

\begin{tabular}{|c|c|c|c|c|c|c|c|}
\hline & \multicolumn{3}{|c|}{ NETWORK LEVEL } & \multicolumn{4}{|c|}{ INDIVIDUAL LEVEL } \\
\hline & $(1)$ & $(2)$ & $(3)$ & $(4)$ & $(5)$ & $(6)$ & $(7)$ \\
\hline Chances to Help (freq.) & $\begin{array}{l}3.11^{* *} \\
(2.48)\end{array}$ & $\begin{array}{l}2.95^{* *} \\
(2.32)\end{array}$ & $\begin{array}{l}3.14^{* *} \\
(2.49)\end{array}$ & $\begin{array}{l}2.34^{* *} \\
(2.39)\end{array}$ & $\begin{array}{l}2.22^{* *} \\
(2.24)\end{array}$ & $\begin{array}{l}2.39^{* *} \\
(2.43)\end{array}$ & $\begin{array}{l}2.14^{* *} \\
(2.07)\end{array}$ \\
\hline Shock Covariance & $\begin{array}{c}-0.55 \\
(-0.12)\end{array}$ & $\begin{array}{c}-1.39 \\
(-0.29)\end{array}$ & $\begin{array}{c}0.77 \\
(0.15)\end{array}$ & $\begin{array}{c}1.07 \\
(0.30)\end{array}$ & $\begin{array}{c}0.44 \\
(0.12)\end{array}$ & $\begin{array}{c}1.47 \\
(0.37)\end{array}$ & $\begin{array}{l}-0.26 \\
(-0.07)\end{array}$ \\
\hline \multicolumn{8}{|l|}{ CONTROL VARIABLES } \\
\hline Shock Size & $\begin{array}{c}0.06 \\
(0.19)\end{array}$ & $\begin{array}{c}-0.05 \\
(-0.13)\end{array}$ & $\begin{array}{c}0.08 \\
(0.23)\end{array}$ & $\begin{array}{c}0.28 \\
(1.10)\end{array}$ & $\begin{array}{c}0.20 \\
(0.69)\end{array}$ & $\begin{array}{c}0.25 \\
(0.91)\end{array}$ & $\begin{array}{c}0.17 \\
(0.59)\end{array}$ \\
\hline Transfer Size & $\begin{array}{c}-0.60 \\
(-0.63)\end{array}$ & $\begin{array}{c}-0.63 \\
(-0.65)\end{array}$ & $\begin{array}{l}-0.26 \\
(-0.25)\end{array}$ & $\begin{array}{l}-1.06 \\
(-1.40)\end{array}$ & $\begin{array}{l}-1.08 \\
(-1.42)\end{array}$ & $\begin{array}{l}-0.85 \\
(-1.03)\end{array}$ & $\begin{array}{l}-1.23 \\
(-1.56)\end{array}$ \\
\hline Network Collaboration & & $\begin{array}{c}3.34 \\
(0.70)\end{array}$ & & & $\begin{array}{c}2.59 \\
(0.70)\end{array}$ & & $\begin{array}{c}1.87 \\
(0.49)\end{array}$ \\
\hline Network Freerider & & & $\begin{array}{c}-1.79 \\
(-0.88)\end{array}$ & & & $\begin{array}{c}-1.15 \\
(-0.73)\end{array}$ & \\
\hline Network Complier & & & $\begin{array}{c}-0.58 \\
(-0.35)\end{array}$ & & & $\begin{array}{c}0.09 \\
(0.07)\end{array}$ & \\
\hline Shock Timing & & & & & & & $\begin{array}{c}0.52 \\
(0.40)\end{array}$ \\
\hline Network Wealth Equality & & & & & & & $\begin{array}{c}1.29 \\
(0.56)\end{array}$ \\
\hline Net Help Receiver & & & & & & & $\begin{array}{l}2.60^{* *} \\
(2.47)\end{array}$ \\
\hline$N$ & 324 & 324 & 324 & 957 & 957 & 957 & 957 \\
\hline$R^{2}$ & 0.154 & 0.157 & 0.158 & 0.066 & 0.067 & 0.068 & 0.080 \\
\hline
\end{tabular}

$t$ statistics in parentheses. Observation with consistency $<600$ and Control excluded.

${ }^{*} p<0.10,{ }^{* *} p<0.05,{ }^{* * *} p<0.01$ 
Table 4.9: Definition of Variables

\begin{tabular}{l|l}
\hline Variable Name & Definition \\
\hline \hline Shock Frequency & $\begin{array}{l}\text { Variable takes on } 1 \text { if participant suffered } 1 \text { shock along the 9 periods of the } \\
\text { solidarity game and } 2 \text { if participant suffered } 2 \text { shocks }\end{array}$ \\
\hline Shock Covariance & $\begin{array}{l}\text { Variable takes on } 0 \text { if only one member of the network was affected per shock and } 1 \\
\text { if } 2 \text { members were affected simultaneously }\end{array}$ \\
\hline Shock Size & $\begin{array}{l}\text { Shocks either caused } 15 \text { 000 COP or } 7500 \text { COP loss of participants income. The } \\
\text { shock size was constant for all participants in each treatment }\end{array}$ \\
\hline Transfer Size & $\begin{array}{l}\text { Unaffected members were either faced with the decision to transfer } 5 \text { 000 COP or } \\
2500 \text { COP of their income. The transfer size was constant for all participants in } \\
\text { each treatment }\end{array}$ \\
\hline Network Collaboration & $\begin{array}{l}\text { Number of times the network members decided to help divided by the times the } \\
\text { network had the chance to help along the 9 periods of the solidarity game }\end{array}$ \\
\hline Network Freerider & $\begin{array}{l}\text { Number of network members that never helped along the } 9 \text { periods of the solidarity } \\
\text { game }\end{array}$ \\
\hline Network Complier & $\begin{array}{l}\text { Number of network members that always helped along the 9 periods of the } \\
\text { solidarity game }\end{array}$ \\
\hline Shock Timing & $\begin{array}{l}\text { Random network position that determined when network members suffered shocks } \\
\text { along the } 9 \text { periods of the solidarity game }\end{array}$ \\
\hline Network Wealth equality & $\begin{array}{l}\text { Dummy whether all } 3 \text { network members had the same wealth after aggregating } \\
\text { incomes of the } 9 \text { periods of the solidarity game }\end{array}$ \\
\hline $\begin{array}{l}\text { Number of times a participant received help minus help participant gave to others } \\
\text { along the } 9 \text { periods of the solidarity game }\end{array}$ \\
\hline
\end{tabular}




\section{References}

A Microinsurance Compendium Vol. II (2012). Protecting the Poor: A Microinsurance Compendium Vol. II. International Labour Organization.

Angelucci, M. and Attanasio, O. (2006). Estimating att effects with non-experimental data and low compliance. IZA Discussion Paper, 2368.

Barnett, B. and Skees, C. B. J. (2008). Poverty traps and index-based risk transfer products. World Development, 36(10):1766-1785.

Bellows, J. and Miguel, E. (2006). War and institutions: New evidence from Sierra Leone. The American economic review, 96(2):394-399.

Bellows, J. and Miguel, E. (2009). War and local collective action in sierra leone. Journal of Public Economics, 93(11-12):1144 - 1157.

Binswanger-Mkhize, H. P. (2012). Is there too much hype about index-based agricultural insurance? Journal of Development Studies, 48(2):187-200.

Blattman, C. (2009). From violence to voting: War and political participation in Uganda. American Political Science Review, 103(2):231-247.

Bose, P. (1998). Formal-informal sector interaction in rural credit markets. Journal of Development Economics, 56(2):265-280.

Boucher, Steve, C. M. R. and Guirkinger, C. (2008). Risk rationing and wealth effects in credit markets: Theory and implications for agricultural development. American Journal of Agricultural Economics, Vol. 90(2):409-423.

Cabas, Juan H.; Leiva, A. J. W. A. (2008). Modeling exit and entry of farmers in a crop insurance program. Agricultural and Resource Economics Review, 37(1):92-105.

Cai, H., Chen, Y., Fang, H., and Zhou, L.-A. (2011). The effect of microinsurance on economic activities: Evidence from a randomized field experiment.

Carter, M. R. and Barrett, C. B. (2006). The economics of poverty traps and persistent poverty: An asset-based approach. The Journal of Development Studies, 42(2):178-199. 
Carter, M. R. and Castillo, M. (2005). Morals, markets and mutual insurance: Using economic experiments to study recovery from hurricane Mitch. The social economics of poverty: on identities, communities, groups, and networks, page 256.

Carter, M. R., Little, P. D., Mogues, T., and Negatu, W. (2007). Poverty traps and natural disasters in Ethiopia and Honduras. World Development, 35(5):835-856.

Carter, M. R. and Maluccio, J. A. (2003). Social capital and coping with economic shocks: An analysis of stunting of South African children. World Development, 31(7):1147-1163.

Carter, M. R. and Olinto, P. (2003). Getting institutions "right" for whom? credit constraints and the impact of property rights on the quantity and composition of investment. American Journal of Agricultural Economics, 85(1):173-186.

Cassar, A., Grosjean, P., and Whitt, S. (2012). Legacies of violence: trust and market development. Journal of Economic Growth, pages 1-34.

Chantarat, S., Mude, A. G., and Barrett, C. B. (2009). Willingness to pay for index based livestock insurance: results from a field experiment in northern Kenya.

Churchill, C. and Matul, M. (2012). Protecting the poor: A microinsurance compendium. vol. ii. ILO, Geneva and Munich Re Foundation, Munich., 24.

Cole, S., Gine, X., and Vickery, J. (2013). How does risk management influence production decisions? evidence from a field experiment.

Cramer, C. (2006). Civil war is not a stupid thing: accounting for violence in developing countries. Hurst \& Company London.

Datt, G. and Hoogeveen, H. (2003). El nino or el peso? crisis, poverty and income distribution in the Philippines. World Development, 31(7):1103-1124.

de Janvry, A., Finan, F., Sadoulet, E., and Vakis, R. (2006). Can conditional cash transfer programs serve as safety nets in keeping children at school and from working when exposed to shocks? Journal of Development Economics, 79(2):349-373.

De Luca, G. and Verpoorten, M. (2012). From vice to virtue? civil war and social impact in uganda. Civil War and Social Impact in Uganda (October 2011). 
Deaton, A. (2010). Instruments, randomization, and learning about development. Journal of economic literature, pages 424-455.

Dekker, M. and Wilms, A. (2010). Health insurance and other risk-coping strategies in uganda: The case of microcare insurance ltd. World Development, 38(3):369-378.

Dercon, S. (2002). Income risk, coping strategies, and safety nets. The World Bank Research Observer, 17(2):141-166.

Dercon, S., editor (2004). Insurance Against Poverty. U.K WIDER Studies in Development Economics. Oxford University Press, Oxford.

Dercon, S. and Kirchberger, M. (2008). Literature review on microinsurance. European Development Research Network (EUDN).

Fafchamps, M. and Lund, S. (2003). Risk-sharing networks in rural Philippines. Journal of Development Economics, 71(2):261-287.

Feigenberg, B., Field, E. M., and Pande, R. (2010). Building social capital through microfinance. Technical report.

Field, C. B., Barros, V., Stocker, T. F., and Dahe, Q. (2012). Managing the Risks of Extreme Events and Disasters to Advance Climate Change Adaptation: Special Report of the Intergovernmental Panel on Climate Change. Cambridge University Press.

Fischbacher, U. (2007). z-tree: Zurich toolbox for ready-made economic experiments. Experimental economics, 10(2):171-178.

Fuchs, A. and Wolff, H. (2011). Concept and unintended consequences of weather index insurance: the case of Mexico. American Journal of Agricultural Economics, 93 (2):505511.

Giesbert, L., Steiner, S., and Bendig, M. (2011). Participation in micro life insurance and the use of other financial services in Ghana. Journal of Risk and Insurance, 78(1):7-35.

Gill, D. and Prowse, V. (2012). A structural analysis of disappointment aversion in a real effort competition. The American Economic Review, 102(1):469-503. 
Gine, X., Townsend, R., and Vickery, J. (2008). Patterns of rainfall insurance participation in rural India. World Bank Econ Rev, 22(3):539-566.

Gine, X. and Yang, D. (2009). Insurance, credit, and technology adoption: Field experimental evidencefrom Malawi. Journal of Development Economics, 89(1):1-11.

Guirkinger, C. and Boucher, S. R. (2008). Credit constraints and productivity in Peruvian agriculture. Agricultural Economics, 39(3):295-308.

Hazarika, G. and Alwang, J. (2003). Access to credit, plot size and cost inefficiency among smallholder tobacco cultivators in Malawi. Agricultural Economics, 29(1):99-109.

Hazell, P., Pomareda, C., and Valdes, A., editors (1986). crop insurance for agricultural development. The Johns Hopkins Univerity Press.

Heltberg, R., Siegel, P. B., and Jorgensen, S. L. (2009). Addressing human vulnerability to climate change: Toward a 'no-regrets' approach. Global Environmental Change, 19(1):89-99.

Hill, R. and Viceisza, A. (2012). A field experiment on the impact of weather shocks and insurance on risky investment. Experimental Economics, 15(2):341-371.

IDEAM (2001). Colombia primera comunicacion nacional ante la convencion marco de las naciones unidas sobre el cambio climatico. Technical report.

Jacoby, H. G. and Skoufias, E. (1997). Risk, financial markets, and human capital in a developing country. Review of Economic Studies, 64(3):311-.

Karlan, D., Osei, R., Osei-Akoto, I., and Udry, C. (2012). Agricultural decisions after relaxing credit and risk constraints.

Khandker, S. R., Koolwal, G. B., and Samad, H. A. (2010). Handbook on impact evaluation: quantitative methods and practices. World Bank Publications.

Kovacevic, R. M. and Pflug, G. C. (2011). Does insurance help to escape the poverty trap?a ruin theoretic approach. Journal of Risk and Insurance, 78(4):1003-1028.

Levitt, S. D. and List, J. A. (2007). What do laboratory experiments measuring social preferences reveal about the real world? The Journal of Economic Perspectives, 21(2):153-174. 
Liebrand, W. B. G. (1984). The effect of social motives, communication and group size on behaviour in an n-person multi-stage mixed-motive game. Eur. J. Soc. Psychol., 14(3):239264.

Macours, K. (2013). Volatility, agricultural risk, and household poverty: micro-evidence from randomized control trials. Agricultural Economics, 44(s1):79-84.

Mobarak, A. and Rosenzweig, M. (2012). Selling formal insurance to the informally insured. Yale University Economic Growth Center Discussion Paper, (1007).

Mobarak, A. M. and Rosenzweig, M. R. (2013). Informal risk sharing, index insurance, and risk taking in developing countries. The American Economic Review, 103(3):375-380.

Mohapatra, S., Joseph, G., and Ratha, D. (2012). Remittances and natural disasters: expost response and contribution to ex-ante preparedness. Environment, Development and Sustainability, 14(3):365-387.

Molm, L. D., Schaefer, D. R., and Collett, J. L. (2009). Fragile and resilient trust: Risk and uncertainty in negotiated and reciprocal exchange. Sociological Theory, 27(1):1-32.

Morduch, J. (1999). Between the state and the market: Can informal insurance patch the safety net? The World Bank Research Observer, 14(2):187-207.

Rose, C. (2007). Does female board representation influence firm performance? the danish evidence. Corporate Governance: An International Review, 15(2):404-413.

Samson, J., Berteaux, D., McGill, B. J., and Humphries, M. M. (2011). Geographic disparities and moral hazards in the predicted impacts of climate change on human populations. Global Ecology and Biogeography, 20(4):532-544.

Sarris, A., Karfakis, P., and Christiaensen, L. (2006). Producer demand and welfare benefits of rainfall insurance in Tanzania. Rome: FAO Commodities and Trade Policy Research Working Paper Series, 18.

Skees, J., Hazell, P. B. R., and Miranda, M. (1999). New approaches to crop yield insurance in developing countries:. EPTD discussion papers 55, International Food Policy Research Institute (IFPRI). 
Skees, J. R. (1999). Agricultural risk management or income enhancement. Regulation, 22:35.

Skees, J. R. (2008). Innovations in index insurance for the poor in lower income countries. Agricultural and Ressource Economics Review, 37(1).

Skoufias, E. (2003). Economic crises and natural disasters: Coping strategies and policy implications. World Development, 31(7):1087-1102.

Smith, V. and Watts, M. (2009). Index based agricultural insurance in developing countries: Feasibility, scalability and sustainability. Gates Foundation.

Sonnemans, J., van Dijk, F., and van Winden, F. (2006). On the dynamics of social ties structures in groups. Journal of Economic Psychology, 27(2):187 - 204.

Sutter, M., Haigner, S. D., and Kocher, M. G. (2010). Choosing the carrot or the stick? endogenous institutional choice in social dilemma situations. Review of Economic Studies, $77(4): 1540-1566$.

Trenerry, C. F. (1926). The origin and early history of insurance. P. S. King \& Son.

van Dijk, F., Sonnemans, J., and van Winden, F. (2002). Social ties in a public good experiment. Journal of Public Economics, 85(2):275-299.

Voors, M. J., Nillesen, E. E., Verwimp, P., Bulte, E. H., Lensink, R., and Van Soest, D. P. (2012). Violent conflict and behavior: a field experiment in Burundi. The American Economic Review, 102(2):941-964.

World Bank (2013). World Development Report 2014: Risk and Opportunity - Managing Risk for Development. Oxford University Press, Incorporated. 


\section{Personal Dates:}

Birth date $\quad 02.02 .1983$ in Munich

Nationality German

\section{Studies:}

since $05 / 2010$

$04 / 2005-04 / 2009$

$09 / 2003-08 / 2004$
Doctoral candidate in Economics at the Georg-August-University Göttingen Study of Economics at the Ludwig-Maximilians-University, Munich (Dipl. Vwl.)

Study of Economics with social-scientific focus, University of Potsdam 